

\section{Avaliação do perfil de resistência genotípica aos anti- retrovirais de crianças infectadas pelo HIV-1 mantendo supressão viral prolongada em vigência de tratamento}

Dissertação apresentada à Faculdade de Medicina da Universidade de São Paulo para obtenção do título de Mestre em Ciências.

Área de concentração: Doenças Infecciosas e Parasitárias

Orientador: Dra. Daisy Maria Machado

São Paulo 
Ao Alexandre e ao Theo

por fazerem tudo acontecer em minha vida. 


\section{AGRADECIMENTOS}

Aos queridos pacientes e responsáveis, de fundamental importância para o estudo, pela participação e pelo crédito.

A Dra. Daisy Maria Machado, pela confiança em mim depositada, pelo carinho, paciência, dedicação e amizade, meu mais profundo agradecimento.

A Dra. Clarisse Martins Machado, pela oportunidade do estágio, primeiro objetivo conquistado na cidade.

Ao Dr. José Eduardo Levi, pela credibilidade e oportunidades a mim cedidas.

Ao Prof. Dr. Cláudio Sergio Pannuti por todo o apoio e acolhida no laboratório.

Ao Prof. Dr. Aluísio Segurado pelas valiosas sugestões na qualificação.

A Dra. Regina Célia de Menezes Succi, pela colaboração, atenção e sugestões importantíssimas.

Aos amigos e colegas do Laboratório de Virologia do Instituto de Medicina Tropical da Universidade de São Paulo: Alexanda, Viviane, Débora Alves, 
Gisele, Nadily, Érica, Larissa, Lucy, Wilton, Silvia Helena, Tânia, Marli, Jussara, Daniel, Cícero, Maria, Sônia, Vera, Débora, Jenifer, José de Paula, Renato, Wanda, Luis Vicente, Elaine, Evelyn, Alessandra, Érica Roberta, Jaila, Ágata, Cristina, Cynthia, Laura, Michela, Luciano.

Aos funcionários do Departamento de Infectologia Pediátrica da Escola Paulista de Medicina pela colaboração.

Aos amigos Adriana F. Machado, Ana Carolina Mamana, Carla Andréia B. F. de Lima, Adriana Tateno, José Eduardo Martins, Anderson Molina Nascimento Filho, Rodrigo Melim e Maria Carolina A. Bernal, companheiros importantes nas principais dificuldades e maiores conquistas.

A Roseli e Rosimeire, secretárias do Programa de Pós-Graduação, pela paciência, carinho e amizade todo o tempo.

A Deus, sem Ele nada seria possível.

Às minhas famílias, mainha Dilma, painho Wellington, irmãos Murilo, Willian, Ceci, Alaor e Sandra, pessoas importantes que confiam, apoiam e enriquecem sem esperar nada em troca.

Ao CNPq pelo auxílio financeiro. 
Esta dissertação está de acordo com:

Referências: adaptado de International Committee of Medical Journals Editors (Vancouver)

Universidade de São Paulo. Faculdade de Medicina. Serviço de Biblioteca e Documentação. Guia de apresentação de dissertações, teses e monografias. Elaborado por Anneliese Carneiro da Cunha, Maria Júlia de A. L. Freddi, Maria F. Crestanha, Marinalva de Souza Aragão, Suely Campos Cardoso, Valéria Vilhena. São Paulo: Serviço de Biblioteca e Documentação: 2004.

Abreviaturas dos títulos dos periódicos de acordo com List of Journals Indexed in Index Medicus. 


\section{SUMÁRIO}

Lista de tabelas

Lista de figuras

Lista de quadros

Lista de gráficos

RESUMO

SUMMARY

1.INTRODUÇÃO .001

1.1. ESTRUTURA E ORGANIZAÇÃO DO HIV .003

1.2. ESTRUTURA DAS ENZIMAS TRANSCRIPTASE REVERSA,

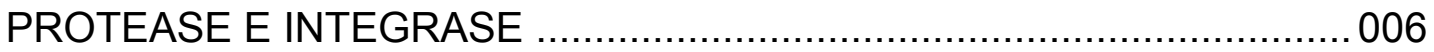

1.2.1.TRANSCRIPTASE REVERSA ......................................... 007

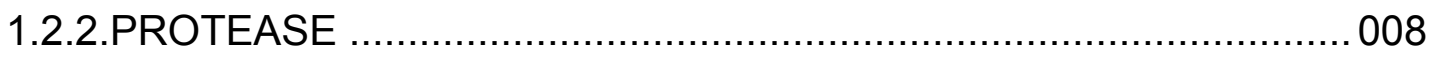

1.2.3.INTEGRASE ............................................................... 010

1.3.CICLO REPLICATIVO DO HIV ....................................................

1.4.ALVOS DA TERAPIA ANTI-RETROVIRAL …............................. 013

1.4.1.TRANSCRIPTASE REVERSA ......................................... 013

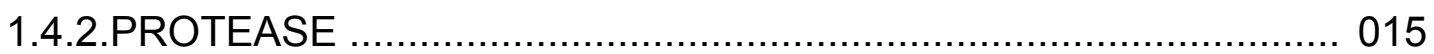

1.4.3.FUSÃO HIV-CÉLULA ....................................................... 016

1.5.MECANISMOS DE VARIAÇÃO VIRAL .................................... 016

1.6.RESISTÊNCIA AOS ANTI-RETROVIRAIS .................................. 018

1.7.RESISTÊNCIA AOS INIBIDORES DA TRANCRIPTASE REVERSA ANÁLOGOS DE NUCLEOSÍDEOS (ITRN) ...................................... 020 
1.8.RESISTÊNCIA AOS INIBIDORES DA TRANSCRIPTASE REVERSA NÃO ANÁLOGOS DE NUCLEOSÍDEOS (ITRNN) ………………….... 025

1.9. RESISTÊNCIA AOS INIBIDORES DA PROTEASE (IP) ............... 028

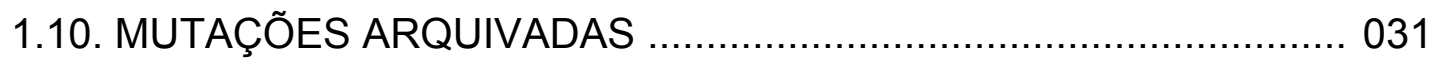

1.11.TESTES UTILIZADOS NA DETECÇÃO DE RESISTÊNCIA ........... 034

1.12. CLASSIFICAÇÃO DA INFECÇÃO PELO HIV EM CRIANÇAS.......... 035

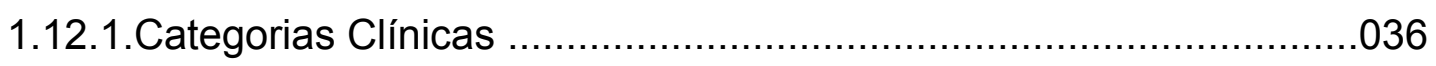

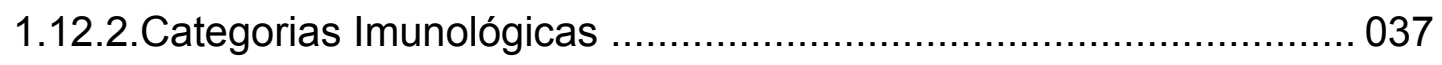

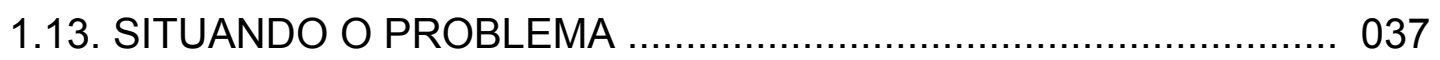

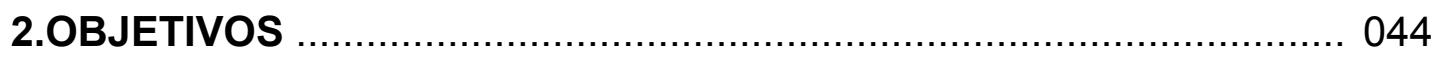

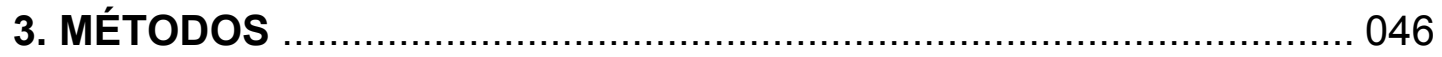

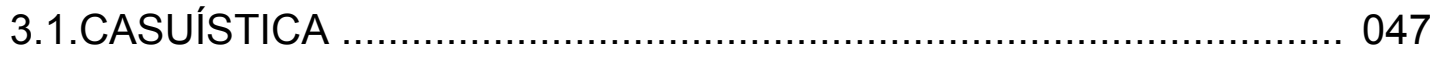

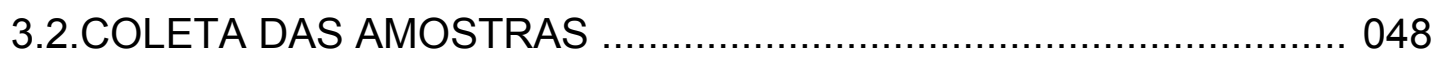

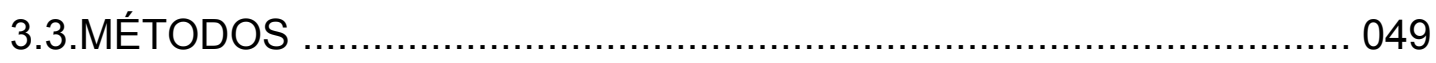

3.3.1.EXTRAÇÃO DO MATERIAL GENÔMICO …................................... 049

3.3.2.AMPLIFICAÇÃO DO MATERIAL GENÔMICO EXTRAÍDO

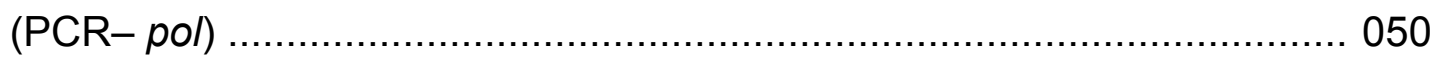

3.3.3.VISUALIZAÇÃO DOS FRAGMENTOS ………........................... 053

3.3.4.PURIFICAÇÃO DO MATERIAL AMPLIFICADO PARA

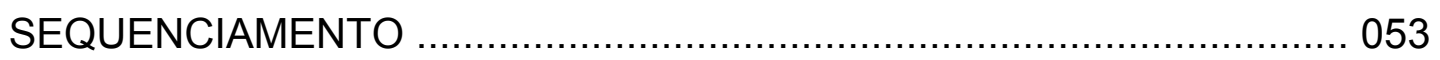

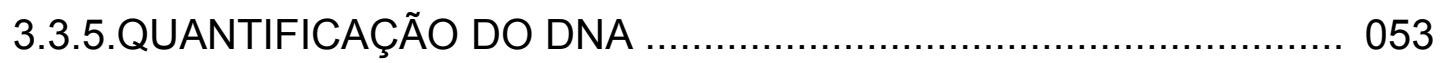

3.3.6.SEQUENCIAMENTO AUTOMÁTICO ………............................... 054

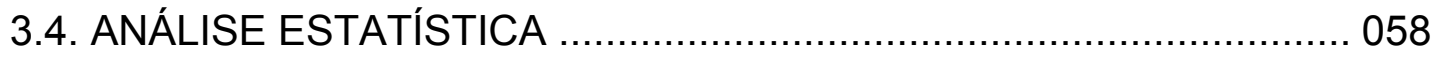


4. RESULTADOS

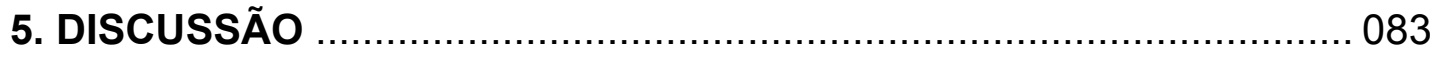

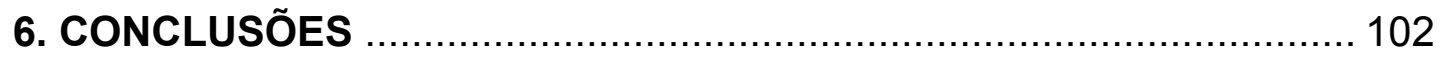

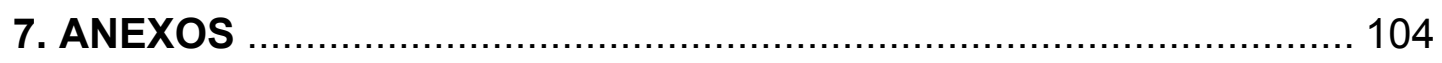

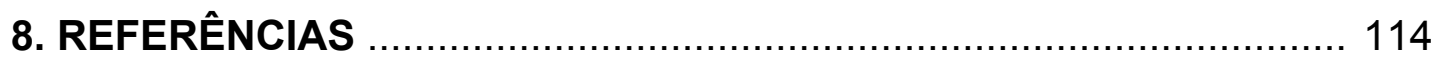

APÊNDICES 


\section{LISTA DE TABELAS}

Tabela 1- Drogas anti-retrovirais aprovadas pelo FDA para uso terapêutico. 015

Tabela 2 - Características dos pacientes no momento da primeira coleta ( $n=16)$, CEADIPe, São Paulo, $2002-2005$ 061

Tabela 3 - Características dos pacientes no momento da segunda coleta

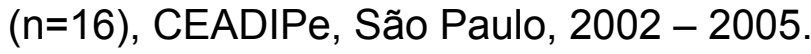

Tabela 4 - Mutações encontradas para cada classe de drogas em uso e drogas utilizadas por cada paciente, CEADIPe, São Paulo, $2002-2005$ 071

Tabela 5 - Número e porcentagem de pacientes na primeira coleta com mutações específicas para cada ARV, de acordo com o momento de uso da droga, CEADIPe, São Paulo, 2002 2005

Tabela 6 - Número e porcentagem de pacientes na segunda coleta com mutações específicas para cada ARV, de acordo com o momento de uso da droga, CEADIPe, São Paulo, 2002 2005 073

Tabela 7 - Número e percentagem de pacientes com mutações associadas à resistência de acordo a exposição aos ARV na primeira coleta, CEADIPe, São Paulo, 2002 - 2005. 074

Tabela 8 - Número e percentagem de pacientes com mutações associadas à resistência de acordo a exposição aos ARV na segunda coleta, CEADIPe, São Paulo, 2002 - 2005 074

Tabela 9 - Episódios de intercorrências clínicas observadas em crianças mantendo supressão viral prolongada no momento das coletas e no período intercoletas, CEADIPe, São Paulo, 2002 2005 079 


\section{LISTA DE FIGURAS}

Figura 1 - Esquema representativo da organização genômica do HIV-1.. 006

Figura 2 - Estrutura da transcriptase reversa do HIV-1 .......................... 008

Figura 3 - Estrutura da protease do HIV-1 …......................................... 009

Figura 4 - Mecanismos de resistência aos ITRN …………………….... 021

Figura 5 - Códons associados a mutações que causam resistência aos

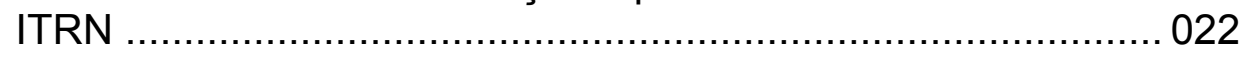

Figura 6 - Mecanismo de resistência aos ITRNN ………......................... 026

Figura 7 - Códons associados a mutações que causam resistência aos

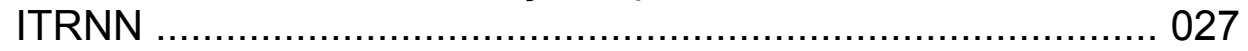

Figura 8 - Códons associados a mutações que causam resistência

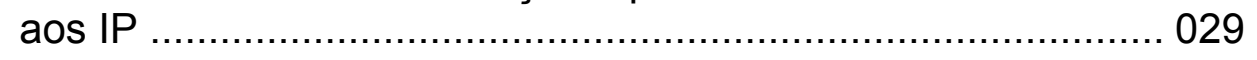

Figura 9 - Perfil terapêutico, imunológico e virológico dos pacientes........ 080 


\section{LISTA DE QUADROS}

Quadro 1- Classificação da infecção pelo HIV em crianças e adolescentes menores de 13 anos.

Quadro 2- Categorias imunológicas da classificação da infecção pelo HIV em crianças e adolescentes menores de 13 anos.

Quadro 3- Resumo dos iniciadores utilizados na amplificação e/ou na reação de sequenciamento...

Quadro 4- Mutações associadas à resistência aos ITR em crianças mantendo supressão viral prolongada, CEADIPe, São Paulo, $2002-2005$ 064

Quadro 5- Mutações associadas à resistência aos IP em crianças mantendo supressão viral prolongada, CEADIPe, São Paulo, $2002-2005$ 


\section{LISTA DE GRÁFICOS}

Gráfico 1 - Mutações associadas à resistência aos ITR em duas coletas, em amostras de crianças mantendo supressão viral prolongada, CEADIPe, São Paulo, 2002 - 2005 069

Gráfico 2 - Mutações associadas à resistência aos IP em duas coletas, em amostras de crianças mantendo supressão viral prolongada, CEADIPe, São Paulo, 2002 - 2005. 070

Gráfico 3 - Graus de resistência aos ITR na primeira coleta, em amostras de crianças mantendo supressão viral prolongada, CEADIPe, São Paulo, 2002 - 2005.

Gráfico 4 - Graus de resistência aos ITR na segunda coleta, em amostras de crianças mantendo supressão viral prolongada, CEADIPe, São Paulo, 2002 - 2005 076

Gráfico 5- Graus de resistência aos IP na primeira coleta, em amostras de crianças mantendo supressão viral prolongada, CEADIPe, São Paulo, $2002-2005$

Gráfico 6 - Graus de resistência aos IP na segunda coleta, em amostras de crianças mantendo supressão viral prolongada, CEADIPe, São Paulo, 2002 - 2005 078 
RESUMO 
De Angelis DSA. Avaliação do perfil de resistência genotípica aos anti-retrovirais de crianças infectadas pelo HIV-1 mantendo supressão viral prolongada em vigência de tratamento [dissertação]. São Paulo: Faculdade de Medicina, Universidade de São Paulo; 2006. 151p.

O tratamento de indivíduos infectados pelo HIV-1 com terapia anti-retroviral (ARV) pode reduzir a viremia plasmática abaixo dos limites de detecção dos ensaios atuais em muitos pacientes, porém difícil de ser alcançada em crianças na vida real. Falha em alcançar ou manter a supressão da replicação viral está geralmente associada com o desenvolvimento de vírus resistentes a drogas. Nós investigamos o perfil de resistência genotípica em crianças com supressão viral prolongada ( $<400$ cópias/mL de RNA viral plasmático) em vigência de tratamento anti-retroviral. Nós obtivemos 32 amostras de células mononucleares do sangue periférico (do inglês PBMC) de 16 crianças do CEADIPe - UNIFESP quem tinham tido carga viral indetectável por 12 meses ou mais, em dois momentos: a primeira amostra na inclusão e a segunda após mínimo de 9 meses de acompanhamento. A análise das seqüências foi realizada em vírus isolado de PBMC pelo "ABI PRISM 377 sequencer" (Applied Biosystems, USA). Dentre as principais características da população do estudo encontramos: mediana da idade na inclusão de 11 (6-15 anos); esquemas terapêuticos com 2 inibidores da transcriptase reversa análogos nucleosídeo (ITRN) + 1 inibidor da protease (IP) ou 2 ITRN + 1 inibidor da transcriptase reversa não-nucleosídeo (ITRNN) ou 2 ITRN + 2 IP + 1 ITRNN ou 2 ITRN + 2 IP ou 2 ITRN; mediana de células CD4 (cél/ $/ \mathrm{mm}^{3}$ ) de 1016 (3472588) e 938 (440-3038) no primeiro e segundo momentos, respectivamente; classificação clínica (CDC 1994): $\mathrm{N}=1, \mathrm{~A}=3, \mathrm{~B}=6$; e classificação imune (Cl): $\mathrm{Cl} 1=4, \mathrm{Cl} 2=6, \mathrm{Cl} 3=$ 6. O tempo médio de seguimento foi $15(9-27)$ meses a partir da inclusão. Seis $(37,5 \%)$ e $7(43,75 \%)$ dos 16 pacientes mostraram no mínimo uma mutação associada aos ITRN, na primeira e na segunda amostra, respectivamente. Dois dos dezesseis (12,5\%) apresentaram mutações associadas aos ITRNN na primeira amostra e 3/16 (18,75\%) na 
segunda. Além disso, 14/16 (87,5\%) mostraram pelo menos uma mutação associada aos IP nos dois momentos. A despeito do tratamento com drogas anti-retrovirais potentes e supressão do RNA do HIV-1 no plasma a níveis indetectáveis por vários meses, resistência parcial à terapia pode ter resultado primariamente de arquivos de vírus ou refletir precocemente condições sub-ótimas de tratamento.

DESCRITORES: RESISTÊNCIA VIRAL A DROGAS; GENÓTIPO; HIV-1; CRIANÇA; CARGA VIRAL; ANTI-RETROVIRAIS. 
De Angelis DAS. Evaluation of the antiretroviral genetic resistance profiles in HIV-1 infected children maintaining viral suppression under treatment [dissertation]. São Paulo: "Faculdade de Medicina, Universidade de São Paulo"; 2006. 151p.

Treatment of HIV1-infected individuals with antiretroviral therapy (ARV) can reduce plasma viremia to below the limits of detection of current assays in many patients, although it is difficult to happen to children in real life. Failure to achieve or maintain suppression of viral replication is often associated with the development of drug-resistant virus. We investigated genetic resistance profiles of low-level plasma HIV-1 in children with prolonged viral suppression ( $<400$ copies/mL of plasma HIV-1 RNA) while receiving ARV. We obtained 32 samples of peripheral-blood mononuclear cells (PBMC) from 16 children from CEADIPe UNIFESP who had had undetectable viral load for 12 months or more, at two moments: first sample at the inclusion and second after a minimum 9-months follow-up time. Sequence analysis was performed on virus isolated from PBMC by "ABI PRISM 377 sequencer" (Applied Biosystems, USA). The main characteristics of the study population were: median age baseline $=11$ (6-15 years); drug combinations $=2$ nucleoside reverse transcriptase inhibitor $(\mathrm{NRTI})+1$ protease inhibitor $(\mathrm{PI})$ or $2 \mathrm{NRTI}+1$ non-nucleoside reverse transcriptase (NNRTI) or $2 \mathrm{NRTI}+2 \mathrm{PI}+1 \mathrm{NNRTI}$ or $2 \mathrm{NRTI}+2 \mathrm{PI}$ or $2 \mathrm{NRTI}$; median CD4 cell count (cells $\left./ \mathrm{mm}^{3}\right)=1016(347-2588)$ and $938(440-3038)$ at first and second time points, respectively; clinic classification (CDC 1994): $N=1, A=3, B=6$; and immune classification (IC): IC $1=4$, IC $2=6$, IC $3=6$. The median follow-up time was $15(9-27)$ months starting from the inclusion. Six $(37,5 \%)$ and $7(43,75 \%)$ of the 16 patients showed at least one NRTIassociated mutation, in the first and second samples, respectively. Two out of sixteen $(12,5 \%)$ presented NNRTI-associated mutation at the first moment and $3 / 16(18,75 \%)$ at the second. In addition, 14/16 (87,5\%) showed at least one Pl-associated mutation at both moments. Despite treatment with potent antiretroviral drugs and plasma HIV-1 RNA suppression to undetectable levels for several months, partial resistance to therapy may result primarily from archival or contemplate earlier sub optimal treatment conditions. 
DESCRIPTORS: VIRAL DRUG RESISTANCE; GENOTYPE; HIV-1; CHILD; VIRAL LOAD; ANTIRETROVIRAL AGENTS. 
O Vírus da Imunodeficiência Humana (HIV), agente etiológico da Síndrome da Imunodeficiência Adquirida (aids), é o vírus mais extensivamente estudado nas últimas décadas. O primeiro alerta para a síndrome foi relatado em 1981 pelo Centro de Controle e Prevenção de Doenças (CDC) dos Estados Unidos, seguido da identificação do HIV como agente causador em 1983-1984 por Montagnier e Gallo e seus colaboradores. Desde então, a epidemia da infecção/doença pelo HIV tem se expandido mundialmente.

De acordo com a UNAIDS (Joint United Nations Programme on HIV/aids) e a OMS (Organização Mundial da Saúde), o número total de pessoas vivendo com HIV/aids até dezembro de 2005 é estimado em 40,3 milhões (36,7 - 45,3 milhões), das quais 2,3 milhões (2,1 - 2,8 milhões) são crianças abaixo de 15 anos.

A transmissão vertical é responsável pela maior parte das infecções pediátricas pelo HIV-1, apesar do tratamento das mulheres grávidas e seus filhos com anti-retrovirais ter reduzido a taxa de transmissão por essa via em muitos países (Luzuriaga \& Sullivan, 2002). Outras medidas profiláticas que têm diminuído a transmissão vertical são utilização da cesárea eletiva e a suspensão do aleitamento materno (Hermione Lyall, 2002).

Nessa seção, além de uma revisão da literatura sobre a estrutura e organização genômica do HIV, ciclo replicativo e enzimas virais, bem como 
os mecanismos de resistência às drogas anti-retrovirais, uma breve explanação sobre a evolução clínica e imunológica da infecção pelo HIV-1 em crianças será abordada.

\subsection{ESTRUTURA E ORGANIZAÇÃO DO HIV}

O HIV é um retrovírus do gênero Lentivírus. A complexidade genômica e heterogeneidade desse vírus explicam sua patogenicidade.

O vírion maduro do HIV é uma partícula icosaédrica, com aproximadamente $100 \mathrm{~nm}$. É um vírus envelopado, com genoma de 9,8kb constituído por duas fitas simples de RNA, que contém não somente os três genes essenciais para a replicação viral (gag, env, pol), mas também sete genes adicionais com funções regulatórias, entre outras, no ciclo replicativo desse agente (Wang et al, 2000) (Figura 1).

O gene gag (primeira ORF - "Open Reading Frame") codifica uma poliproteína Gag de $55 \mathrm{kDa}$ que é proteoliticamente clivada durante a maturação do vírus para dar origem às proteínas da matriz (MA, p17), do capsídeo (CA, p24), do nucleocapsídeo (NC, p7/p9), além de produtos de baixa massa molecular, p1, p2 e p6 (Barré-Sinoussi, 1996; Wang et al, 2000). 
A proteína da matriz (MA) está envolvida na fase precoce do ciclo de replicação viral e participa na formação e transporte do complexo de integração no núcleo da célula hospedeira (Barré-Sinoussi, 1996; Freed et al, 1997). As proteínas do capsídeo (CA) formam uma estrutura cônica, eletrodensa no centro do vírus maduro, que envolve o RNA viral, proteínas do nucleocapsídeo (NC) e outras enzimas (Turner \& Summers, 1999).

A segunda ORF, o gene pol, codifica as enzimas protease (PR), transcriptase reversa (TR) e integrase (IN), que serão detalhadas posteriormente. O gene env codifica duas proteínas de envelope, a SU, glicoproteína de superfície (gp120) e a TM, proteína transmembrana (gp41), que formam um complexo que interage especificamente com receptores celulares. Essa interação leva à fusão da membrana viral com a membrana celular (Wang et al, 2000).

Além das proteínas estruturais, encontradas em todos os retrovírus, todos os complexos lentivírus primatas contém uma série de proteínas acessórias, codificadas pelos genes nef, vpu, vif e vpr e proteínas reguladoras codificadas pelos genes tat, tev e rev (Barré-Sinoussi, 1996; Wang et al, 2000).

O gene nef produz uma proteína importante tanto para elevados níveis de replicação viral, como para a progressão da doença. É responsável 
pela regulação negativa da expressão de receptores CD4 na superfície celular de linfócitos (Mangarasian \& Trono, 1997).

Vpu é uma proteína com função dupla de modulação negativa de CD4 e aumento da liberação viral. O "fator de infectividade viral" ou Vif atua durante a montagem do vírus, permitindo a formação de partículas competentes para a fase precoce da infecção (Trono, 1995). Vpr é, provavelmente, a mais controversa proteína do HIV. Parece ser componente de complexos pré-integração e interagir diretamente com poros da membrana nuclear (Lehmann-Che \& Saïb, 2004; Nisole \& Saïb, 2004).

A proteína codificada pelo gene tat é responsável pela transativação viral, funcionando como potente amplificador da expressão viral. O gene rev é o segundo fator regulador necessário para a expressão do HIV, participando do transporte de mRNAs virais do núcleo para o citoplasma (Bogerd et al, 1995; Turner \& Summers, 1999). O gene tev codifica uma proteína de fusão Tat-Env-Rev, que apresenta funções semelhantes às proteínas Tat e Rev (Wang et al, 2000).

Um segundo tipo de HIV, o HIV-2, possui potencial de transmissão vertical cerca de 15 a 20 vezes menor que o HIV-1 e indivíduos infectados por esse vírus tem sobrevida mais longa (Barbosa, Machado \& Succi, 1999). O HIV-2 é prevalente no oeste da África e não está presente no nosso grupo de estudo, por esse motivo será dada atenção especial ao HIV-1. 


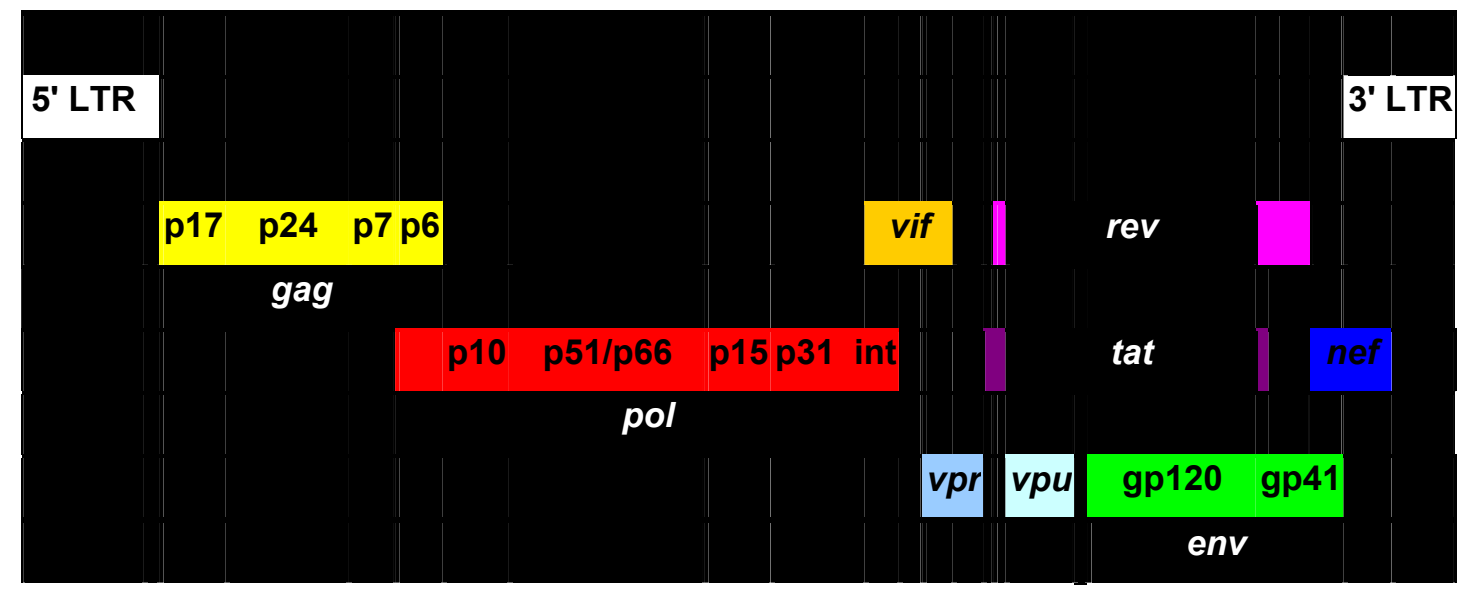

Figura 1 - Esquema representativo da organização genômica do HIV-1.

Fonte: Adaptado de Human Retroviruses and AIDS 1998: Los Alamos National Laboratory, Los Alamos, NM.

\subsection{ESTRUTURA DAS ENZIMAS TRANSCRIPTASE REVERSA,} PROTEASE E INTEGRASE

A cristalografia de alta resolução revelou a estrutura dessas três enzimas virais como proteínas oligoméricas. O funcionamento de cada uma delas é inteiramente dependente de sua estrutura quaternária (Sluis-Cremer \& Tachdjian, 2002). 


\subsubsection{TRANSCRIPTASE REVERSA}

A TR é um heterodímero composto de uma subunidade p66 (de 66KDa e 560 aminoácidos) que compreende os domínios DNA polimerase e RNAse $\mathrm{H}$, e uma subunidade derivada da p66, a p51 (51KDa e 440 aminoácidos) (Mulky et al, 2004). A subunidade p51 é produzida durante a montagem e maturação do vírus a partir da clivagem do domínio $C$ terminal (RNAse H) da p66, mediada pela protease do HIV-1, resultando na falta do domínio RNAse H na p51 (Sluis-Cremer \& Tachedjian, 2002).

A Figura 2 mostra que a subunidade p66 apresenta forma semelhante à da mão direita e além do domínio RNAse, apresenta na polimerase, os subdomínios denominados de "dedos" (resíduos 1-85; 118-155), "palma" (resíduos 86-117; 156-237), "polegar" (resíduos 238-318) e "conexão" (resíduos 319-426) (Sundaravaradan, Hahn \& Ahmad, 2005). Os mesmos domínios estão presentes na subunidade p51 e apesar da estrutura semelhante em ambos p66 e p51, a disposição espacial difere (Götte, Li \& Wainberg, 1999). 


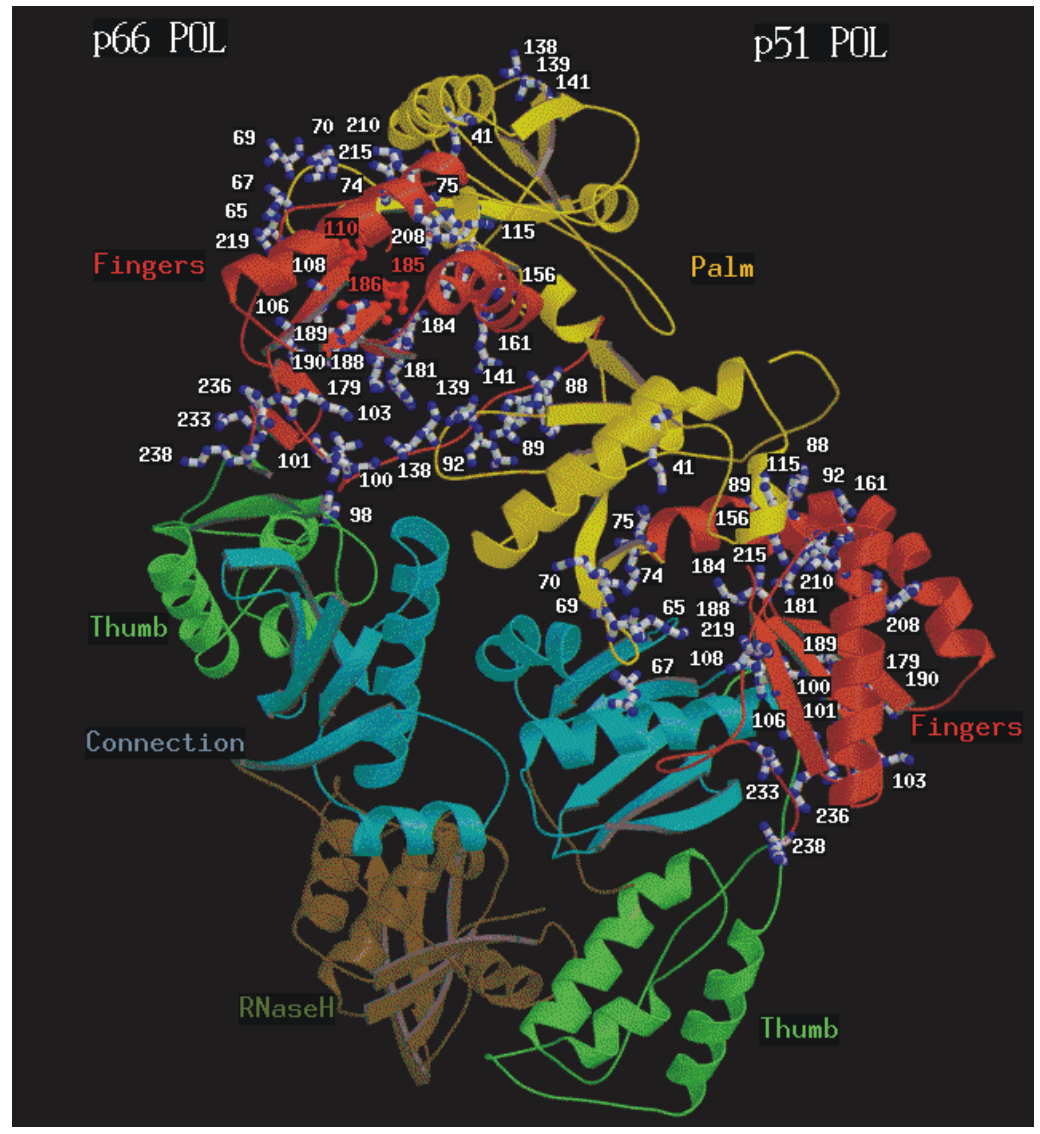

Figura 2 - Estrutura da transcriptase reversa do HIV-1.

Fonte: Los Alamos National Laboratory

\subsubsection{PROTEASE}

A protease é um homodímero simétrico composto de duas subunidades quimicamente idênticas de 99 aminoácidos (Sluis-Cremer \& Tachedjian, 2002).

O sítio ativo da enzima, representado na Figura 3 pelos pontos vermelhos, é formado na interface das duas subunidades e contém uma 
tríade catalítica (Asp25-Thr26-Gly27), responsável pelas reações de clivagem da PR (Turner \& Summers, 1999).

Essa enzima é codificada no final 5' do gene pol e é expressa como parte da poliproteína Gag-Pol. É responsável pela proteólise de Gag (para produzir as proteínas estruturais p24, p17 e p7 do core viral) e de Gag-Pol (para produzir enzimas essenciais como TR e IN), sendo absolutamente necessária para o ciclo replicativo do vírus e importante alvo de terapia antiretroviral (Gavin \& Yogen, 2002).

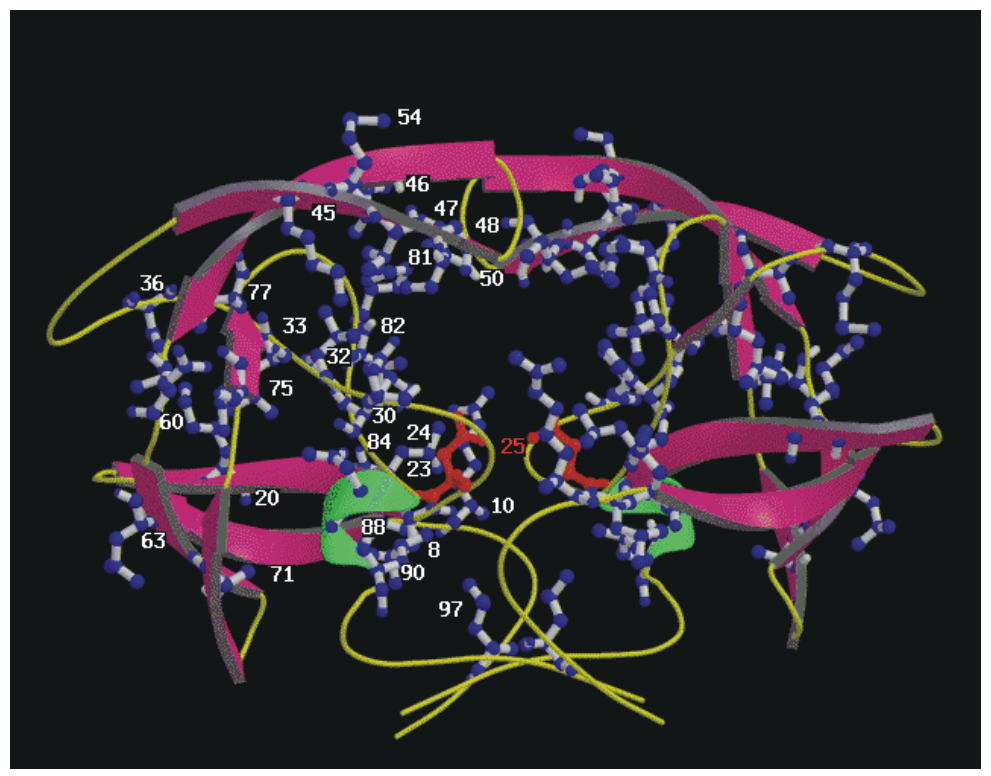

Figura 3 - Estrutura da protease do HIV-1.

Fonte: Los Alamos National Laboratory 


\subsubsection{INTEGRASE}

A integrase retroviral é uma enzima de 32KDa (288 aminoácidos) composta de uma cadeia de polipeptídeos dividida em três domínios funcionais distintos: o domínio $\mathrm{N}$ terminal (resíduos 1-50), o domínio central catalítico (resíduos 50-212) e o domínio C terminal (resíduos 212-288) (Barreca et al, 2003).

É responsável pela integração do cDNA viral no cromossomo celular e, conseqüentemente, pela persistência do vírus na célula (Cherepanov et al, 2003).

Essa proteína realiza ainda outras funções no ciclo replicativo do HIV1, que incluem cooperação na transcrição reversa, importação nuclear dos complexos de pré-integração e produção de partículas do vírus (Mulder, Chakrabarti \& Muesing, 2002).

\subsection{CICLO REPLICATIVO DO HIV}

O HIV-1 existe em diferentes formas em vários compartimentos e com diferentes taxas de replicação. O HIV-1 está presente como vírus livre no plasma ou ligado a células dendríticas, como provírus integrado em células T 
$\mathrm{CD}^{+}$e macrófagos ativados infectados produtivamente e na forma latente em células T CD4 ${ }^{+}$de memória (Persaud et al, 2000).

O ciclo replicativo dos retrovírus está dividido em duas fases distintas: a fase precoce, que se refere aos passos de infecção da célula até a integração do cDNA viral no genoma celular, e a fase tardia, que resulta na expressão de genes virais e continua com a liberação e maturação dos vírus (Nisole \& Saïb, 2004). A entrada do HIV-1 na célula envolve uma ligação de alta afinidade entre a glicoproteína gp120 e o receptor celular CD4 (determinante clonal), presente na superfície de linfócitos $T$ auxiliares, monócitos e células dendríticas (Wang et al, 2000; Matthews et al, 2004).

Essa interação é suficiente para ligar o vírus, mas não para a infecção (Turner \& Summers, 1999). Interações adicionais com receptores de quimiocinas ativam uma mudança conformacional na gp41, que leva à fusão das membranas do vírus e da célula alvo (Matthews et al, 2004).

O receptor CXCR4 (receptor de $\alpha$-quimiocinas) é o principal coreceptor para cepas de HIV-1 com tropismo por células T enquanto o CCR5 (receptor de $\beta$-quimiocinas) é o receptor primário para cepas macrófagotrópicas (Cooley \& Lewin, 2003).

Após a fusão, o capsídeo do HIV-1 libera seu conteúdo no citoplasma (Peçanha \& Antunes, 2002). No citosol a transcrição reversa do RNA viral é catalisada pela enzima transcriptase reversa, resultando numa dupla fita de 
DNA complementar (cDNA). A proteína acessória Vif é importante facilitadora nos estágios iniciais da transcrição reversa (Turner \& Summers, 1999).

Uma vez sintetizado, o cDNA viral é transportado para o núcleo a partir de complexos pré-integração (PICs) (Lehmann-Che \& Saïb, 2004), quando então a enzima viral integrase promove a integração estável do cDNA viral no genoma da célula hospedeira, onde é chamado de provirus (Peçanha \& Antunes, 2002).

Após a integração, o provirus pode permanecer dormente ou ser transcrito a RNA. O conjunto de RNAs transcritos é transportado para o citoplasma, onde serão traduzidos, ou constituirão novas partículas virais em um processo regulado pela proteína Rev (Peçanha \& Antunes, 2002).

Após o brotamento a PR viral cliva as poliproteínas Gag e Gag-Pol completando o ciclo de replicação do HIV-1. Os vírions maduros são então capazes de infectar uma nova célula (Peçanha \& Antunes, 2002). 


\subsection{ALVOS DA TERAPIA ANTI-RETROVIRAL}

Atualmente, existem quatro classes de drogas que inibem a replicação do HIV-1, disponíveis para o uso pediátrico. O mecanismo de ação dessas drogas baseia-se na inibição da transcriptase reversa (TR) do vírus [inibidores da transcriptase reversa análogos de nucleosídeos (ITRN) ou não-análogos de nucleosídeos (ITRNN)] (Whitcomb et al, 2002), assim como da protease (inibidores da protease) (Ammaranond et al, 2003). Mais recententemente surgiu uma nova classe de drogas que inibe a fusão do vírus à célula alvo (Matthews et al, 2004).

\subsubsection{TRANSCRIPTASE REVERSA}

Existem duas classes de drogas que inibem a TR:

- Análogos nucleosídeos ou nucleotídeos da TR timidínicos e não timidínicos. As drogas pertencentes a esse grupo são sucessivamente fosforiladas no citoplasma da célula alvo para atingir sua forma trifosfato (ativa), sendo que cada droga pode necessitar de vias metabólicas distintas. Enzimas específicas na célula hospedeira são responsáveis por esse processo (King et al, 2002).

Essas drogas competem com o substrato natural, ligando-se ao sítio ativo da TR, sendo incorporados na cadeia crescente de DNA, provocando 
sua terminação e, conseqüentemente, inibindo a transcrição do RNA viral em DNA. Os análogos de timidina (AZT e d4T) são fosforilados em células ativadas enquanto os não-timidínicos são fosforilados, de preferência, em células de memória (King et al, 2002).

- Não análogos nucleosídeos da TR. Diferem dos análogos nucleosídeos porque não interagem com o sítio ativo da TR, mas com o sítio de ligação alostérico e não necessitam de ativação intracelular (King et al, 2002).

O sítio de ligação dos não análogos é uma cavidade hidrofóbica, presente próximo ao sítio ativo da p66. Análises cristalográficas de vários complexos não análogos com a TR levam à proposta de que os inibidores não análogos bloqueiam a TR por promover alteração conformacional nessa enzima (Mitsuya \& Erickson, 1999).

Em virtude dos inibidores não análogos apresentarem praticamente o mesmo modo de ligação à $T R$, mutações que causam resistência a uma droga dessa classe, inviabilizam a terapia com os outros inibidores não análogos, devido à resistência cruzada (Peçanha \& Antunes, 2002). As drogas existentes aprovadas para uso terapêutico estão relacionadas na Tabela 1. 
Tabela 1- Drogas anti-retrovirais aprovadas pelo FDA para uso terapêutico.

Inibidores da RT

\begin{tabular}{ccccc} 
& Inibidores da RT & Inibidores da PR & $\begin{array}{c}\text { Inibidor de } \\
\text { Fusão }\end{array}$ \\
\hline $\begin{array}{c}\text { Análogos } \\
\text { timidínicos }\end{array}$ & $\begin{array}{c}\text { Análogos não- } \\
\text { timidínicos }\end{array}$ & $\begin{array}{c}\text { Não análogos } \\
\text { nucleosídeos }\end{array}$ & & \\
\hline Estavudina(d4T) & Abacavir (ABC) & Delavirdina(DLV) & Atazanavir (ATV) & Enfuvirtide(ENF) \\
Zidovudina(ZDV) & Didanosina (ddl) & Efavirenz (EFV) & Amprenavir(APV) & \\
& Entricitabina(FTC) & Nevirapina(NVP) & Indinavir (IDV) & \\
& Lamivudina (3TC) & & Lopinavir (LPV) & \\
& Tenofovir (TDF)* & & Nelfinavir (NFV) & \\
& Zalcitabina (ddC) & & Ritonavir (RTV) & \\
& & & Saquinavir(SQV) & \\
& & & Tipranavir (TPV) & \\
\hline
\end{tabular}

* O Tenofovir é um inibidor de transcriptase reversa análogo nucleotídeo.

Fonte: Los Alamos National Laboratory

\subsubsection{PROTEASE}

A protease é responsável pelo processamento das poliproteínas dos genes gag e gag-pol, que resulta nas proteínas estruturais e enzimas da partícula viral madura. Esse processamento é necessário para a infectividade viral (Potter et al, 2004). O conhecimento da estrutura e da função da protease levou ao desenvolvimento de diferentes inibidores potentes e quimicamente distintos. Os inibidores da protease representam o maior avanço no tratamento da infecção pelo HIV (De Souza \& De Almeida, 2003). 


\subsubsection{FUSÃO HIV-CÉLULA}

A fusão HIV-célula se dá em cascata com vários passos envolvendo uma série de mudanças conformacionais na gp120 e gp41. O primeiro evento é a ligação da gp120 com o receptor CD4. Isso provoca a expressão de um segundo sítio de ligação da gp120 a co-receptores de quimiocinas. A ligação com o co-receptor leva a uma conformação ativa de fusão da gp41. O domínio externo da gp41 contém duas regiões: HR1 (próxima ao $\mathrm{N}$ terminal) e HR2 (próxima ao C terminal). A região HR1 forma uma estrutura helicoidal e a região HR2 se volta para dentro da área hidrofóbica da estrutura helicoidal HR1, formando uma outra estrutura que contém seis hélices estáveis termodinamicamente levando à fusão completa das membranas vírus-célula.

O Enfuvirtide, inibidor de fusão aprovado pelo FDA, bloqueia a formação da estrutura de seis hélices da gp41 e, conseqüentemente, a fusão HIV-célula (Matthews et al, 2004). Maior atenção será dada aos inibidores da TR e PR, objetos do nosso estudo.

\subsection{MECANISMOS DE VARIAÇÃO VIRAL}

Grande parte do nosso conhecimento atual a respeito da estrutura e função dos genes derivou-se da análise de alterações em suas seqüências nucleotídicas. 
Variações genéticas são inerentes a todos os vírus RNA, mas têm sido mais bem caracterizadas para o HIV-1. A extensiva heterogeneidade observada mundialmente na epidemia pelo HIV-1 é originada da rápida replicação viral num indivíduo infectado e da elevada taxa de substituições incorretas de nucleotídeos durante a transcrição reversa do HIV na ausência de mecanismos de correção, que resulta em mutações (Lal, Chakrabarti \& Yang, 2005).

Outro fato importante para o surgimento de variantes é a rápida seleção de vírus com distintas capacidades replicativas devido à pressão imune, seleção de co-receptores e/ou de drogas anti-retrovirais (Cornelissen et al, 1997).

As mutações podem ser definidas em diversas classes e cada uma delas envolve alteração em um único ou em múltiplos nucleotídeos:

- Substituições: mutações pontuais que resultam na substituição de um único nucleotídeo. Quando ocorrem na porção codificante do gene podem criar códons prematuros de parada, resultando na expressão de um polipeptídeo truncado e fenótipo mutante. Em regiões não codificantes, podem alterar seqüências regulatórias funcionais, levando ao aumento ou diminuição da expressão gênica. 
- Inserções e deleções: mutações decorrentes da adição ou remoção de um ou mais nucleotídeos, respectivamente. Quando ocorrem em regiões codificantes e envolvendo múltiplos de três nucleotídeos, podem resultar na produção de polipeptídeos com comprimento incorreto. Inserções e deleções não envolvendo múltiplos de três nucleotídeos resultarão em mutações com deslocamento do quadro de leitura. Isso altera efetivamente o código, prevenindo a expressão de uma proteína funcional. Tanto inserções como deleções podem também afetar a expressão de determinado gene, se alterarem seqüências regulatórias associadas ao gene (Walker, 1999).

A elevada taxa de mutação do HIV-1 pode resultar na geração de numerosas variantes, geneticamente relacionadas, chamadas de

quasispécie (Lal, Chakrabarti \& Yang, 2005). É importante ressaltar a diversidade genética em âmbito global e a distribuição mundial de diversos subtipos de HIV que compõem a pandemia.

\subsection{RESISTÊNCIA AOS ANTI-RETROVIRAIS}

O HIV desenvolve resistência aos anti-retrovirais muito rapidamente como conseqüência da alta variabilidade nos genes da TR e PR, devido ao acúmulo de mutações (Clavel \& Hance, 2004). Na ausência de pressão seletiva, os variantes resistentes têm menor capacidade replicativa que o vírus selvagem. Na presença de drogas anti-retrovirais os variantes são capazes de emergir e tornar-se dominantes (Doukhan \& Delwart, 2001). 
Alguns fatores celulares também podem colaborar para a diminuição da sensibilidade aos anti-retrovirais, tais como fosforilação intracelular deficiente (necessária para transformar alguns fármacos na sua forma ativa) ou mecanismos de membrana celular que retiram os fármacos da célula, impedindo seu acesso ao vírus. Isoladamente, ou mais freqüentemente em conjunto, esses fatores contribuem para os insucessos terapêuticos (Camacho, 2000).

Como resultado do aparecimento relativamente rápido de resistência a todas as drogas anti-HIV conhecidas, o sucesso do tratamento pode depender do desenvolvimento de drogas anti-retrovirais distintas que possam ser usadas em conjunto, bem como a intervenção precoce no curso da infecção, a fim de reduzir o acúmulo de vírus variantes contendo mutações de resistência contra todas as drogas do coquetel (Janeway et al, 2001).

Algumas mutações são capazes por si só de diminuir a susceptibilidade do vírus ou causar resistência a uma ou mais drogas (mutações primárias); outras parecem reforçar efeitos de um evento primário e estão associadas com a restauração do "fitness" viral original na presença de inibidores (mutações acessórias) (Huang et al, 1998; Brindeiro et al, 2002). Então, o aparecimento de mutações primárias em um genoma que já contém mutações acessórias, pode influenciar na velocidade com que os 
vírus altamente resistentes são selecionados durante a terapia (Vergne et al, 2000; Zhong et al, 2003).

\subsection{RESISTÊNCIA AOS INIBIDORES DA TRANCRIPTASE REVERSA ANÁLOGOS DE NUCLEOSÍDEOS (ITRN)}

A resistência aos ITRN pode ocorrer por dois mecanismos distintos, conforme demonstrado na figura 4 :

- Interferência na incorporação do análogo: várias mutações, ou grupos de mutações na TR podem promover resistência por dificultar a capacidade da TR de incorporar o análogo na cadeia de DNA. Inclui a mutação M184V, o complexo de mutações Q151M e a mutação K65R (Clavel \& Hance, 2004).

- Remoção do análogo da cadeia de DNA terminada: associada com o grupo de mutações chamado "mutações aos análogos de timidina - do inglês TAM". As TAMs promovem resistência por permitir a remoção da droga incorporada ao DNA mediada por ATP ou pirofosfato. Chamadas de "mutações de excisão de nucleotídeo - do inglês NEM" (Clavel \& Hance, 2004).

Na figura 5 estão descritos os códons da TR associados com mutações que conferem resistência aos ITRN. 


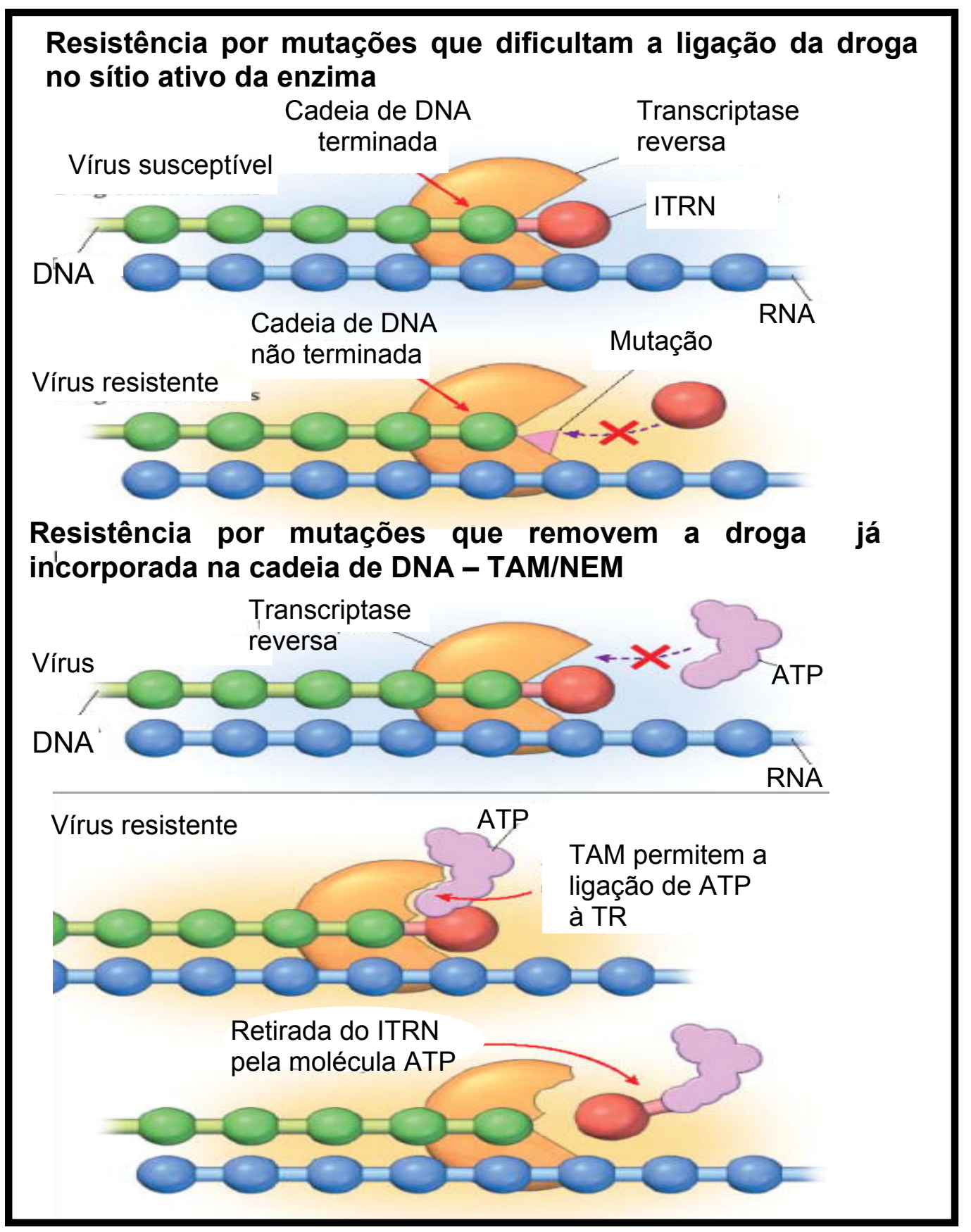

Figura 4 - Mecanismos de resistência aos ITRN.

Fonte: Adaptado de Clavel \& Hance, 2004. 



\begin{tabular}{|c|c|c|c|c|c|c|c|c|c|c|c|c|c|c|c|c|c|c|c|c|c|}
\hline $\begin{array}{l}\stackrel{\mathscr{0}}{0} \\
\text { 융 }\end{array}$ & $\overline{\bar{f}}$ & 焉 & 요 & $\stackrel{\mathscr{8}}{\stackrel{8}{0}}$ & $\grave{ঃ}$ & : & $\stackrel{R}{\underline{r}}$ & $\Xi$ & $\stackrel{10}{5}$ & $\stackrel{20}{\Sigma}$ & $\stackrel{\infty}{\lessgtr}$ & $\frac{\bar{s}}{0}$ & $\frac{5}{2}$ & 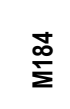 & 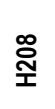 & $\stackrel{\circ}{\stackrel{I}{Y}}$ & $\underset{\approx \Sigma}{\bar{\Sigma}}$ & 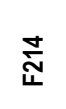 & $\stackrel{\mathscr{I}}{\Sigma}$ & 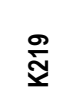 & ల్ల్ర \\
\hline ABC & L & & & $R$ & del/N & ins & $R$ & V & & $\mathrm{F}$ & & M & & VII & & W & & & Y/F & $E / Q$ & \\
\hline ddl & L & & & $\mathrm{R}$ & del/N & $\begin{array}{l}\text { ins/A/D } \\
S / N / G\end{array}$ & $R$ & V & T & & & M & & VII & & W & & & YIF & $E / Q$ & \\
\hline $3 \mathrm{TC}$ & & $A / D$ & & $R$ & del & ins & & & & & 1 & M & s & V/I & & & & & & & \\
\hline $\mathrm{d} 4 \mathrm{~T}$ & L & & T & & del/N & $\begin{array}{l}\text { ins/ } \\
A / G / S\end{array}$ & $\mathrm{R}$ & & M/ST/A & & & M & & VII & & W & & & Y/F & $E / Q$ & \\
\hline TDF & L & & & $\mathrm{R}$ & del/N & ins & $R$ & & & & & M & & VII & & W & & & YIF & $E / Q$ & \\
\hline AZT & L & & & & del/N & ins & $\mathrm{R}$ & & & & & M & & & & & & & Y/F & $E / Q$ & \\
\hline $\begin{array}{l}\text { AZT + } \\
\text { 3TC }\end{array}$ & L & $A / D$ & & & del/N & ins & $\mathrm{R}$ & & & & 1 & M & S & VII & $Y$ & W & K & $\mathrm{F}$ & Y/F & $E / Q$ & $\mathrm{D} / \mathrm{E}$ \\
\hline
\end{tabular}

Figura 5 - Códons associados a mutações que causam resistência aos ITRN.

Fonte: Adaptado do algoritmo da base de dados da RENAGENO 2006. 
A ZDV foi o primeiro análogo nucleosídeo desenvolvido como droga anti-HIV (De Souza \& De Almeida, 2003). É um análogo de timidina, com um grupo 3'-azido no lugar do grupo 3'-hidroxila. Essa substituição impede a forma trifosfato da droga (AZT) de realizar ligações fosfodiéster 5'-3', promovendo, assim, a terminação da cadeia de DNA. Essa droga também inibe a timidina endógena, por competição (Serchuck, Welles \& Yarchoan, 1999).

Cepas virais com sensibilidade reduzida a ZDV foram observadas em 1989, três anos após sua introdução no tratamento de pacientes com HIV. Subseqüentemente, resistência a cada droga anti-retroviral licenciada até o momento foi observada (Stevens, Kaye \& Corrah, 2004).

Várias mutações nos aminoácidos são selecionadas primeiramente com tratamento com ZDV. Essas mutações, referidas como mutações análogas de timidina (TAMs), incluem M41L (substituição de uma metionina por uma valina no códon 41), D67N (ácido aspártico por asparagina), K70R (lisina por arginina), L210N (leucina por asparagina), T215Y/F (triptofano por tirosina ou fenilalanina) e K219Q (lisina por glutamina) (Maxeiner et al, 2002; Sundaravaradan, Hahn \& Ahmad, 2005).

Em contraste, mutações que causam resistência a abacavir (ABC) (Moyle, 2001), didanosina (ddl) e lamivudina (3TC) (L74V e M184I/V) restauram parcialmente a sensibilidade a ZDV nos mutantes T215Y/F, mas o 
efeito não é recíproco (Huang et al, 1998). A taxa de replicação de vírus mutante M184V é substancialmente diminuída com relação ao vírus selvagem (Sarafianos et al, 1999).

Outras mutações associadas à resistência a drogas foram relatadas por serem selecionadas pelo abacavir in vitro: K65R e Y115F (Walter et al, 2002; Stone et al, 2004). Além disso, resistência ao abacavir ocorre por meio do complexo Q151M e da família de inserções de aminoácidos entre os códons 67 e 70 da transcriptase reversa, associados a multi-resistência (Walter et al, 2002).

Resistência a 3TC na ausência da mutação M184I/V foi associada com novo padrão de mutações nos códons 44 (E44D/A) e/ou 118 (V118I). Essa última também está envolvida na resistência a d4T (Montes \& Segondy, 2002).

A mutação V75T (valina por triptofano) é selecionada pela estavudina e confere resistência da ddl e ddC (zalcitabina). Ocorre em cerca de $4 \%$ dos pacientes que falham a estavudina (Turner, Brenner \& Wainberg, 2004).

O tenofovir, inibidor da transcriptase reversa análogo de nucleotídeo, (in vitro) parece ser ativo contra ampla variedade de cepas resistentes a inibidores de transcriptase reversa análogos de nucleosídeo, incluindo as que apresentam algumas TAMs (D67N + K70R + T215Y) e mutações de 
resistência a ddl (L74V) ou ddC (T69D). A susceptibilidade ao tenofovir pode ser aumentada pela presença de M184V induzida pela lamivudina (3TC) (McColl \& Miller, 2003).

Diferente de outros inibidores de transcriptase reversa análogos nucleosídeos, o tenofovir retém atividade frente ao complexo Q151M, enquanto que a inserção T69SS mostra elevado grau de resistência ao tenofovir (White et al, 2004).

\subsection{RESISTÊNCIA AOS INIBIDORES DA TRANSCRIPTASE REVERSA NÃo ANÁLOGOS DE NUCLEOSÍDEOS (ITRNN)}

As mutações selecionadas pela falha de tratamento com ITRNN estão localizadas no sítio alvo desses compostos e reduzem a afinidade da droga (Clavel \& Hance, 2004). O mecanismo é demonstrado na Figura 6.

As principais mutações que ocorrem em vírus selecionados por ITRNN são L100I, K103N, V106A, V108I, V181C/I, Y188C/L, G190A/E/S, P225H, M230L e P236L (Potter et al, 2004).

Os códons da TR associados a mutações de resistência aos ITRNN podem ser vistos na Figura 7. 


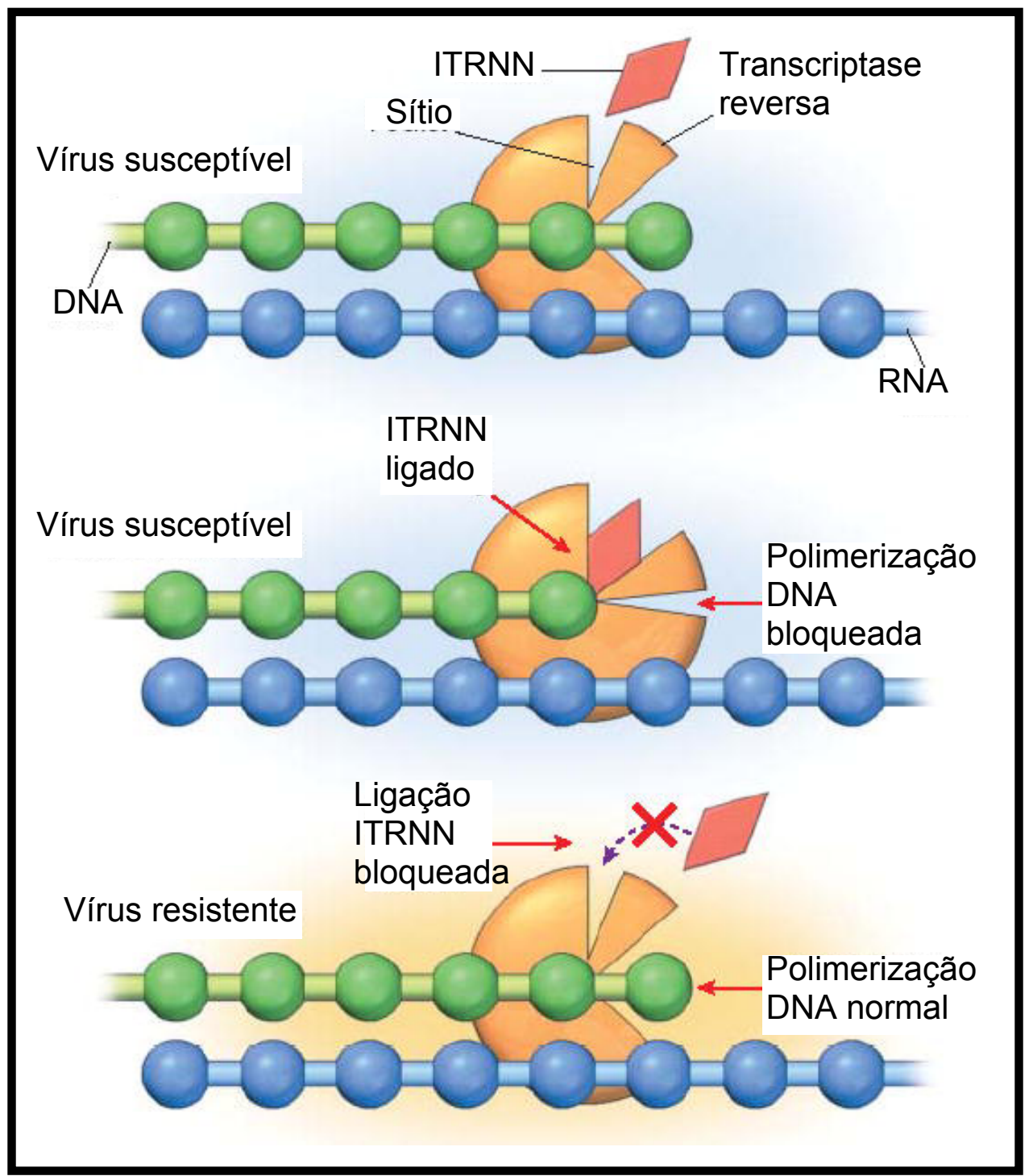

Figura 6- Mecanismo de resistência aos ITRNN.

Fonte: Adaptado de Clavel \& Hance, 2004. 


\begin{tabular}{|c|c|c|c|c|c|c|c|c|c|c|c|c|c|c|}
\hline $\begin{array}{l}0 \\
0 \\
0 \\
0\end{array}$ & $\stackrel{\infty}{8}$ & 욤 & $\stackrel{m}{\dot{x}}$ & $\stackrel{\circ}{\infty}$ & $\stackrel{\infty}{\circ}$ & $\sum^{\infty}$ & 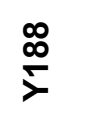 & $\frac{\circ}{5}$ & $\stackrel{\text { N }}{\text { N }}$ & ลิ & $\begin{array}{l}\stackrel{\mathscr{N}}{\mathbf{\Sigma}} \\
\text { }\end{array}$ & $\stackrel{0}{\stackrel{N}{\Delta}}$ & $\underset{\mathscr{N}}{\tilde{\Upsilon}}$ & 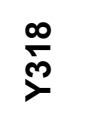 \\
\hline DLV & & I & $\begin{array}{c}\text { NHT } \\
\text { SV }\end{array}$ & A & & $\mathrm{CIL}$ & L & $E$ & $\mathrm{H}$ & $L$ & L & L & & \\
\hline EFV & G & I & $\begin{array}{c}\text { NHT } \\
\text { SV }\end{array}$ & AM & & $\mathrm{Cl}$ & $\mathrm{CHL}$ & $\begin{array}{l}\text { AEQ } \\
\text { STV }\end{array}$ & $\mathrm{H}$ & & L & & & \\
\hline NVP & G & I & $\begin{array}{l}\text { NHT } \\
\text { SV }\end{array}$ & A & 1 & CIS & $\mathrm{CHL}$ & $\begin{array}{c}\text { ACEQ } \\
\text { STV }\end{array}$ & & $\mathrm{L} / \mathrm{C}$ & & & $\mathrm{T} / \mathrm{N}$ & $\mathrm{F} / \mathrm{W}$ \\
\hline
\end{tabular}

Figura 7 - Códons associados a mutações que causam resistência aos ITRNN.

Fonte:Adaptado do algoritmo da base de dados da RENAGENO 2006.

A perda de atividade anti-retroviral está associada com a aquisição de mutações ao redor da cavidade hidrofóbica na subunidade p66 da TR, principalmente nas posições dos aminoácidos 103 (K-N), 106 (V-M), 181 (YC/I), 188 (Y-C) e 190 (G-A). Algumas dessas alterações têm efeito não só na resistência fenotípica, mas também em propriedades enzimáticas (IglesiasUssel et al, 2002).

Passagens in vitro do HIV-1, na presença de DLV, leva à emergência de uma única mutação na TR, a P236L, que confere aumento da susceptibilidade a outros ITRNN (Demeter et al, 2000). 
Em cultura de células, o EFV é potente inibidor da replicação do HIV-1 e retém significante atividade contra cepas virais resistentes a outros ITRNN. Essa droga seleciona mutações nos códons 100, 108, 179 e 181 da TR. Além disso, a dupla mutação L100I/K103N está associada com elevado grau de resistência ao EFV (Bacheler et al, 2001).

\subsection{RESISTÊNCIA AOS INIBIDORES DA PROTEASE (IP)}

Para alguns ITRN e ITRNN, uma única mudança de nucleotídeo está associada com elevado nível de resistência a essas drogas, enquanto para alguns IP o alto nível de resistência requer o acúmulo de cinco ou mais mutações. As mutações no sítio ativo, centrais para desenvolvimento de alto nível de resistência a IP estão nas posições 30,46 , 48, 50, 82, 84 e 90 (mutações primárias). A presença de 1 ou 2 mutações primárias pode resultar em elevado grau de resistência. Além disso, a resistência a IP se desenvolve com aquisição de múltiplas mutações acessórias na protease viral (Gavin \& Yogev, 2002).

Os códons associados a mutações que causam resistência aos IP estão demonstrados na Figura 8. 


\begin{tabular}{|c|c|c|c|c|c|c|c|c|c|c|c|c|c|c|c|c|c|c|c|c|c|c|c|c|c|c|c|c|c|c|c|c|c|c|c|}
\hline $\begin{array}{l}0 \\
\text { o. } \\
.0 \\
0\end{array}$ & 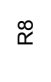 & $\stackrel{\circ}{\Xi}$ & $\frac{0}{0}$ & ঙ̃ & $\stackrel{\Xi}{\Xi}$ & ס̊ & $\stackrel{N}{s}$ & $\stackrel{m}{9}$ & 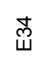 & 芭 & $\begin{array}{l}\stackrel{\infty}{\infty} \\
\stackrel{m}{\Sigma}\end{array}$ & $\underset{\check{z}}{\bar{z}}$ & $\stackrel{m}{\square}$ & 导 & $\stackrel{0}{\stackrel{0}{2}}$ & 至 & $\stackrel{\infty}{0}$ & 요 & 莡 & $\underline{f}$ & tô & 足 & ๕ & $\stackrel{\widetilde{\sigma}}{0}$ & @̊ & $\bar{\alpha}$ & S. & $\stackrel{+}{\stackrel{5}{F}}$ & 5 & $\stackrel{\infty}{\infty}$ & $\begin{array}{l}\not{D} \\
\underline{n^{\prime}}\end{array}$ & $\stackrel{\substack{\infty \\
z}}{\infty}$ & $\stackrel{\circledR}{9}$ & $\stackrel{9}{9}$ & $\stackrel{\mathscr{\rho}}{9}$ \\
\hline APV & & FIV & & MR & & & 1 & $\mathrm{~F}$ & & D & & K & & & IL & v & & v & & LMV & & & & & P & & $s$ & & & $\begin{array}{l}\text { AFI } \\
\text { TS }\end{array}$ & v & & & M & \\
\hline IDV & & IRV & & MR & 1 & & & & & & 1 & & & & IL & & V & & & LTV & & $E$ & & & $\begin{array}{l}\text { AlPQ } \\
\text { VYT }\end{array}$ & ITV & s & & & AFT & V & s & M & M & L \\
\hline NFV & & FIRV & & MR & & $N$ & & & & & IV & & & & IL & & V & & & LTV & & & & V & PI & ITV & & & 1 & AFT & V & DS & & M & L \\
\hline LPV & & FIRV & $\mathrm{AE}$ & IMR & IV & & 1 & $\mathrm{~F}$ & Q & & & & T & & IL & AV & v & v & L & $\begin{array}{l}\text { ALM } \\
\text { STV }\end{array}$ & & & & & PT & ITV & SP & s & & $\begin{array}{l}\text { AF } \\
\text { ST }\end{array}$ & v & & IMV & M & \\
\hline RTV & Q & FIRV & & MR & 1 & & 1 & $\mathrm{~F}$ & & & 1 & & & & IL & & V & & L & LMV & & & & v & $\begin{array}{l}\text { AIPQ } \\
\text { VYT }\end{array}$ & ITV & s & & & AFT & V & & & M & \\
\hline SQV & & FIRV & & MR & & & & & & & IV & & & & 1 & & V & & & LTV & K & $\mathrm{E}$ & ENY & V & APV & ITV & s & AS & & AFT & V & & & M & \\
\hline ATV & & FIV & & IMR & 1 & & I & FIV & & & ILV & & & $R$ & ILV & & V & L & & L & & & & & P & IV & ACST & & & $\begin{array}{l}\text { AFI } \\
\text { TS }\end{array}$ & AVC & $s$ & & M & \\
\hline AMP/r & & FIV & & MR & & & 1 & $\mathrm{~F}$ & & D & & K & & & IL & V & & V & & LMV & & & & & $P$ & & s & & & $\begin{array}{l}\text { AFI } \\
\text { TS }\end{array}$ & V & & & M & \\
\hline$S Q V / r$ & & FIRV & & MR & & & & & & & IV & & & & 1 & & V & & & LTV & K & $\mathrm{E}$ & ENY & V & APV & ITV & S & AS & & AFT & V & & & M & \\
\hline IDV/r & & IRV & & MR & 1 & & & & & & 1 & & & & IL & & V & & & LTV & & E & & & $\begin{array}{l}\text { AIPQ } \\
\text { VYT }\end{array}$ & ITV & $s$ & & & AFT & v & s & M & M & L \\
\hline
\end{tabular}

Figura 8 - Códons associados a mutações que causam resistência aos IP.

Fonte: Adaptado do algoritmo da base de dados da RENAGENO 2006. 
A substituição chave de aminoácidos selecionada durante vários experimentos in vitro com APV é a I50V, localizada no sítio ativo da protease e usualmente acompanhada pela M46I/L e menos freqüentemente, pela substituição 174V (Paulsen et al, 2003).

Apesar de dados in vitro sugerirem a mutação $150 \mathrm{~V}$ como principal perfil de resistência (Ohtaka et al, 2002), dados clínicos indicam diferente perfil com mutações nas posições 54, 82, 84 e 90, que são associadas com resistência cruzada (Schmidt et al, 2000). A mutação N88S, selecionada pelo ATV causa hipersusceptibilidade ao APV e reduzida capacidade replicativa (Lam \& Parkin, 2003).

A primeira mutação de resistência encontrada no HIV-1 de pacientes adultos tratados com nelfinavir ocorre no códon 30 do gene da protease, uma substituição de ácido aspártico por asparagina (D30N). Outras mutações secundárias geralmente ocorrem em virus mutante D30N e podem contribuir para resistência. Essas substituições incluem M36I, M46I, A71V, V77I e N88D.

A mutação L90M, mais comum selecionada pelo Saquinavir, confere resistência cruzada a outros IP quando associados com mutações secundárias (Marcelin et al, 2004). Também é encontrada em pacientes tratados com NFV (Fitzgibbon et al, 2001). Reduzida susceptibilidade a SQV 
é mais geralmente associada com aquisição das mutações G84V e L90M, quando SQV é usado como primeiro inibidor de protease.

Substituição de aminoácidos na posição 82 da protease viral é a mutação inicial associada com resistência ao IDV e RTV (Gavin \& Yogev, 2002). Indinavir e Saquinavir (SQV) são intrinsecamente potentes e requerem a emergência de múltiplas mutações antes de ocorrer alto grau de resistência, no entanto, resistência a SQV geralmente confere resistência ao IDV e vice-versa (Potter et al, 2004).

Com relação ao atazanavir, estudos in vitro demonstram a seleção de mutantes, quando na presença da droga, associadas com substituições N88S, M46I, A71V, I84V e L33F (Havlir \& O'Marro, 2004). A mutação I84V parece ser importante quando acompanhada da I50L (Colonno et al, 2004).

\subsection{MUTAÇÕES ARQUIVADAS}

O maior sucesso obtido nos pacientes em uso de terapia combinada é a redução da CV a níveis indetectáveis, porém, as células infectadas não são erradicadas (Yang, 2004).

Nas primeiras semanas após a infecção o vírus pode infectar vários compartimentos celulares, dentre os quais estão células de meia-vida longa, 
células latentes e células inativas, onde o vírus permanece pouco acessível ao sistema imune e ao tratamento (Muñoz-Almagro et al, 2002).

A forma mais estável de latência ocorre em células $\mathrm{T} C D 4^{+}$com provirus integrado. A princípio, se a integração requer a ativação dessas células para permitir transcrição reversa eficiente, a latência pós-integração pode resultar da reversão de células $T$ infectadas ativadas para um estado quiescente (Marcello, 2006).

A redução da CV plasmática não corresponde a uma redução semelhante do DNA proviral integrado ou pré-integrado em células mononucleares do sangue periférico (Zhang et al, 1999).

Alguns estudos sugerem que baixos níveis de replicação viral persistem nos reservatórios e conseqüentemente prolongam a meia-vida do vírus em pacientes recebendo TARV (Chun et al, 2005). Resistência pode se desenvolver mesmo quando a viremia está consistentemente indetectável $(20-400 \mathrm{cp} / \mathrm{mL})$. Em pacientes submetidos a regimes com uma ou duas drogas, incapazes de suprimir a viremia, vírus resistentes selecionados pela terapia não supressora podem ser arquivados em reservatório latente e persistir mesmo após a terapia combinada. Esses reservatórios podem manter arquivo de todas as espécies virais previamente circulantes, em altos níveis, no paciente (Blankson, Persaud \& Siliciano, 2002). 
Existem várias razões para acreditar que a dinâmica do reservatório latente em crianças com infecção perinatal seja diferente da encontrada em adultos, pois a infecção se estabelece na presença de elevados níveis de replicação viral e na presença de atividade deficiente de células T citotóxicas (Persaud et al, 2000). Além disso, o timo, importante para maturação e proliferação de linfócitos T é mais funcional em crianças e a reconstituição da população de células $\mathrm{T} \mathrm{CD} 4^{+}$ocorre mais precocemente (Saitoh et al, 2002).

É importante destacar que alguns estudos mostraram o aparecimento de mutações no plasma viral antes que elas ocorressem nos linfócitos, tanto em pacientes tratados com IP (Bi et al, 2003), como em pacientes tratados com ITRN - AZT (Usuku et al, 2006).

A partir dos resultados obtidos em estudo avaliando mutações no RNA e no DNA proviral, Usuku e colaboradores (2006) sugerem que vírus em replicação ativa com resistência a drogas no plasma têm propriedades distintas do DNA proviral de células mononucleares de sangue periférico e que cepas virais com tropismo para macrófagos podem contribuir para a aquisição de resistência.

Outro fato importante, notado por Devereux e colaboradores (1999), é que pacientes apresentando mutações enquanto submetidos ao TARV, quando suspendiam $\circ$ tratamento, o genótipo tipo selvagem reemergia 
enquanto os genótipos com mutações de resistência eram reduzidos em uma média de 6,4 semanas sem uso de drogas anti-retrovirais e essa redução era maior ainda com média de 12,9 semanas.

Esse genótipo tipo selvagem não resulta de reversão genética clássica de vírus multiresistentes que voltam a ser tipo selvagem susceptível a drogas, simplesmente reflete a reemergência de vírus que entraram em reservatório latente antes de qualquer tratamento. Os vírus resistentes também são estocados no reservatório latente e podem reemergir se submetidos a condições seletivas apropriadas (Blankson, Persaud \& Siliciano, 2002).

\subsection{TESTES UTILIZADOS NA DETECÇÃO DE RESISTÊNCIA}

Para a detecção de resistência aos anti-retrovirais, dois tipos de ensaios podem ser realizados: testes genotípicos, que medem susceptibilidade à droga indiretamente pela detecção de mutações associadas com resistência, e testes fenotípicos, que medem a susceptibilidade diretamente (Petropoulos et al, 2000; Lucas, 2005).

Nos ensaios fenotípicos, os vírus, presentes no sangue do paciente, são cultivados e então testados com certas drogas anti-retrovirais, em diferentes concentrações. Se na presença da droga o patógeno continua se replicando, é resistente a ela; se inibido, é sensível e a droga pode ser 
usada no tratamento do paciente em questão (Sociedade Brasileira de Infectologia, 2003). Esses testes também medem a concentração da droga necessária para inibir em 50\% (IC 50$)$ ou em $90 \%\left(\mathrm{IC}_{90}\right)$ a replicação viral (Ammaranond et al, 2003).

Ensaios genotípicos que detectam mutações de resistência a drogas na TR e PR do HIV-1 são os ensaios mais amplamente utilizados para a testagem de resistência a drogas (Eshleman et al, 2004). Esses ensaios são baseados na técnica original descrita por Sanger e colaboradores (1977), cujo princípio é o uso de inibidores que terminam as cadeias sintetizadas na amplificação em resíduos específicos.

\subsection{CLASSIFICAÇÃO DA INFECÇÃO PELO HIV EM CRIANÇAS}

A infecção pelo HIV em crianças e adolescentes causa um largo espectro de doenças e tem curso clínico variado. A aids representa o espectro clínico final e mais grave.

A classificação da infecção pelo HIV em crianças utiliza sistema alfanumérico, baseando-se em parâmetros clínicos e imunológicos, respectivamente, propostos pelo Centers for Disease Control and Prevention (CDC), em 1994 (quadros 1 e 2). 


\subsubsection{Categorias Clínicas}

Categoria N - Assintomática: ausência de sinais e/ou sintomas;

Categoria A - Sinais e/ou sintomas leves;

Categoria B - Sinais e/ou sintomas moderados;

Categoria C - Sinais e/ou sintomas graves.

Quadro 1- Classificação da infecção pelo HIV em crianças e adolescentes menores de 13 anos.

\begin{tabular}{|c|c|c|c|c|}
\hline $\begin{array}{l}\text { Alteração } \\
\text { imunológica }\end{array}$ & $\begin{array}{c}\mathrm{N}=\text { Ausência } \\
\text { de sinais e/ou } \\
\text { sintomas } \\
\text { clínicos }\end{array}$ & $\begin{array}{c}\text { A = Sinais e/ou } \\
\text { sintomas } \\
\text { clínicos leves }\end{array}$ & $\begin{array}{c}\mathrm{B}=\text { Sinais e/ou } \\
\text { sintomas } \\
\text { clínicos } \\
\text { moderados }\end{array}$ & $\begin{array}{c}\text { C = Sinais e/ou } \\
\text { sintomas clínicos } \\
\text { graves }\end{array}$ \\
\hline Ausente (1) & N1 & A1 & B1 & C1 \\
\hline Moderado (2) & $\mathrm{N} 2$ & $\bar{A} 2$ & $\overline{B 2}$ & $\mathrm{C} 2$ \\
\hline Grave (3) & N3 & A3 & B3 & C3 \\
\hline
\end{tabular}




\subsubsection{Categorias Imunológicas}

Baseiam-se na contagem de linfócitos $\mathrm{T} \mathrm{CD}^{+}$de acordo com a idade, conforme quadro abaixo:

Quadro 2- Categorias imunológicas da classificação da infecção pelo HIV em crianças e adolescentes menores de 13 anos.

\begin{tabular}{|l|c|c|c|}
\hline \multirow{2}{*}{ Alteração } & \multicolumn{3}{|c|}{ Contagem de linfócitos T CD4 ${ }^{+}$} \\
\cline { 2 - 4 } Imunológica & \multicolumn{3}{|c|}{ Idade } \\
\cline { 2 - 4 } & $<12$ meses & 1 a 5 anos & 6 a 12 anos \\
\hline Ausente (1) & $>1500(\geq 25 \%)$ & $\geq 1000(\geq 25 \%)$ & $\geq 500(\geq 25 \%)$ \\
\hline Moderada (2) & $750-1499(15-24 \%)$ & $500-999(15-24 \%)$ & $200-499(15-24 \%)$ \\
\hline Grave(3) & $<750(<15 \%)$ & $<500(<15 \%)$ & $<200(<15 \%)$ \\
\hline
\end{tabular}

\subsection{SITUANDO O PROBLEMA}

A patogênese da infecção pelo HIV-1 em crianças difere da observada em adultos em vários aspectos, sendo geralmente mais grave, com importante impacto na evolução clínica. Elevadas taxas de replicação viral ocorrem por período mais prolongado seguindo a infecção perinatal, com declínio gradual na carga viral (CV) somente após dois anos de vida, 
refletindo a imaturidade do sistema imune nesse período (Bongertz, 2001; Cohen et al, 2002; Mullen et al, 2002).

Aproximadamente $20 \%$ das crianças infectadas verticalmente apresentam, precocemente, sintomas graves da doença com possibilidade de evolução para óbito (progressores rápidos). A doença progride mais lentamente na maioria dos infectados (progressores moderados) e um pequeno grupo permanece clinicamente assintomático por vários anos (progressores lentos) (De Rossi et al, 1996; Hermione Lyall, 2002).

O HIV destrói, preferencialmente, os linfócitos $\mathrm{T} \mathrm{CD}^{+}$e interfere no funcionamento do sistema imune, reduzindo a defesa contra agentes infecciosos (Weinberg \& Pott, 2003).

Após a introdução da terapia anti-retroviral combinada (HAART, do inglês "Highly Active Anti-retroviral Therapy") no tratamento da infecção pelo HIV-1, temos presenciado importante redução da progressão da doença e da mortalidade causada por esse vírus (Palella et al, 1998), principalmente devido à significante diminuição dos níveis de RNA viral no plasma e tecido linfóide e à restauração do número de células $\mathrm{T} \mathrm{CD}^{+}$(Weinberg \& Pott, 2003; Persaud et al, 2004). 
Porém, para que o benefício dessa abordagem terapêutica seja duradouro, é preciso que haja uma supressão contínua da replicação viral (Hermankova et al, 2001).

A incapacidade de manter-se essa supressão fará com que ocorra, invariavelmente, a seleção de variantes resistentes às drogas em uso (Hermankova et al, 2001; Jagodzinski et al, 2003). Esse é o mais recente desafio para médicos e pesquisadores da área. Estudos têm mostrado que a falha virológica pode ocorrer em $50 \%$ das pessoas no primeiro ano de tratamento (Grant et al, 2003).

As causas da falha virológica são múltiplas, incluindo concentrações plasmáticas inadequadas de drogas devido a interações medicamentosas, fracas adesão e/ou absorção. No entanto, a falha está, quase sempre, relacionada ao surgimento de variantes resistentes (Ammaranond et al, 2003).

A transcriptase reversa do HIV-1, componente essencial para replicação do vírus, apresenta considerável infidelidade durante a replicação do RNA viral (Gao et al, 1993). Além disso, eventos de recombinação dos retrovírus e alta taxa de produção viral podem ser causas do surgimento de vírus resistentes à terapia (Mansky et al, 1995; Izopet et al, 1999). 
A não supressão completa da replicação viral, em vigência de esquemas combinados de anti-retrovirais, pode resultar ainda em um complexo de mutações de resistência a uma ou mais drogas, além de resistência cruzada a agentes anti-retrovirais que não tenham sido usados pelo paciente e poderiam ser alternativas ao tratamento (Sayer et al, 2003).

A resistência in vitro do HIV-1 já foi observada com todos os agentes anti-retrovirais aprovados pelo FDA (Food and Drug Administration) e pode ter início dentro de semanas a meses após administração da terapia, particularmente nos estágios mais tardios da doença (Japour et al, 1993).

Análises da prevalência de resistência a drogas anti-retrovirais nos Estados Unidos e Reino Unido indicam que mais de $50 \%$ das pessoas infectadas abrigam variantes do HIV que já são resistentes a, no mínimo, uma droga anti-retroviral. Além disso, a transmissão de cepas virais com resistência maior que 10 vezes a um ou mais dos agentes anti-retrovirais supera $14 \%$ das pessoas infectadas recentemente (Marcus, Dittmar \& Kräusslich, 2002).

$\mathrm{Na}$ Europa Ocidental e nos Estados Unidos, a prevalência de variantes resistentes em pacientes com infecção recente pelo HIV nos últimos anos é de aproximadamente 10\%. Essa alta taxa de transmissão de variantes resistentes é de grande interesse no que se refere à eficácia da terapia anti-retroviral no futuro e sugere a recomendação de testagem de 
resistência nos indivíduos infectados recentemente, em algumas regiões (Yerly et al, 2001).

No Brasil, como a taxa de resistência primária é baixa, esta testagem não se justifica como política de saúde pública para o país. No entanto, essa questão deve ser considerada regionalmente, uma vez que, segundo a Sociedade Brasileira de Infectologia (2003), estudo realizado na cidade de Santos-SP no ano de 2002, mostrou que 35\% dos indivíduos com infecção recente já tinham vírus mutante.

Alguns estudos também já observaram que é possível que vírus apresentando mutações que conferem resistência parcial a agentes antiretrovirais sejam encontrados em pessoas infectadas nunca tratadas com o agente respectivo (Marcus, Dittmar \& Kräusslich, 2002).

Além disso, a maioria dos relatos indica que as mutações transmitidas ocorrem mais no gene que codifica a transcriptase reversa que na protease, apesar das freqüências relativas variarem de um estudo para outro e talvez dependerem dos fatores de risco dominantes associados com a transmissão (Ammaranond et al, 2003).

Métodos de seqüenciamento molecular comercialmente disponíveis, bem como os "in-house", têm sido desenvolvidos para determinar a presença de mutações associadas à resistência do HIV aos ARV em 
amostras de sangue dos pacientes (Galli et al, 2003). A monitoração para resistência através do teste de genotipagem pode permitir aos médicos uma mudança nos agentes terapêuticos antes de uma significante deterioração dos estados imunológico e clínico dos pacientes.

A indicação do teste de genotipagem na falha terapêutica é unanimidade. Mas existem outras situações em que, potencialmente, ele pode ser útil: na profilaxia da transmissão vertical do HIV, na profilaxia após acidente ocupacional, ou antes de iniciar a terapia anti-retroviral (TARV).

Crianças em uso de tratamento anti-retroviral potente (HAART) apresentam dificuldade em manter os níveis de carga viral indetectáveis. A maioria obtém um sucesso parcial, ou seja, uma redução da carga viral, embora essa não fique indetectável. Vários fatores podem influenciar no padrão de resposta terapêutica, especialmente o grau de adesão ao esquema.

Dados recentes mostram que algumas crianças tratadas precocemente têm níveis indetectáveis de HIV persistentemente (De Rossi, 2002). No entanto, a duração de uma resposta completa ao TARV não é facilmente estabelecida. Algumas crianças conseguem manter a $\mathrm{CV}$ indetectável por apenas alguns meses, outras, por vários anos. Essa diferença no padrão de resposta terapêutica dirigiu nosso questionamento para os seguintes pontos: 1) Como seria o perfil genotípico de crianças 
apresentando supressão viral completa e prolongada? 2) A presença de mutações de resistência no momento em que ainda há supressão viral completa pode ser um preditor de falha virológica posterior?

Em vista dessas questões, elaboramos esse estudo, que se propôs a avaliar o perfil genotípico de forma longitudinal, ou seja, no momento da inclusão da criança no estudo e em mais um momento posterior (após mínimo de 9 meses de acompanhamento), na tentativa de uma melhor compreensão das questões levantadas anteriormente.

A compreensão dos padrões de mutações que conferem resistência é imprescindível para a escolha de esquemas apropriados, que maximizem o benefício clínico da terapia anti-retroviral, bem como para o desenvolvimento de novas opções e abordagens terapêuticas. 
2.OBJETIVOS 
2.1) Determinar o perfil de resistência genotípica aos anti-retrovirais em crianças apresentando supressão viral prolongada (período mínimo de 12 meses) em uso de terapia anti-retroviral e observar o padrão de evolução genotípica do gene pol do HIV após um período mínimo de 9 meses.

2.2) Descrever o comportamento clínico e imunológico dessas crianças durante o período de seguimento. 
3. MÉTODOS 


\subsection{CASUÍSTICA}

Cento e oitenta crianças infectadas pelo HIV-1 são acompanhadas no Centro de Atendimento da Disciplina de Infectologia Pediátrica (CEADIPe) do Departamento de Pediatria da UNIFESP-EPM. Fizeram parte do presente estudo um grupo bastante especial composto por 28 crianças que têm conseguido manter carga viral indetectável por um período maior ou igual a 12 meses, em uso de terapia anti-retroviral.

Foi critério de inclusão a presença de supressão viral de no mínimo 12 meses (ensaio Cobas Amplicor HIV-1 Monitor Test, Roche, limite de detecção de 400 cópias $/ \mathrm{mL}$ ), com até um episódio de viremia intermitente menor que 1000 cópias $/ \mathrm{mL}$. Os pais ou responsáveis assinaram termo de consentimento livre e esclarecido (Anexo A).

O presente estudo foi aprovado pela Comissão de Ética para Análise de Projetos de Pesquisa - CAPPesq da Diretoria Clínica do Hospital das Clínicas e da Faculdade de Medicina da Universidade de São Paulo (USP) em 27/01/2005, conforme documento anexo (Anexo B) e pelo Comitê de Ética em Pesquisa da Universidade Federal de São Paulo - UNIFESP (Anexo C).

Todas as crianças foram avaliadas clinicamente em consultas mensais ou com intervalos de 2 meses, conforme a rotina do serviço. Cada 
participante possui uma ficha de avaliação clínico-laboratorial contendo dados necessários ao estudo (Anexo D). Além dos dados demográficos, foram observados dados referentes à infecção, ao tratamento ARV, intercorrências clínicas e informações sobre adesão obtidas por meio de entrevista do clínico com o paciente ou responsável.

\subsection{COLETA DAS AMOSTRAS}

As amostras utilizadas nesse estudo foram coletadas no período de outubro de 2002 a março de 2005. A coleta das amostras de sangue foi feita através de punção venosa periférica. Foi colhido 1 tubo de $5 \mathrm{~mL}$ de sangue com EDTA, em dois momentos distintos, para a realização do estudo virológico abaixo:

a) $1^{\text {a }}$ amostra no momento da inclusão - avaliação do perfil genotípico (região pol)

b) $2^{\mathrm{a}}$ amostra após período mínimo de 9 meses de acompanhamento avaliação do perfil genotípico (região pol)

É rotina da assistência a realização dos seguintes exames: quantificação da carga viral (CV) e contagem de linfócitos T CD4 ${ }^{+}(\mathrm{CD} 4)$ com intervalos de 3-4 meses. Os exames laboratoriais foram realizados no Laboratório de Retrovirologia da UNIFESP. 
O estudo do perfil genotípico foi realizado no Laboratório de Virologia do Instituto de Medicina Tropical da Universidade de São Paulo (LIM52-HCFMUSP).

\subsection{MÉTODOS}

\subsubsection{EXTRAÇÃO DO MATERIAL GENÔMICO}

O material genômico foi extraído de preparações de creme leucocitário (buffy-coat) utilizando-se para esse procedimento uma solução detergente (Saponina) previamente preparada no laboratório, a partir de $0,4 \mathrm{~g}$ de Saponina e $100 \mathrm{~mL}$ de solução fisiológica $0,5 \%$ estéril. Para cada amostra, duas alíquotas de $0,5 \mathrm{~mL}$ de sangue total foram lavadas duas vezes com $1 \mathrm{~mL}$ de solução saponina em centrifugações de $9000 \mathrm{~g}$ por $3 \mathrm{~min}$. Depois, o sedimento foi lavado outras três vezes com $1 \mathrm{~mL}$ de solução salina $0,9 \%$ com tempo e rotação já citados. O creme leucocitário obtido foi estocado a $-70^{\circ} \mathrm{C}$ até sua utilização, quando necessário.

O DNA proviral foi então extraído através do QIAamp Blood Kit (QIAGENInc., Santa Clarita, C.A., EUA). O procedimento técnico foi realizado conforme as instruções do fabricante. Durante uma rápida centrifugação, o DNA é adsorvido a uma membrana de sílica. Seguem duas lavagens com tampão de lavagem, para que as proteínas e outros contaminantes sejam retirados, garantindo a pureza de DNA e posterior 
eluição do DNA da coluna de sílica com tampão de eluição. O DNA extraído foi mantido a $-20^{\circ} \mathrm{C}$ até sua utilização.

\subsubsection{AMPLIFICAÇÃO DO MATERIAL GENÔMICO EXTRAÍDO (PCR- po)}

A região do gene $p o l$, contendo a protease e a transcriptase reversa foi amplificada, inicialmente, como região única a partir de dois diferentes pares de iniciadores. Num primeiro momento, um fragmento externo do gene pol foi obtido pela amplificação com os iniciadores PR outer 5' - GAG CAG ACC AGA GCC AAC AGC CCA - 3' e RT outer 5' - GCC CCT GCT TCT GTA TTT CTG C - 3'. O produto dessa amplificação foi então transferido

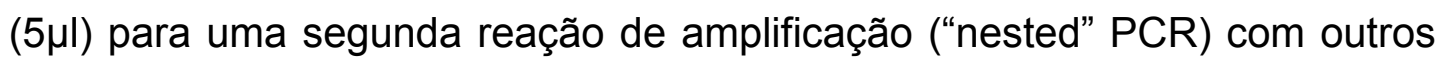
iniciadores PR inner 5' - GAA GCA GGA GCC GAT AGA CAA GG - 3' e RT inner 5' - GTG GTA CTA CTT CTG TTA GTG C - 3', dando origem a um fragmento mais interno de, aproximadamente, $1,2 \mathrm{~kb}$, contendo a região codificadora da protease e da transcriptase reversa, como descrito por Zhang e colaboradores (1999).

A mistura para a reação foi constituída de $0,25 \mathrm{mM}$ de dNTPs, 20 pmoles de cada iniciador e 1,25 unidades de Taq DNA polimerase platinum (Invitrogen) em 1x tampão de reação em $1,5 \mathrm{mM} \mathrm{MgCl}{ }^{2}$. A reação ocorreu com 5 ciclos de $94^{\circ} \mathrm{C}$ por $1 \mathrm{~min}, 52^{\circ} \mathrm{C} 1 \mathrm{~min}$ e $72^{\circ} \mathrm{C} 1 \mathrm{~min}$, seguidos de 25 ciclos de $94^{\circ} \mathrm{C} 1 \mathrm{~min}, 55^{\circ} \mathrm{C} 1 \mathrm{~min}$ e $72^{\circ} \mathrm{C} 1 \mathrm{~min}$. Ao término dos ciclos de amplificação, os amplicons foram mantidos a $4^{\circ} \mathrm{C}$ até a corrida eletroforética. 
Quando da não obtenção de produtos amplificados a partir dos iniciadores acima citados, foram feitas diversas tentativas com outros pares de iniciadores, com o objetivo de produzir amplicons suficientes para posterior genotipagem.

Os seguintes iniciadores foram testados. Num primeiro momento, um fragmento externo do gene pol foi obtido pela amplificação com os iniciadores KOZAL 1: 5'- CAG AGC CAA CAG CCC CAC CA - 3', KOZAL 2: 5'- TTT CCC CAC TAA CTT CTG TAT GTC ATT GAC A - 3' (Kozal et al,

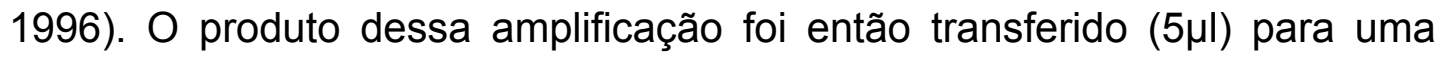
segunda reação de amplificação, "nested" PCR com outros iniciadores FRENKEL 1: 5'- GTT GAC TCA GAT TGG TTG CAC - 3', FRENKEL 2: 5'GTA TGT CAT TGA CAG TCC AGC - 3' (Frenkel et al, 1995), dando origem a um fragmento mais interno de, aproximadamente, $800 \mathrm{bp}$, contendo a região codificadora da transcriptase reversa e DP 10: 5'- TAA CTC CCT CTC AGA AGC AGG AGC CG - 3', DP 11: 5'- CCA TTC CTG GCT TTA ATT TTA CTG GTA - 3', dando origem a um fragmento mais interno de aproximadamente $400 \mathrm{bp}$ da protease.

A mistura para a reação foi constituída de $0,2 \mathrm{mM}$ de dNTPs, 20 pmoles de cada iniciador e 2,5 unidades de Taq DNA polimerase platinum (Invitrogen) em 1x tampão de reação em $1,5 \mathrm{mM} \mathrm{MgCl}{ }^{2}$. A reação ocorreu com denaturação inicial de $2 \min$ a $94^{\circ} \mathrm{C}$, seguida de 40 ciclos de $94^{\circ} \mathrm{C}$ por 
$1 \mathrm{~min}, 55^{\circ} \mathrm{C} 1 \mathrm{~min}$ e $72^{\circ} \mathrm{C} 90 \mathrm{seg}$, finalizando com extensão adicional de $72^{\circ} \mathrm{C}$ 10min. Ao término dos ciclos de amplificação, os amplicons foram mantidos a $4^{\circ} \mathrm{C}$ até a corrida eletroforética.

Outras tentativas foram realizadas nas condições descritas a seguir. Num primeiro momento, um fragmento externo do gene pol foi obtido pela amplificação com os iniciadores KOZAL 1: 5'- CAG AGC CAA CAG CCC CAC CA - 3', KOZAL 2: 5'- TTT CCC CAC TAA CTT CTG TAT GTC ATT

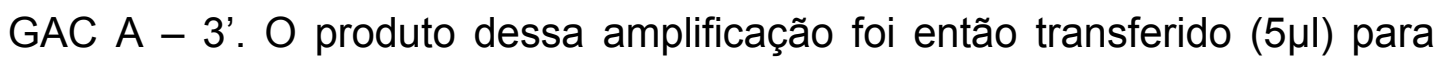
uma segunda reação de amplificação ("nested” PCR) com outros iniciadores DP 16: 5' - CCT CAA ATC ACT CTT TGG CAA - 3' e DP 17: 5' - AAA ATT TAA AGT GCA GCC AAT - 3', dando origem a um fragmento de aproximadamente $300 \mathrm{bp}$ da protease.

A mistura para a reação foi constituída de $0,2 \mathrm{mM}$ de dNTPs, 20 pmoles de cada iniciador e 2,5 unidades de Taq DNA polimerase platinum (Invitrogen) em 1x tampão de reação em 1,5mM $\mathrm{MgCl}^{2}$. A reação ocorreu com denaturação inicial de $2 \min$ a $94^{\circ} \mathrm{C}$, seguida de 40 ciclos de $94^{\circ} \mathrm{C}$ por $1 \mathrm{~min}, 55^{\circ} \mathrm{C} 1 \mathrm{~min}$ e $72^{\circ} \mathrm{C} 90 \mathrm{seg}$, finalizando com extensão adicional de $72^{\circ} \mathrm{C}$ 10min. Ao término dos ciclos de amplificação, os amplicons foram mantidos a $4^{\circ} \mathrm{C}$ até a corrida eletroforética. 


\subsubsection{VISUALIZAÇÃO DOS FRAGMENTOS}

As amostras amplificadas foram submetidas a eletroforese em gel de Agarose (ultra pura GIBCO- BRL, Gai Hersburg, MD, EUA) 1,5\% corado pelo Brometo de Etídio $(10 \mathrm{mg} / \mathrm{mL})$ em tampão TAE $1 \mathrm{x}$, simultaneamente a 0,25 $\mu \mathrm{g}$ do marcador de peso molecular de 100 pares de base (bp) (GIBCOBRL, Gai Hersburg, MD, EUA), para detecção do gene pesquisado. O gel foi visualizado através de transiluminador eletrônico U.V. (Alphalmager EC, Alpha Innotech Corporation).

\subsubsection{PURIFICAÇÃO DO MATERIAL AMPLIFICADO PARA SEQÜENCIAMENTO}

Os produtos das reações de PCR para a região do gene pol foram purificados utilizando-se o kit de purificação da QIAGENInc QIAquick Spin Handbook kit (QIAGENInc., Santa Clarita, CA) de acordo com as instruções do fabricante.

\subsubsection{QUANTIFICAÇÃO DO DNA}

Os produtos purificados foram submetidos a eletroforese em gel de Agarose (ultra pura GIBCO- BRL, Gai Hersburg, MD, EUA) 1,5\% corado pelo Brometo de Etídio $(10 \mathrm{mg} / \mathrm{mL})$ em tampão TAE 1x, simultaneamente ao marcador de massa molecular do DNA a $<0,1 \%$ (ng) (ABBOTT), para 
quantificação do material genômico, de acordo com orientações do fabricante. O gel foi visualizado através de transiluminador eletrônico U.V. (Alphalmager EC, Alpha Innotech Corporation).

\subsubsection{SEQÜENCIAMENTO AUTOMÁTICO}

Os métodos de seqüenciamento automático utilizam como princípio básico, o método desenvolvido por Sanger, Nicklen \& Coulson (1977). As DNA polimerases copiam moldes de DNA de fita simples através da adição de nucleotídeos, a partir de um iniciador oligonucleotídeo, alongando a cadeia e, sintetizando assim, uma molécula complementar, até a incorporação de um "nucleotídeo de terminação" ou dideoxinucleotídeo.

O didesoxinucleotídeo (ddNTP) não apresenta o grupo hidroxila 3' terminal, impedindo a formação de ligações fosfodiéster e, conseqüentemente, a extensão da cadeia de DNA (Rosenthal, 1995). Na reação de seqüência são incorporados marcadores fluorescentes na extensão do DNA usando ddNTPs marcados com corantes fluorescentes distintos. A cadeia de DNA é terminada e marcada simultaneamente quando o ddNTP é incorporado. Esse processo cria uma marcação de seqüência de DNA tal que cada produto de extensão é uma base maior do que a seguinte. Após a conclusão do ensaio, os dados são automaticamente analisados. 
O kit de seqüenciamento utilizado nesse trabalho foi o "ViroSeqTM HIV-1 Genotyping System" (Nº de lista: 04J94-08/07/13, Abbott Laboratories, USA). Quando da não obtenção de um fragmento único da região do gene pol, foram realizadas reações de seqüências com os mesmos primers utilizados nas reações de amplificação.

A mistura para a reação foi constituída de 16 pmoles de cada iniciador e 2,0 $\mu \mathrm{l}$ de Big Dye Taq DNA polimerase platinum (Invitrogen) em 1x tampão de reação Save\$, com volume final de $20 \mu$ l. A reação ocorreu com 20 ciclos de $96^{\circ} \mathrm{C}$ por $30 \mathrm{seg}, 50^{\circ} \mathrm{C} 15 \mathrm{seg}$ e $60^{\circ} \mathrm{C} 4 \mathrm{~min}$. Ao término dos ciclos de amplificação, os amplicons foram mantidos a $4^{\circ} \mathrm{C}$ até a corrida eletroforética.

Imediatamente antes da corrida eletroforética, as amostras foram precipitadas para melhor qualidade do produto a ser seqüenciado, como descrito a seguir. Para cada mistura de amostra foram adicionados $20 \mu \mathrm{l}$ de água deionizada e $60 \mu \mathrm{l}$ de isopropanol a $100 \%$. A mistura foi homogeneizada, incubada no escuro, à temperatura ambiente, por $15 \mathrm{~min}$. Seguiu centrifugação a 1500-2000g por 45 minutos e inversão dos tubos em papel absorvente até total secagem do pellet. Segue denaturação com adição de formamida e aquecimento a $96^{\circ} \mathrm{C}$ por 2 min.

A corrida eletroforética foi realizada em um seqüenciador automático "ABI PRISM 377 DNA sequencer" (Applied Biosystems, USA), de acordo com orientações do fabricante. A fonte de luz empregada nesse sistema é 
laser de íon argônio. À medida que cada fragmento passa pela região de leitura do laser, é excitado. A fluorescência é detectada e convertida a uma seqüência de bases pelo software para análise de seqüenciamento do $A B I$ PRISM DNA.

As seqüências obtidas foram editadas manualmente por comparação de complementaridade das fitas, alinhadas com a seqüência de referência HXB2, usando o programa "ABI Sequence Navigator".

A presença de mutações associadas à resistência foi avaliada com base nos dados do programa da Universidade de Stanford (Stanford HIV Drug Resistance Database - http://hivdb6.stanford.edu) e o perfil de resistência às drogas foi determinado de acordo com o algoritmo da Rede Nacional de Genotipagem, RENAGENO (www.aids.gov.br).

O alinhamento das seqüências obtidas juntamente com a seqüência referência HXB2 foi realizado pelo ClustalW, opção de alinhamento múltiplo através do software MegAlign DNA Star.

No Quadro 3 pode ser visto um resumo de todos os iniciadores utilizados durante a pesquisa. 
Quadro 3- Resumo dos iniciadores utilizados na amplificação e/ou na reação de seqüenciamento.

\begin{tabular}{|l|l|l|}
\hline \multicolumn{1}{|c|}{ Nome } & \multicolumn{1}{|c|}{ Seqüência } & Posição* \\
\hline PR outer & 5' - GAG CAG ACC AGA GCC AAC AGC CCA - 3' & $2139-2162$ \\
\hline RT outer & 5'- GCC CCT GCT TCT GTA TTT CTG C - 3' & $3549-3528$ \\
\hline PR inner & 5' - GAA GCA GGA GCC GAT AGA CAA GG - 3' & $2211-2233$ \\
\hline RT inner & 5' - GTG GTA CTA CTT CTG TTA GTG C - 3' & $3432-3411$ \\
\hline Kozal 1 & 5'- CAG AGC CAA CAG CCC CAC CA - 3' & $2147-2166$ \\
\hline Kozal 2 & 5'- TTT CCC CAC TAA CTT CTG TAT GTC ATT GAC A - 3' & $3338-308$ \\
\hline Frenkel 1 & 5'- GTT GAC TCA GAT TGG TTG CAC - 3' & $2519-2539$ \\
\hline Frenkel 2 & 5'- GTA TGT CAT TGA CAG TCC AGC - 3' & $3321-3301$ \\
\hline DP 10 & 5'- TAA CTC CCT CTC AGA AGC AGG AGC CG - 3' & $2198-2223$ \\
\hline Dp11 & 5'- CCA TTC CTG GCT TTA ATT TTA CTG GTA - 3' & $2598-2572$ \\
\hline DP 16 & 5'- CCT CAA ATC ACT CTT TGG CAA - 3' & $2253-2273$ \\
\hline DP17 & 5'- AAA ATT TAA AGT GCA GCC AAT - 3' & $2549-2529$ \\
\hline
\end{tabular}

* Obtida a partir do alinhamento com o HXB2 pelo programa PrimAlign do

Laboratório Nacional de Los Alamos disponível em http://hiv-web.lanl.gov 


\subsection{ANÁLISE ESTATÍSTICA}

Foi realizado cálculo das freqüências pelo programa SPSS (Statistical Package for the Social Sciences) para avaliação dos dados demográficos . 
4.RESULTADOS 
Vinte e oito crianças que preencheram os critérios de inclusão tiveram suas amostras colhidas e processadas. Destas, apenas 16 crianças permaneceram no estudo, tendo em vista a dificuldade encontrada durante a amplificação de algumas amostras, por tratarem-se de amostras com valores de carga viral abaixo de 400 cópias $/ \mathrm{mL}$.

Para cada paciente foram colhidas duas amostras, sendo a primeira, após período mínimo de 12 meses de indetecção da carga viral e a segunda obtida, em média, após acompanhamento de 15 meses (9-27meses) a partir do momento de inclusão.

Oito pacientes (50\%) eram do sexo feminino. A mediana da idade em anos foi de 11 (6-15 anos) na época da primeira coleta e 12 (7-15 anos) na segunda coleta. Os dados referentes às características dos pacientes são mostrados separadamente para as duas amostras nas tabelas 2 e 3 , respectivamente. Podemos observar que não houve alteração com relação à classificação clínico-imunológica em nenhum dos pacientes acompanhados.

1/16 paciente (ID 10) tinha carga viral detectável no momento da primeira coleta, mas foi incluída no estudo por se tratar de episódio isolado de baixa viremia, com alteração menor que 0,5 log.

Observamos no momento da segunda coleta que houve falha ao tratamento em 3/16 pacientes, sendo a fraca adesão ao esquema 
terapêutico uma das possíveis causas, segundo informações contidas no prontuário.

Tabela 2 - Características dos pacientes no momento da primeira coleta $(n=16)$, CEADIPe, São Paulo, 2002 - 2005.

\begin{tabular}{|c|c|c|c|c|c|c|c|}
\hline ID & $\begin{array}{l}\text { Idade } \\
\text { (anos) }\end{array}$ & Data & $\begin{array}{c}\text { CD4/CD8 } \\
\text { (cél/ul) }\end{array}$ & $\begin{array}{c}\mathrm{CV}^{*} \\
(\mathrm{cp} / \mathrm{ml})\end{array}$ & $\begin{array}{l}\text { Classificação } \\
\text { Imunológica }\end{array}$ & $\begin{array}{l}\text { Classificação } \\
\text { clínica }\end{array}$ & TARV** \\
\hline 1 & 6 & $22 / 05 / 03$ & $522 / 532$ & $<400$ & 1 & B & $\mathrm{D} 4 \mathrm{~T}+\mathrm{ddl}+\mathrm{NFV}$ \\
\hline 2 & 13 & $20 / 05 / 03$ & $925 / 577$ & $<400$ & 3 & $A$ & $d d l+3 T C+R T V$ \\
\hline 3 & 11 & $18 / 02 / 03$ & $1126 / 1444$ & $<400$ & 2 & $\mathrm{C}$ & $\begin{array}{c}\text { D4T+3TC+ } \\
\text { RTV }\end{array}$ \\
\hline 4 & 12 & $10 / 06 / 03$ & $347 / 582$ & $<400$ & 3 & C & $\begin{array}{c}\text { D4T+3TC+ } \\
\text { EFV }\end{array}$ \\
\hline 5 & 13 & $20 / 02 / 03$ & $352 / 538$ & $<400$ & 3 & C & $\begin{array}{c}\text { AZT+ddl+ } \\
\text { EFV }\end{array}$ \\
\hline 6 & 11 & $17 / 04 / 03$ & $595 / 856$ & $<400$ & 3 & B & $\begin{array}{c}\text { D4T+3TC+ } \\
\text { NFV }\end{array}$ \\
\hline 7 & 7 & $06 / 04 / 04$ & $1217 / 825$ & $<400$ & 2 & $A$ & D4t+ddl+ RTV \\
\hline 8 & 6 & 09/09/03 & $1487 / 1322$ & $<400$ & 2 & B & $\begin{array}{c}\text { D4T+3TC+ } \\
\text { NFV }\end{array}$ \\
\hline 9 & 11 & $23 / 01 / 03$ & $742 / 676$ & $<400$ & 2 & B & $\begin{array}{c}\text { D4T+3TC+ } \\
\text { NFV }\end{array}$ \\
\hline 10 & 15 & $08 / 04 / 04$ & $1164 / 1059$ & 820 & 1 & B & $\mathrm{D} 4 \mathrm{~T}+3 \mathrm{TC}$ \\
\hline 11 & 8 & $22 / 05 / 03$ & $781 / 731$ & $<400$ & 2 & $A$ & $A Z T+d d l$ \\
\hline 12 & 12 & $26 / 06 / 03$ & $728 / 854$ & $<400$ & 2 & $\mathrm{C}$ & $\begin{array}{c}\text { D4T+3TC+ } \\
\text { RTV }\end{array}$ \\
\hline 13 & 13 & $29 / 10 / 02$ & $1539 / 1154$ & $<80$ & 3 & B & $\begin{array}{c}\text { D4T+3TC+ } \\
\text { RTV }\end{array}$ \\
\hline 14 & 9 & $13 / 02 / 03$ & $2588 / 2146$ & $<400$ & 3 & C & $\begin{array}{c}\text { D4T+ddl+ } \\
\text { EFV + LPV/r }\end{array}$ \\
\hline 15 & 6 & $06 / 05 / 03$ & $1107 / 734$ & $<400$ & 1 & $\mathrm{~N}$ & $\begin{array}{c}\text { AZT+3TC+ } \\
\text { RTV }\end{array}$ \\
\hline 16 & 8 & $13 / 04 / 04$ & $1801 / 757$ & $<400$ & 1 & $\mathrm{C}$ & $\begin{array}{c}\mathrm{ABC}+3 \mathrm{TCC} \\
+\mathrm{LPV} / \mathrm{r}\end{array}$ \\
\hline
\end{tabular}


Tabela 3 - Características dos pacientes no momento da segunda coleta ( $n=16)$, CEADIPe, São Paulo, 2002 - 2005.

\begin{tabular}{|c|c|c|c|c|c|c|c|}
\hline ID & $\begin{array}{l}\text { Idade } \\
\text { (anos) }\end{array}$ & Data & $\begin{array}{l}\text { CD4/CD8 } \\
\text { (cél/ul) }\end{array}$ & $\begin{array}{l}\mathrm{CV}^{*} \\
(\mathrm{cp} / \mathrm{ml})\end{array}$ & $\begin{array}{l}\text { Classificação } \\
\text { Imunológica }\end{array}$ & $\begin{array}{l}\text { lassificação } \\
\text { clínica }\end{array}$ & $\mathrm{TARV}^{* *}$ \\
\hline 1 & 7 & 05/08/04 & $1623 / 1441$ & $<400$ & 1 & B & $\mathrm{D} 4 \mathrm{~T}+\mathrm{ddl}+\mathrm{NFV}$ \\
\hline 2 & 14 & $11 / 05 / 04$ & $1175 / 792$ & $<400$ & 3 & $A$ & ddl+3TC+RTV \\
\hline 3 & 12 & 02/09/04 & $932 / 1438$ & 10.500 & 2 & C & $\begin{array}{c}\text { D4T+3TC+ } \\
\text { RTV }\end{array}$ \\
\hline 4 & 13 & $20 / 09 / 04$ & $440 / 669$ & $<400$ & 3 & C & $\begin{array}{c}\text { D4T+3TC+ } \\
\text { EFV }\end{array}$ \\
\hline 5 & 15 & $29 / 11 / 04$ & $503 / 622$ & 1.950 & 3 & C & $\mathrm{AZT}+\mathrm{ddl}+\mathrm{EFV}$ \\
\hline 6 & 12 & $26 / 10 / 04$ & $635 / 752$ & $<400$ & 3 & B & $\begin{array}{c}\mathrm{AZT}+3 \mathrm{TC}+ \\
\mathrm{EFV}\end{array}$ \\
\hline 7 & 7 & $15 / 02 / 05$ & $3038 / 3053$ & $<400$ & 2 & A & D4t+ddl+ RTV \\
\hline 8 & 8 & $15 / 02 / 05$ & $487 / 562$ & $<400$ & 2 & B & $\begin{array}{c}\text { D4T+3TC+ } \\
\text { NFV }\end{array}$ \\
\hline 9 & 12 & $22 / 04 / 04$ & $938 / 1492$ & 75.000 & 2 & B & $\begin{array}{c}\text { D4T+3TC+ } \\
\text { NFV }\end{array}$ \\
\hline 10 & 15 & $10 / 01 / 05$ & NR & $<400$ & 1 & B & $\mathrm{AZT}+3 \mathrm{TC}+\mathrm{NVP}$ \\
\hline 11 & 10 & $22 / 03 / 05$ & $587 / 615$ & $<400$ & 2 & $A$ & $A Z T+d d l$ \\
\hline 12 & 13 & 06/07/04 & $817 / 850$ & $<400$ & 2 & C & $\begin{array}{c}\text { D4T+3TC+ } \\
\text { RTV }\end{array}$ \\
\hline 13 & 15 & $28 / 01 / 05$ & $1392 / 1188$ & $<400$ & 3 & B & $\begin{array}{c}\text { D4T+3TC+ } \\
\text { RTV }\end{array}$ \\
\hline 14 & 11 & $17 / 02 / 05$ & $2580 / 2032$ & $<400$ & 3 & C & $\begin{array}{c}\mathrm{D} 4 \mathrm{~T}+\mathrm{ddl}+\mathrm{EFV} \\
+\mathrm{LPV} / \mathrm{r}\end{array}$ \\
\hline 15 & 7 & $27 / 07 / 04$ & $1070 / 883$ & $<400$ & 1 & $\mathrm{~N}$ & $\begin{array}{c}\text { AZT+3TC+ } \\
\text { RTV }\end{array}$ \\
\hline 16 & 9 & $29 / 03 / 05$ & $1494 / 737$ & $<400$ & 1 & C & $\begin{array}{c}\mathrm{ABC}+3 \mathrm{TC} \\
+\mathrm{LPV} / \mathrm{r}\end{array}$ \\
\hline
\end{tabular}

$\mathrm{NR}=$ Não Realizado; ${ }^{*} \mathrm{CV}=$ Carga Viral; ${ }^{* *} \mathrm{TARV}=$ Tratamento anti-retroviral 
O cálculo da distribuição das freqüências, obtido pelo programa SPSS mostrou tratar-se de grupo extremamente homogêneo. Apesar de 6 crianças serem da categoria imunológica 3, não houve diferença estatisticamente significante entre estas e o restante do grupo que pertencia à categoria imunológica $2(\mathrm{~N}=6)$ ou $1(\mathrm{~N}=4)$.

Os perfis genotípicos foram obtidos para todas as amostras e todas as substituições estão descritas nos Apêndices 2 e 3, diferenciadas, de acordo com o algoritmo da base de dados da RENAGENO, como explicado na legenda.

As variações encontradas nos códons associados à resistência aos inibidores da transcriptase reversa e inibidores de protease foram reorganizadas nos Quadros 4 e 5, respectivamente, para melhor visualização. 
Quadro 4- Mutações associadas à resistência aos ITR em crianças mantendo supressão viral prolongada, CEADIPe, São Paulo, $2002-2005$.

\begin{tabular}{|c|c|c|c|c|c|c|c|c|c|c|c|c|c|c|c|c|c|c|c|c|}
\hline $\begin{array}{l}0 \\
0 \\
0\end{array}$ & $\frac{\bar{f}}{\Sigma}$ & $\underset{W}{\mathbb{Z}}$ & 오 & ષ̊ & $\stackrel{8}{\mathscr{6}}$ & $\stackrel{R}{x}$ & $\stackrel{\infty}{\gtrless}$ & 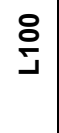 & $\begin{array}{l}\frac{0}{x} \\
\frac{1}{2}\end{array}$ & $\stackrel{8}{>}$ & $\stackrel{\infty}{5}^{\frac{1}{2}}$ & $\frac{\overline{5}}{\sigma}$ & $\sum_{\Sigma}^{\Phi}$ & $\frac{8}{0}$ & $\begin{array}{l}\text { ָे } \\
\text { İ }\end{array}$ & $\stackrel{\Sigma}{\tilde{N}}$ & $\underset{⿱ 亠 䒑}{\stackrel{\nabla}{~}}$ & $\stackrel{n}{\stackrel{N}{N}}$ & 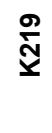 & ָֻల్ \\
\hline $01-1$ & . & . & 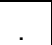 & & . & . & . & & & . & DV & & & & . & & & & & \\
\hline $01-2$ & . & & & & & . & . & & & . & . & & & & . & & & & & \\
\hline $02-1$ & . & & & & & . & . & & & . & & & & & . & G & & & & \\
\hline $02-2$ & 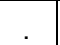 & & & & & & & & & & & & V & & 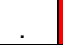 & G & & & & \\
\hline 03-1 & . & K & & $\mathrm{N}$ & & . & . & & & . & & & . & K & . & K & & 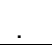 & & \\
\hline 03-2 & $\mathrm{L}$ & & & & & & . & & & . & & & V & & . & K & & Y & & \\
\hline 04-1 & . & & & & & . & . & & & . & . & & & & . & K & & . & & \\
\hline $04-2$ & . & & & & & . & . & & & . & . & & 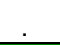 & & . & K & & . & & \\
\hline $05-1$ & L & & . & . & . & . & G & LV & $\mathrm{N}$ & 1 & IV & & V & & . & . & L & $\mathrm{F}$ & & \\
\hline $05-2$ & L & & . & & . & $\mathrm{KQ}$ & $G$ & & & 1 & 1 & & V & & $Y$ & . & L & $\mathrm{F}$ & & \\
\hline $06-1$ & . & & & & & & & & & 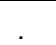 & & & & & & . & & & & \\
\hline $06-2$ & . & & & & & . & & & & 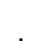 & . & & & GR & . & $\mathrm{KR}$ & 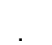 & & & \\
\hline $07-1$ & . & & . & & . & . & & & & . & . & & & & . & $x$ & . & & & \\
\hline $07-2$ & . & & & & & . & . & & & . & 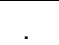 & & & & . & K & 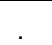 & & & \\
\hline 08-1 & . & $\mathrm{DE}$ & V & & . & . & . & & & . & 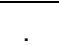 & & & & . & & L & & & \\
\hline 08-2 & . & & & & & . & . & & & & & & & & . & & L & & & IM \\
\hline 09-1 & . & . & &. & . & . & . & & & . & D & & & & . & . & $\dot{\varphi}$ & . & & \\
\hline $09-2$ & L & & & & & . & $G$ & & & 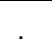 & . & & & & . & & & $S$ & & \\
\hline $\begin{array}{l}10-1 \\
10\end{array}$ & . & & & & & . & . & & & . & . & & & & . & & & . & & \\
\hline $10-2$ & . & & & & & . & . & & & . & D & & & & . & & & & & \\
\hline $11-1$ & . & & & & 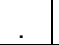 & . & . & & & . & . & & & & . & & & & & \\
\hline $11-2$ & & & & & & . & . & & & & & & & & 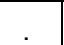 & & & & & \\
\hline $12-1$ & I & & & & & 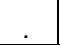 & . & & & & & & & $\mathrm{R}$ & & K & & & & I \\
\hline $12-2$ & . & . & . & & . & . & . & $*$ & & . & & 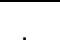 & 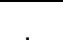 & & . & K & & . & & \\
\hline 13-1 & L & & & & & . & . & & & . & & & V & & . & & & Y & & \\
\hline 13-2 & $\mathrm{L}$ & & & . & . & . & . & & & . & & & V & & . & . & . & $Y$ & . & \\
\hline $14-1$ & . & . & & $\mathrm{N}$ & D & $\mathrm{R}$ & G & & & . & & & & & . & K & L & $F$ & Q & \\
\hline 14-2 & . & . & & $\mathrm{N}$ & D & $\mathrm{R}$ & G & & & . & . & . & & & $Y$ & K & L & $\mathrm{F}$ & $Q$ & \\
\hline $15-1$ & & & & $\mathrm{~N}$ & & $R$ & & * & & & & & & & & $K$ & & & & \\
\hline $15-2$ & & . & & $\mathrm{N}$ & & $R$ & . & & & . & & & & & & K & & & & \\
\hline $16-1$ & & & & & & . & 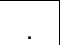 & & & & & & & & . & & & & & \\
\hline $16-2$ & & & & & & 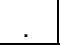 & & & & 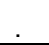 & & & & & & & & & & \\
\hline
\end{tabular}

Mutações associadas com resistência a ITR

Mutações inesperadas em códons de resistência 
Foram observadas substituições em 18 posições na região que codifica a transcriptase reversa na primeira coleta, sendo os valores da freqüência com que divergiram do consenso distribuídos da seguinte forma: em 11 posições (resíduos 44, 50, 69, 70, 98, 100, 103, 106, 184, 219 e 230) menor que 13\%; em outras 6 posições (resíduos 41, 67, 118, 190, 214 e 215) foi de $19 \%$; e a maior freqüência encontrada no resíduo 211 , de $48 \%$.

A maior divergência encontrada na segunda coleta continuou sendo no resíduo 211 (50\%), seguida do resíduo 215 (31,25\%). Em outras 5 posições (resíduos 41, 70, 98, 184 e 214) houve freqüência entre $19 \%$ e $25 \%$ e nas 8 posições restantes (resíduos $67,69,106,118,208,219$ e 230) a freqüência em que diferiram do consenso foi menor que $13 \%$.

Observamos que em $62,5 \%$ (10/16) dos pacientes não houve alteração relevante no genótipo viral. Do restante, em 83,3\% (5/6) surgiram novas substituições na região da transcriptase reversa no momento da segunda coleta. Em outros 50\% (3/6) algumas mutações observadas na primeira coleta não se mantiveram na segunda amostra.

Com relação às substituições encontradas na região da protease, foram observadas 28 regiões polimórficas, quando avaliamos as seqüências obtidas na primeira coleta. A maior freqüência de divergência do consenso foi no resíduo 63 (56\%), seguido dos resíduos 36 e 41 com freqüência de 37,5\%. Em 4 posições (resíduos 16, 35, 60 e 62) as substituições ocorreram 
numa freqüência entre $19 \%$ e $25 \%$. Nas 21 posições restantes (resíduos 10, $20,24,30,32,33,34,46,47,48,57,71,73,74,77,82,84,88,89,90$ e 93) os resíduos diferiram do consenso em menos de $13 \%$.

Na segunda coleta encontramos 23 regiões polimórficas. Em 17 posições (resíduos 8, 10, 16, 20, 30, 33, 45, 54, 57, 60, 71, 74, 82, 88, 89, 90 e 93) os resíduos diferiram numa freqüência menor que 13\%. Em 4 posições (resíduos 35, 36, 62 e 77), as substituições ocorreram numa freqüência entre $19 \%$ e $25 \%$. Na posição 63 a freqüência de divergência manteve-se a maior (62,5\%), seguida da posição 41 (43,75\%).

Em 37,5\% (6/16) dos pacientes não houve alteração relevante no genótipo viral. Do restante, em 30\% (3/10) surgiram novas substituições na região da protease no momento da segunda coleta. Em outros 30\% (3/10) algumas mutações observadas na primeira coleta não se mantiveram na segunda amostra. Nos $3 / 10$ pacientes restantes $(30 \%)$, houve as duas situações de aparecimento e omissão relacionados a polimorfismos. 
Quadro 5- Mutações associadas à resistência aos IP em crianças mantendo supressão viral prolongada, CEADIPe, São Paulo, $2002-2005$.

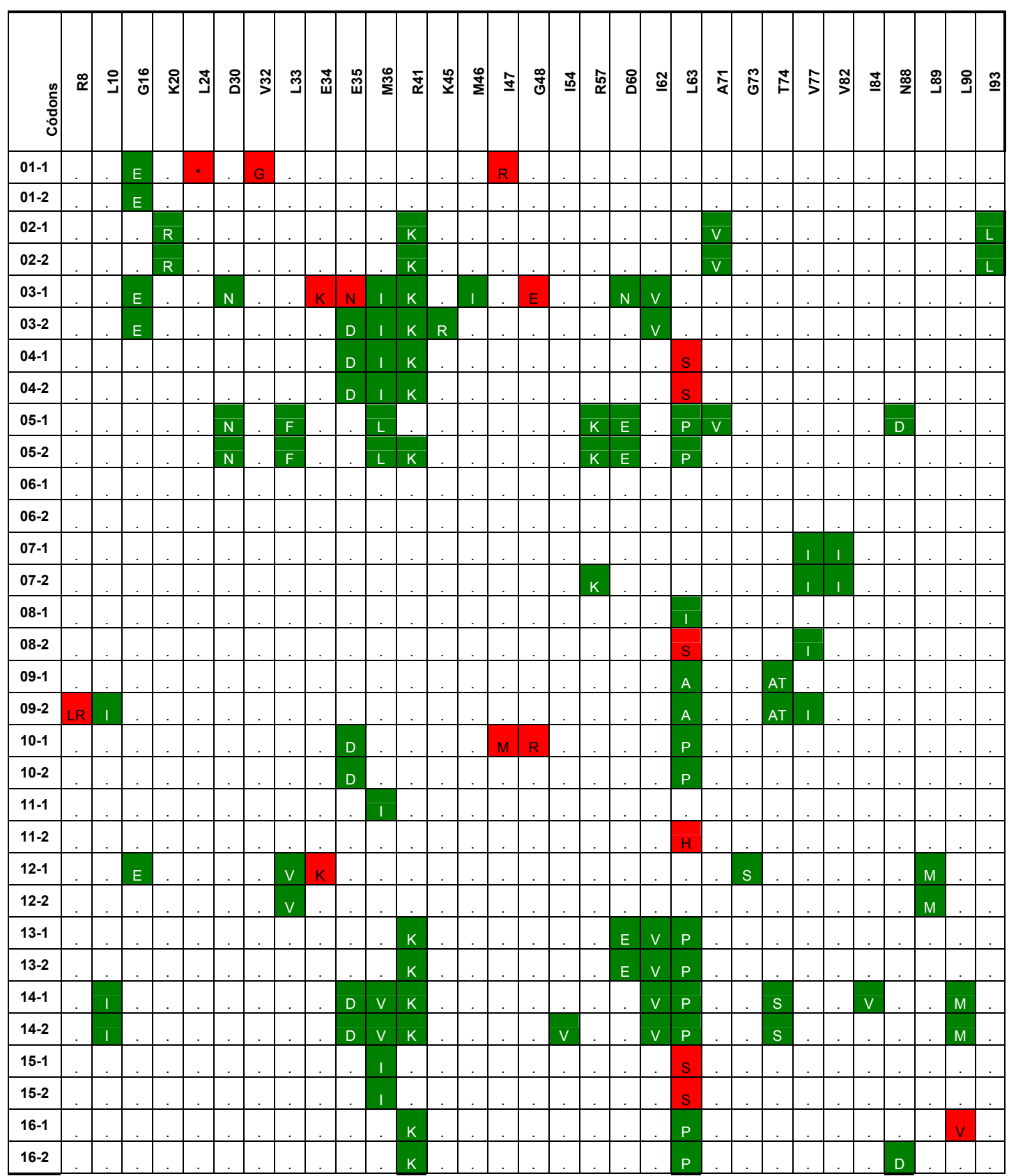

Mutações associadas com resistência a IP

Mutações inesperadas em códons de resistência 
No seqüenciamento da transcriptase reversa nas amostras da primeira coleta, 4 eram do tipo selvagem e 12 (75\%) apresentaram algum tipo de mutação. Para os ITRN, das 12 amostras mutantes, 25\% apresentaram resistência total a pelo menos uma droga e 33,3\% resistência intermediária. Para os ITRNN, das 12 amostras variantes, $16,7 \%$ apresentaram alta resistência a pelo menos uma droga e 8,3\% resistência intermediária.

Na segunda coleta, a partir do seqüenciamento das 16 amostras estudadas, observamos que 2 pacientes mantiveram tipo selvagem e um paciente (ID 01) que apresentou uma substituição na primeira amostra, mostrou seqüência do tipo selvagem na segunda coleta. Os $13(81,3 \%)$ pacientes restantes apresentaram vírus com alguma mutação.

Para os ITRN, das 13 amostras mutantes, 33,3\% apresentaram alta resistência e $37,5 \%$ resistência intermediária a pelo menos uma droga. Para os ITRNN, das 13 amostras variantes, 18,8\% apresentaram resistência total a pelo menos uma droga da classe e 18,8\% resistência intermediária.

A freqüência de mutações por códons, entre aqueles apresentando mutações associadas com resistência ou redução da susceptibilidade aos ITR nas duas coletas, pode ser vista no Gráfico 1. 
Gráfico 1 - Mutações associadas à resistência aos ITR em duas coletas, em amostras de crianças mantendo supressão viral prolongada, CEADIPe, São Paulo, 2002 - 2005.

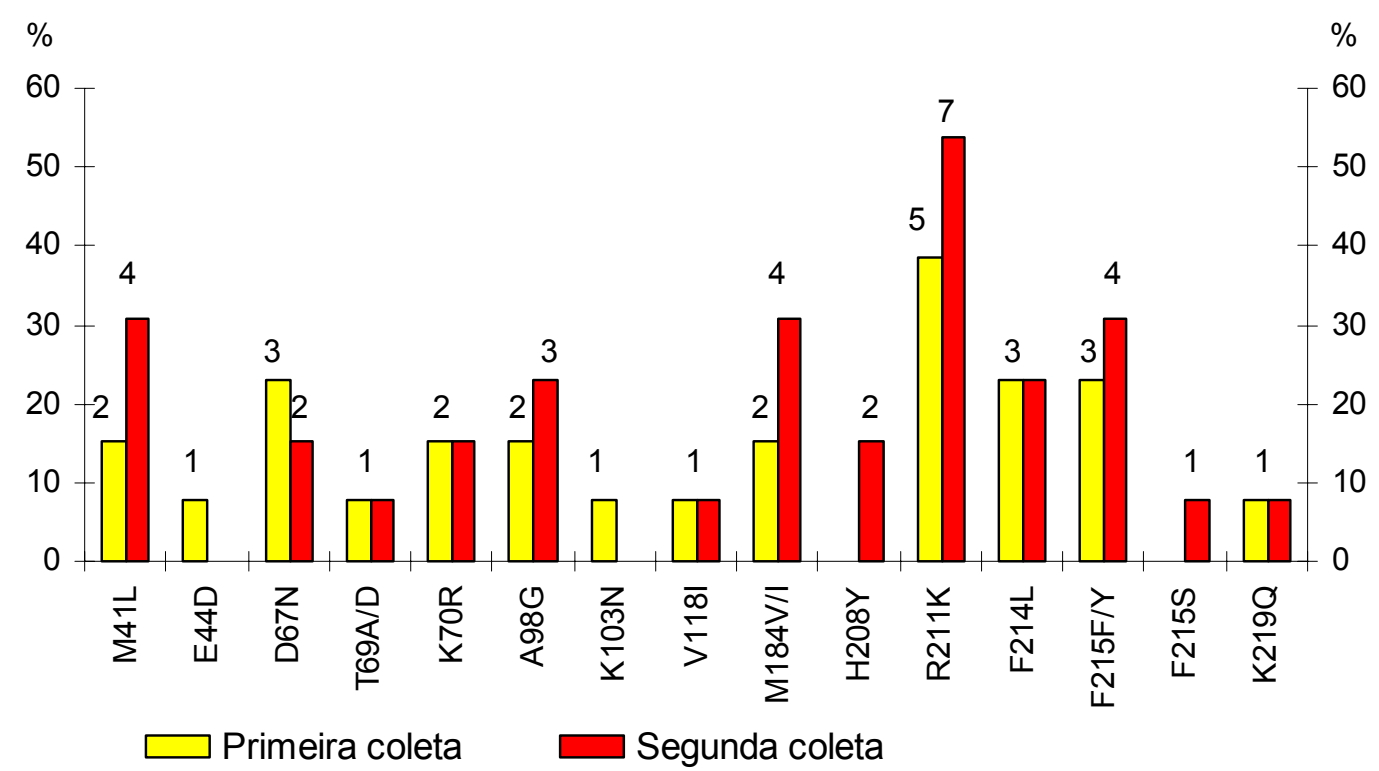

No seqüenciamento da protease, obtido das 16 amostras na primeira coleta, 15 amostras (94\%) apresentaram algum tipo de substituição e apenas uma amostra era do tipo selvagem (ID 06).

Das 15 amostras com mutações, 3 (20\%) apresentavam resistência total a pelo menos uma droga. Além disso, 5 (33,3\%) das 15 amostras mutantes, também apresentaram resistência intermediária.

Na segunda coleta, 1 das 16 seqüências obtidas, permaneceu com perfil do tipo selvagem e 15 (94\%) com alguma mutação. Destas, 2 (13,3\%) apresentaram alta resistência a pelo menos uma droga. Além disso, 4 $(26,5 \%)$ das 15 amostras mutantes apresentaram também resistência intermediária. 
A freqüência de mutações por códons, entre aqueles apresentando mutações associadas com resistência ou redução da susceptibilidade aos IP nas duas coletas, pode ser vista no Gráfico 2.

Gráfico 2 - Mutações associadas à resistência aos IP em duas coletas, em amostras de crianças mantendo supressão viral prolongada, CEADIPe, São Paulo, 2002 - 2005.

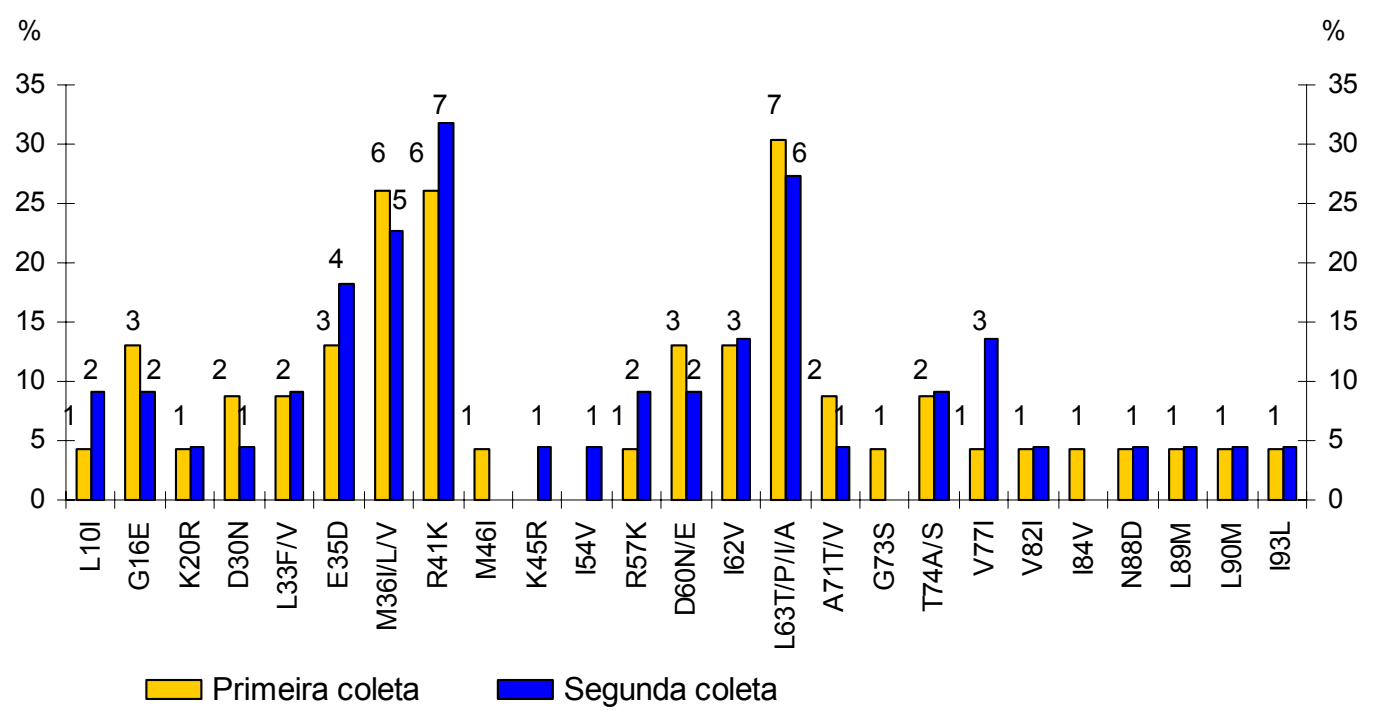

$\mathrm{Na}$ tabela 4 estão descritas as mutações encontradas para cada classe de droga e as drogas utilizadas por cada paciente. 

Tabela 4 - Mutações encontradas para cada classe de drogas em uso e drogas utilizadas por cada paciente, CEADIPe, São Paulo, 2002 - 2005.

\begin{tabular}{|c|c|c|c|c|}
\hline ID & ITRN & ITRNN & IP & TARV $^{*}$ \\
\hline 01-1 & V118DV & nenhuma & G16E;L24*;V32G;I47R & AZT;NVP;DDI;D4T;NFV \\
\hline $01-2$ & nenhuma & nenhuma & G16E & AZT;NVP;DDI;D4T;NFV \\
\hline 02-1 & R211G & nenhuma & K20R;R41K;A71V;I93L & AZT;3TC;DDI;RTV \\
\hline $02-2$ & M184V;R211G & nenhuma & K20R;R41K;A71V;I93L & $\mathrm{AZT} ; 3 T C ; D D I ; R T V$ \\
\hline 03-1 & E44K;D67N;R211K & G190K & $\begin{array}{l}\text { G16E;D30N;E34K;E35N;M36I;R41K; } \\
\text { M46I:G48F-D60N:I62V }\end{array}$ & $\mathrm{AZT} ; 3 T C ; D 4 T ; R T V$ \\
\hline 03-2 & M41L;M184V;R211K;T215Y & nenhuma & G16E;E35D;M36I;R41K;K45R;I62V & $\mathrm{AZT} ; 3 T C ; D 4 T ; R T V$ \\
\hline 04-1 & R211K & nenhuma & E35D;M36I;R41K;L63S & DDI;NFV;D4T;3TC;EFV \\
\hline 04-2 & R211K & nenhuma & E35D;M36I;R41K;L63S & DDI;NFV;D4T;3TC;EFV \\
\hline 05-1 & M41L;V118IV;M184V;F214L;T215F & A98G;L100LV;K103N;V106I & D30N;L33F;M36L;R57K;D60E;L63P;A71V;N88D & 3TC;D4T;NFV;DDI;AZT;EFV \\
\hline $05-2$ & M41L;K7OKQ;V118I;M184V;H208Y;F214L; T215F & A98G;V106I & D30N;L33F;M36L;R41KR;R57K; D60E;L63P & 3TC;D4T;NFV;DDI;AZT;EFV \\
\hline 06-1 & nenhuma & nenhuma & nenhuma & AZT;RTV;EFV;3TC;D4T;NFV \\
\hline 06-2 & R211KR & G190GR & nenhuma & $A Z T ; R T V ; E F V ; 3 T C ; D 4 T ; N F V$ \\
\hline 07-1 & $\mathbf{R} 211 X$ & nenhuma & V771;V821 & AZT;EFV;NVP;DDI;D4T;RTV \\
\hline 07-2 & R211K & nenhuma & R57K;V771;V82I & AZT;EFV;NVP;DDI;D4T;RTV \\
\hline 08-1 & E44DE;F214L & nenhuma & L63I & AZT;DDI;EFV;D4T;3TC;NFV \\
\hline $08-2$ & F214L & M230IM & L63S;V77I & AZT;DDI;EFV;D4T;3TC;NFV \\
\hline $09-1$ & V118D & nenhuma & L63A;T74AT & AZT;DDI;D4T;3TC;NFV \\
\hline 09-2 & M41L;T215S & A98G & L10I;L63A;T74AT;V77I & AZT;DDI;D4T;3TC;NFV \\
\hline 10-1 & nenhuma & nenhuma & E35D;I47M;G48R;L63P & AZT;DDI;EFV;D4T;3TC \\
\hline $10-2$ & V118D & nenhuma & E35D;L63P & $A Z T ; \mathrm{DDI} ; \mathrm{D} 4 \mathrm{~T} ; \mathbf{3 T C}$;EFV;NVP \\
\hline $11-1$ & nenhuma & nenhuma & M36I & $A Z T ; D D I$ \\
\hline $11-2$ & nenhuma & nenhuma & L63H & $A Z T ; D D I$ \\
\hline 12-1 & R211K & nenhuma & G16E;L33V;E34K;G73S;L89M & AZT;DDI;3TC;D4T;RTV \\
\hline $12-2$ & R211K & nenhuma & L33V;L89M & AZT;DDI;3TC;D4T;RTV \\
\hline 13-1 & M41L;M184V;T215Y & nenhuma & R41K;D60E;162V;L63P & AZT;EFV;3TC;D4T;RTV \\
\hline 13-2 & M41L;M184V;T215Y & nenhuma & R41K;D60E;I62V;L63P & AZT;EFV;3TC;D4T;RTV \\
\hline 14-1 & D67N;T69D;K70R;R211K;F214L;T215F;K219Q & A98G & L10I;E35D;M36V;R41K;I62V;L63P;T74S;I84V;L90M & AZT;3TC;NFV;RTV;DDI;D4T;EFV;LPV/r \\
\hline $\begin{array}{l}14-2 \\
15-1\end{array}$ & D67N;T69D;K70R;H208Y;R211K;F214L;T215F;K219Q & $\begin{array}{c}\text { A98G } \\
\text { nenhuma }\end{array}$ & L10I;E35D;M36V;R41K;I54V;I62V;L63P;T74S;L90M & $\begin{array}{c}\text { AZT;3TC;NFV;RTV;DDI;D4T;EFV;LPV/r } \\
\text { AZT:3TC;RTV }\end{array}$ \\
\hline $15-2$ & D67N;K70R;R211K & nenhuma & $\begin{array}{l}\text { M36l;:L63S } \\
\text { M36I;L63S; }\end{array}$ & $\begin{array}{l}\text { AZT;3TC;RTV } \\
A Z T ; 3 T C ; R T V\end{array}$ \\
\hline 16-1 & nenhuma & nenhuma & R41K;L63P;L90V & AZT;RTV;D4T;DDI;NFV;EFV;3TC;ABC;LPV/r \\
\hline $16-2$ & nenhuma & nenhuma & R41K;L63P;N88D & AZT;RTV;D4T;DDI;NFV;EFV;3TC;ABC;LPV/r \\
\hline
\end{tabular}

* As drogas escritas em itálico representam as drogas em uso no momento da coleta. 
As Tabelas 5 e 6 mostram os resultados da análise em que consideramos as mutações para cada anti-retroviral, obtidas após submissão das seqüências ao programa da Universidade de Stanford, com relação ao momento de uso da droga.

Tabela 5 - Número e porcentagem de pacientes na primeira coleta com mutações específicas para cada ARV, de acordo com o momento de uso da droga, CEADIPe, São Paulo, 2002 - 2005.

\begin{tabular}{|c|c|c|c|}
\hline \multirow[t]{2}{*}{ ARV } & \multicolumn{2}{|c|}{ Pacientes com mutações/n (\%) } & \multirow[t]{2}{*}{ Códons avaliados } \\
\hline & Uso pregresso & Uso atual & \\
\hline AZT & $3 / 12(25 \%)$ & $2 / 3(66,7 \%)$ & $41,67,70,210,215,219,151,69 s s$ \\
\hline $3 T C$ & $1 / 2(50 \%)$ & $1 / 11(9,1 \%)$ & $184,65,151,69 s s$ \\
\hline ddl & $0 / 6(0 \%)$ & $0 / 6(0 \%)$ & $65,74,75 \mathrm{~T}, 151,69 \mathrm{ss}$ \\
\hline $\mathrm{d} 4 \mathrm{~T}$ & $1 / 2(50 \%)$ & $2 / 11(18,2 \%)$ & $41,210,215,75 \mathrm{~T}, 151,69 \mathrm{ss}$ \\
\hline$A B C$ & - & $0 / 1(0 \%)$ & $65,67,74,115,184,215,151,69 \mathrm{ss}$ \\
\hline NVP & $0 / 2(0 \%)$ & - & $\begin{array}{c}\text { 100I,101EPQ,103NS, 106AM, 108I, } \\
181,188 \mathrm{LC}, 190,230,238\end{array}$ \\
\hline EFV & $0 / 6(0 \%)$ & $1 / 3(33,3 \%)$ & $\begin{array}{c}\text { 100I, 101EPQ, 103NS, 106AM, 108I, } \\
\text { 181,188LC, 190,230,238 }\end{array}$ \\
\hline RTV & $1 / 3(33,3 \%)$ & $1 / 6(16,7 \%)$ & 82,84 \\
\hline NFV & $2 / 4(50 \%)$ & $0 / 4(0 \%)$ & $30,84,90$ \\
\hline $\mathrm{LPV} / \mathrm{r}$ & - & $1 / 2(50 \%)$ & 82,84 \\
\hline
\end{tabular}


Tabela 6 - Número e porcentagem de pacientes na segunda coleta com mutações específicas para cada ARV, de acordo com o momento de uso da droga, CEADIPe, São Paulo, 2002 - 2005.

\begin{tabular}{|c|c|c|c|}
\hline \multirow[t]{2}{*}{ ARV } & \multicolumn{2}{|c|}{ Pacientes com mutações/n (\%) } & \multirow[t]{2}{*}{ Códons avaliados } \\
\hline & Uso pregresso & Uso atual & \\
\hline AZT & $4 / 10(40 \%)$ & $2 / 5(40 \%)$ & $41,67,70,210,215,219,151,69 s s$ \\
\hline 3TC & $1 / 2(50 \%)$ & $3 / 11(27,3 \%)$ & $184,65,151,69 \mathrm{ss}$ \\
\hline ddl & $0 / 6(0 \%)$ & $0 / 6(0 \%)$ & $65,74,75 \mathrm{~T}, 151,69 \mathrm{ss}$ \\
\hline d4T & $1 / 4(25 \%)$ & $4 / 9(44,4 \%)$ & $41,210,215,75 \mathrm{~T}, 151,69 \mathrm{ss}$ \\
\hline$A B C$ & - & $0 / 1(0 \%)$ & $65,67,74,115,184,215,151,69 s s$ \\
\hline NVP & $0 / 2(0 \%)$ & $0 / 1(0 \%)$ & $\begin{array}{c}\text { 100I,101EPQ,103NS,106AM,108I, } \\
\text { 181,188LC,190,230,238 }\end{array}$ \\
\hline EFV & $0 / 5(0 \%)$ & $0 / 4(0 \%)$ & $\begin{array}{c}\text { 100I,101EPQ,103NS,106AM,108I, } \\
\text { 181,188LC,190,230,238 }\end{array}$ \\
\hline RTV & $0 / 3(0 \%)$ & $1 / 6(16,7 \%)$ & 82,84 \\
\hline NFV & $2 / 5(40 \%)$ & $0 / 3(0 \%)$ & $30,84,90$ \\
\hline LPV/r & - & $0 / 2(0 \%)$ & 82,84 \\
\hline
\end{tabular}

As Tabelas 7 e 8 mostram os resultados do número de pacientes expostos ou não a cada anti-retroviral presente no estudo, de acordo com o momento da coleta. 
Tabela 7 - Exposição aos ARV e número de pacientes com mutações associadas à resistência na primeira coleta, CEADIPe, São Paulo, 2002 - 2005.

\begin{tabular}{ccc}
\hline ARV & $\begin{array}{c}\text { Pacientes expostos com } \\
\text { mutações } / n(\%)\end{array}$ & $\begin{array}{c}\text { Pacientes não expostos com } \\
\text { mutações } / \mathrm{n}(\%)\end{array}$ \\
\hline AZT & $5 / 15(33,3 \%)$ & $0 / 1(0 \%)$ \\
3TC & $2 / 13(15,4 \%)$ & $0 / 3(0 \%)$ \\
ddl & $0 / 12(0 \%)$ & $0 / 4(0 \%)$ \\
d4T & $3 / 13(23,1 \%)$ & $0 / 3(0 \%)$ \\
ABC & $0 / 1(0 \%)$ & $3 / 15(38,5 \%)$ \\
\hline NVP & $0 / 2(0 \%)$ & $1 / 14(7,1 \%)$ \\
EFV & $1 / 9(11,1 \%)$ & $0 / 7(0 \%)$ \\
\hline RTV & $2 / 9(22,2 \%)$ & $0 / 7(0 \%)$ \\
NFV & $2 / 8(25 \%)$ & $0 / 8(0 \%)$ \\
LPV/r & $1 / 2(50 \%)$ & $1 / 14(7,1 \%)$ \\
\hline
\end{tabular}

Tabela 8 - Exposição aos ARV e número de pacientes com mutações associadas à resistência na segunda coleta, CEADIPe, São Paulo, 2002 - 2005.

\begin{tabular}{ccc}
\hline ARV & $\begin{array}{c}\text { Pacientes com mutações/n } \\
\text { expostos(\%) }\end{array}$ & $\begin{array}{c}\text { Pacientes com mutações/n não } \\
\text { expostos }(\%)\end{array}$ \\
\hline AZT & $6 / 15(40 \%)$ & $0 / 1(0 \%)$ \\
3TC & $4 / 13(30,8 \%)$ & $0 / 3(0 \%)$ \\
ddl & $0 / 12(0 \%)$ & $0 / 4(0 \%)$ \\
d4T & $5 / 13(38,5 \%)$ & $0 / 3(0 \%)$ \\
ABC & $0 / 1(0 \%)$ & $5 / 15(33,3 \%)$ \\
\hline NVP & $0 / 3(0 \%)$ & $0 / 13(0 \%)$ \\
EFV & $0 / 9(0 \%)$ & $0 / 7(0 \%)$ \\
\hline RTV & $1 / 9(11,1 \%)$ & $0 / 7(0 \%)$ \\
NFV & $2 / 8(25 \%)$ & $0 / 8(0 \%)$ \\
LPV/r & $0 / 2(0 \%)$ & $1 / 14(7,1 \%)$ \\
\hline
\end{tabular}


Para a análise do perfil de resistência do HIV para cada ARV dos 16 pacientes envolvidos no estudo, os resultados obtidos estão nos gráficos a seguir, sendo as duas coletas e os graus de resistência para os ITR e IP mostrados separadamente.

Esses dados foram obtidos por meio da submissão dos resultados ao banco de dados da RENAGENO, que classifica o vírus como susceptível, resistência intermediária ou alta para cada ARV. Apesar do grande número de presença de substituições em códons associados com resistência, a grande maioria das amostras apresentou-se como susceptível aos ARV, quando avaliados individualmente.

Contudo, a percentagem de pacientes com algum grau de resistência a drogas variou de acordo com as classes de drogas empregadas. Ao considerar as classes de ARV, observou-se na primeira coleta $31,3 \%$ para ITRN, $12,5 \%$ para ITRNN e $31,3 \%$ para os IP. Na segunda coleta os valores encontrados foram $37,5 \%$ para os ITRN, $18,8 \%$ para os ITRNN e $31,3 \%$ para os IP.

Na avaliação dos ITR, na primeira coleta encontramos $18,8 \%$ de alta resistência a D4T e AZT e 12,5\% de resistência intermediária ao ddl e AZT (gráfico 3). Enquanto na segunda coleta, os resultados encontrados foram de alta resistência ao D4T e AZT (25\%) e para resistência intermediária a maior freqüência foi ao ddl e EFV (18,8\%) (gráfico 4). 
Gráfico 3 - Graus de resistência aos ITR na primeira coleta, em amostras de crianças mantendo supressão viral prolongada, CEADIPe, São Paulo, $2002-2005$.

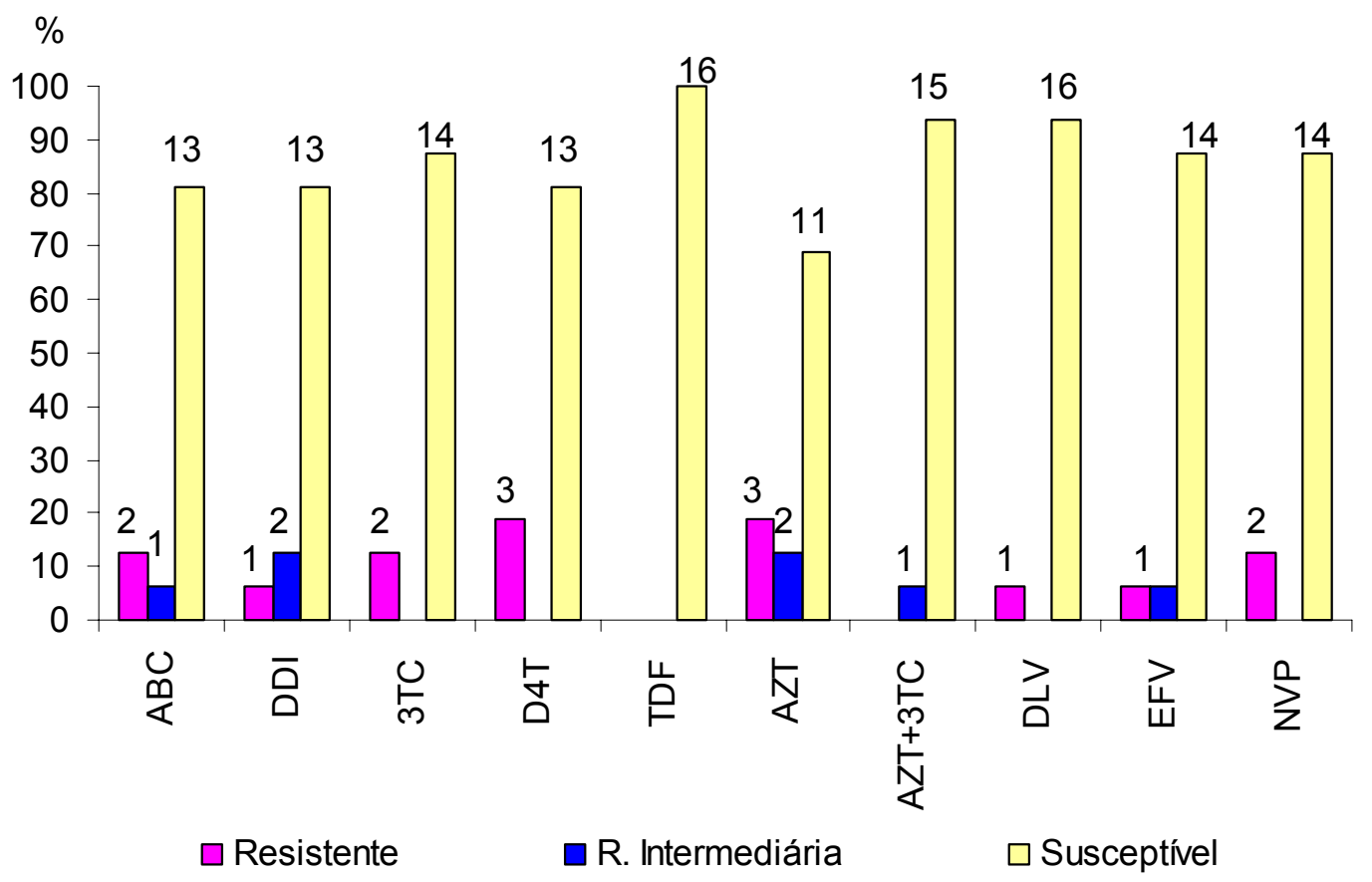

Gráfico 4 - Graus de resistência aos ITR na segunda coleta, em amostras de crianças mantendo supressão viral prolongada, CEADIPe, São Paulo, $2002-2005$.

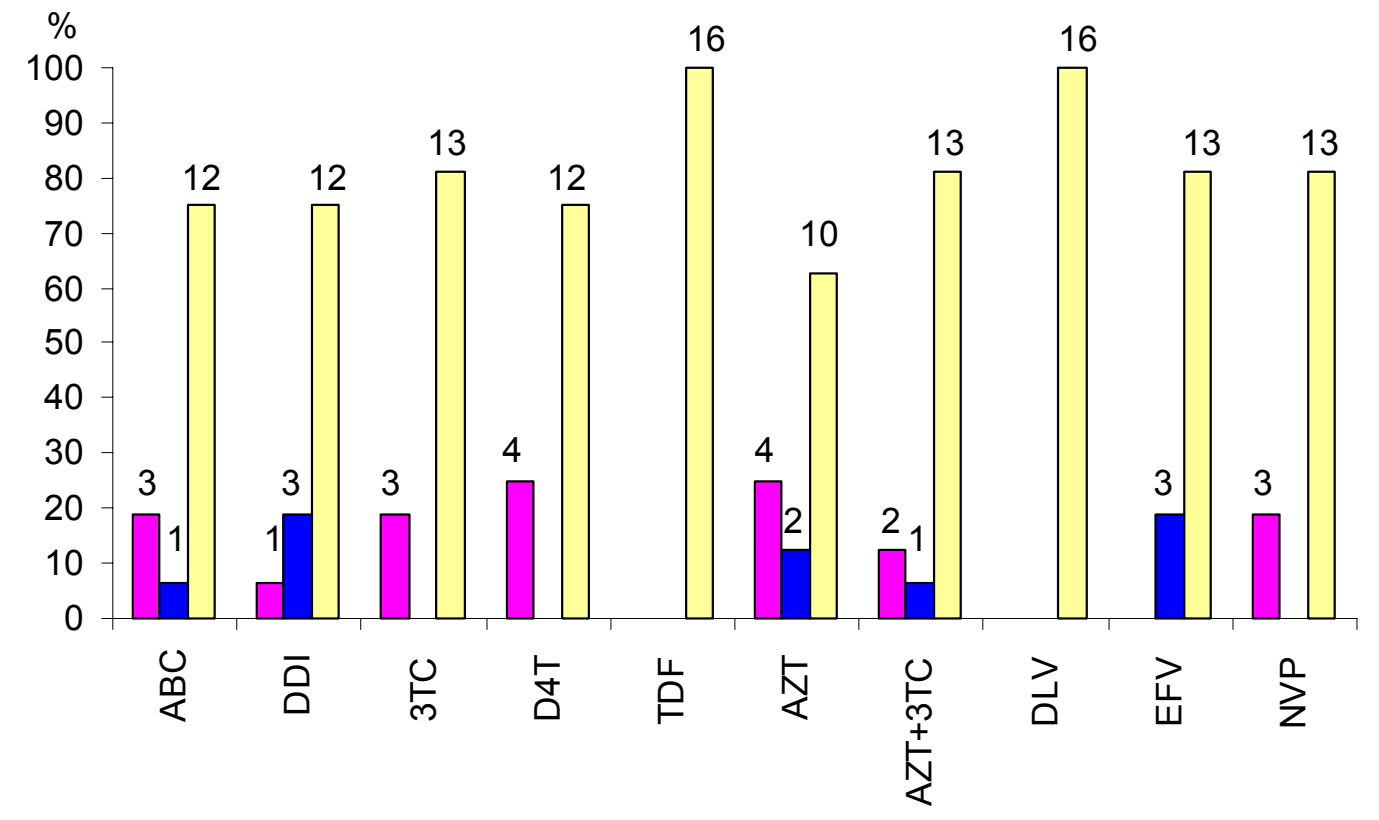

$\square$ Resistente $\quad \square$ R. Intermediária $\quad \square$ Susceptível 
Com relação aos IP a maior freqüência de alta resistência encontrada na primeira coleta foi de $18,8 \%$ para o NFV e para resistência intermediária, de 12,5\% (IDV e SQV) (gráfico 5). Na segunda coleta a maior freqüência de alta resistência foi ao NFV $(12,5 \%)$ e de resistência intermediária ao SQV $(12,5 \%)$ (gráfico 6).

Gráfico 5- Graus de resistência aos IP na primeira coleta, em amostras de crianças mantendo supressão viral prolongada, CEADIPe, São Paulo, $2002-2005$.

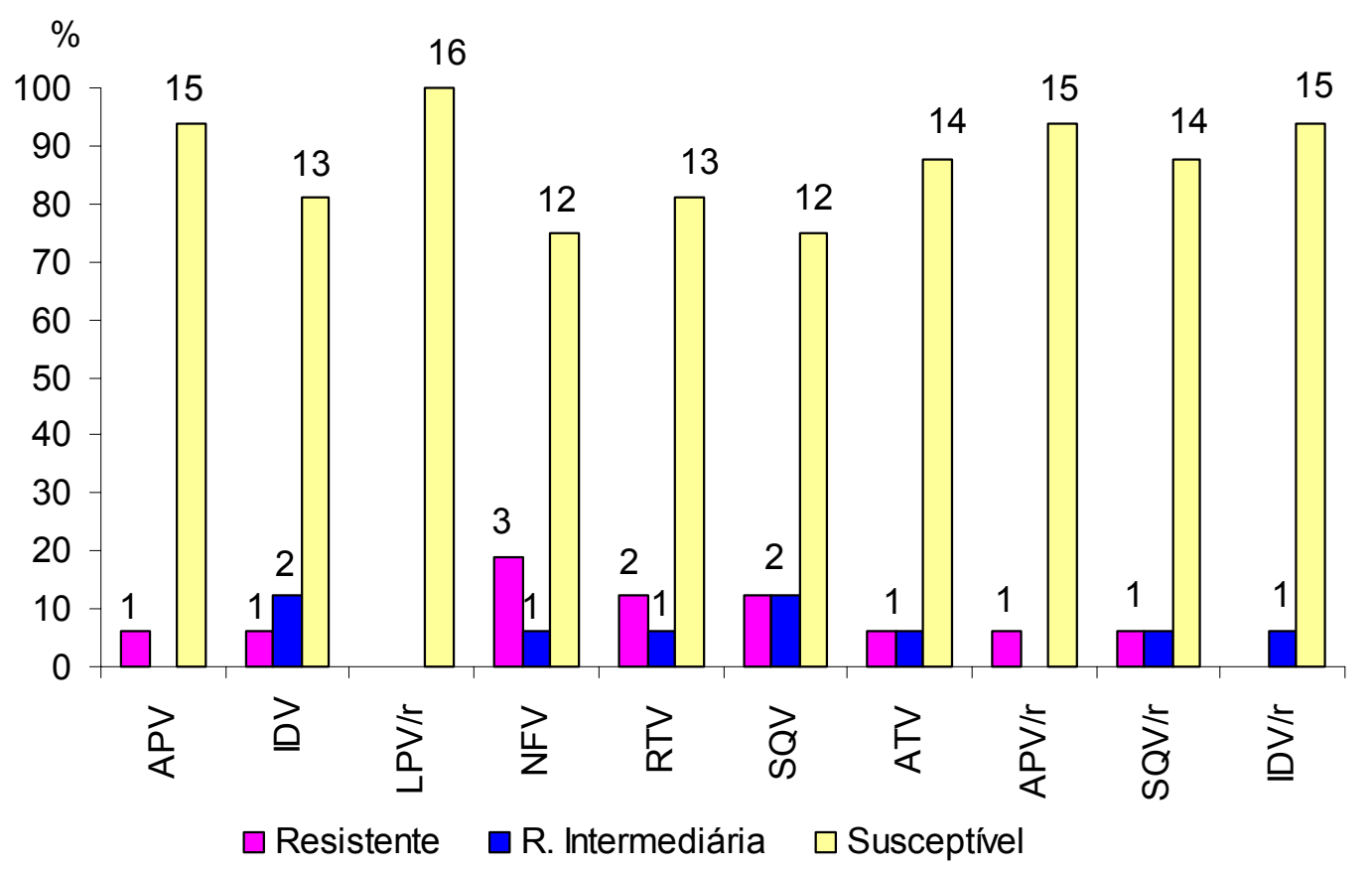


Gráfico 6 - Graus de resistência aos IP na segunda coleta, em amostras de crianças mantendo supressão viral prolongada, CEADIPe, São Paulo, $2002-2005$.

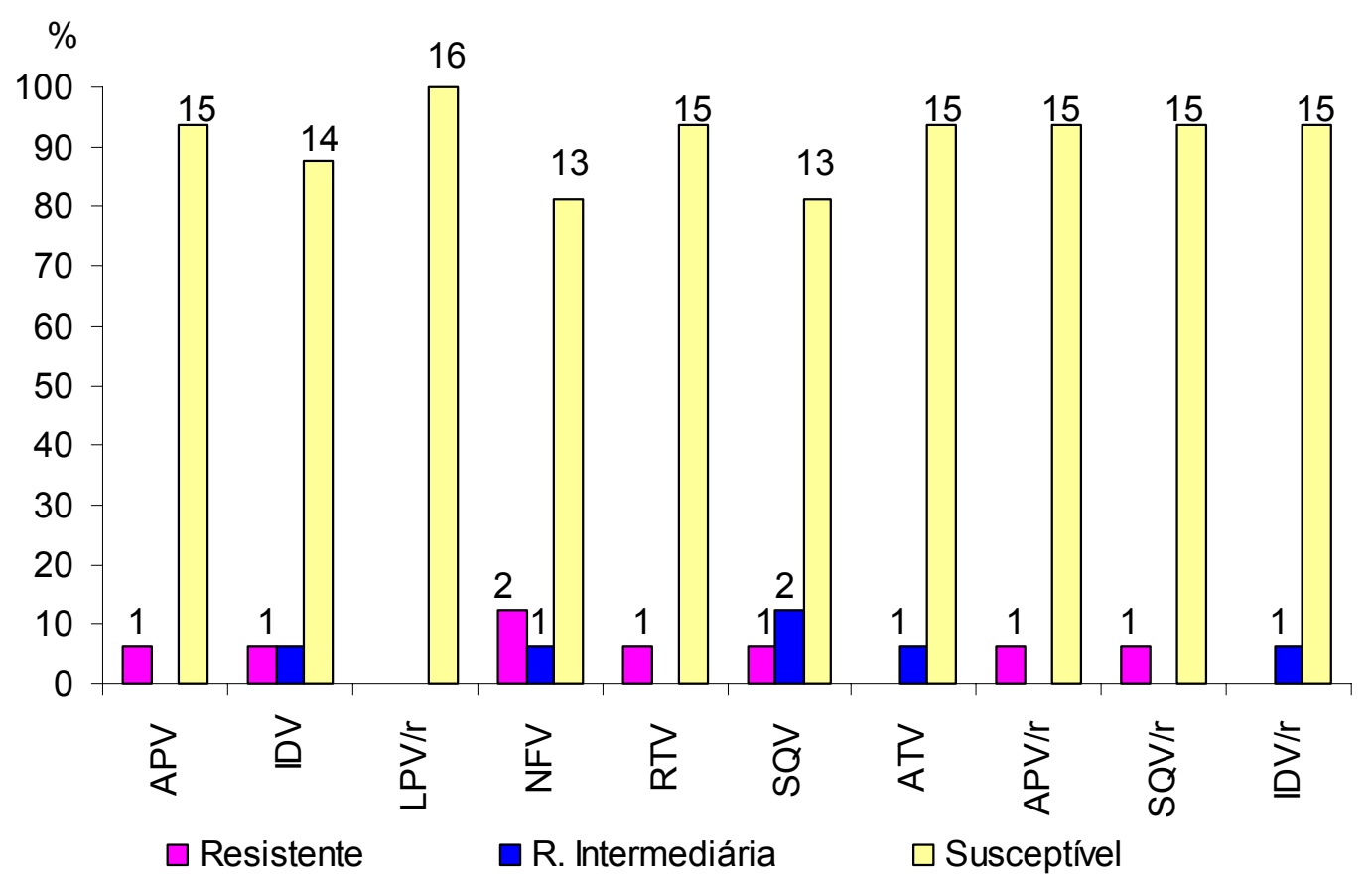

Na Tabela 9 podemos ver a ocorrência ou não de episódios de intercorrências clínicas e o tipo para cada paciente durante o estudo. 
Tabela 9 - Episódios de intercorrências clínicas observadas em crianças mantendo supressão viral prolongada no momento das coletas e no período intercoletas, CEADIPe, São Paulo, 2002 - 2005.

\begin{tabular}{|c|c|c|c|c|}
\hline \multirow{2}{*}{ ID } & \multirow{2}{*}{$\mathrm{n}$ (total) } & \multicolumn{3}{|c|}{ TIPO } \\
\hline & & $1^{\mathrm{a}}$ coleta & Intercoletas & $2^{\mathrm{a}}$ coleta \\
\hline 1 & 3 & otite, ITU & otite*$^{*}$ ITU*, IVAS & - \\
\hline 2 & - & - & - & - \\
\hline 3 & 1 & - & IVAS & - \\
\hline 4 & 3 & sinusite & amigdalite, candidíase & candidíase $^{*}$ \\
\hline 5 & 2 & - & pneumonia & IVAS \\
\hline 6 & 6 & $\begin{array}{c}\text { sinusite, faringite, } \\
\text { herpes }\end{array}$ & IVAS, parasitose & sinusite \\
\hline 7 & - & - & - & - \\
\hline 8 & 3 & - & $\begin{array}{c}\text { amigdalite, diarréia, } \\
\text { pneumonia }\end{array}$ & - \\
\hline 9 & 3 & - & conjuntivite, parasitose & IVAS \\
\hline 10 & 1 & - & sinusite & - \\
\hline 11 & 2 & - & piodermite, IVAS & - \\
\hline 12 & 4 & herpes, pneumonia & $\begin{array}{c}\text { pneumonia }^{*} \text {, herpes } \\
\text { otite } \\
\text { ot* }^{* *} \text {, sinusite }\end{array}$ & - \\
\hline 13 & 1 & - & IVAS & - \\
\hline 14 & 3 & - & laringite, amigdalite & conjuntivite \\
\hline 15 & 3 & - & IVAS $^{* *}$, parasitose & - \\
\hline 16 & 2 & otite & otite* & amigdalite \\
\hline
\end{tabular}


Na figura 9, podemos observar dados relacionados com marcadores prognósticos para cada um dos pacientes e as drogas utilizadas durante todo o período de seguimento no CEADIPe, com destaque para os momentos das coletas envolvidas no estudo.

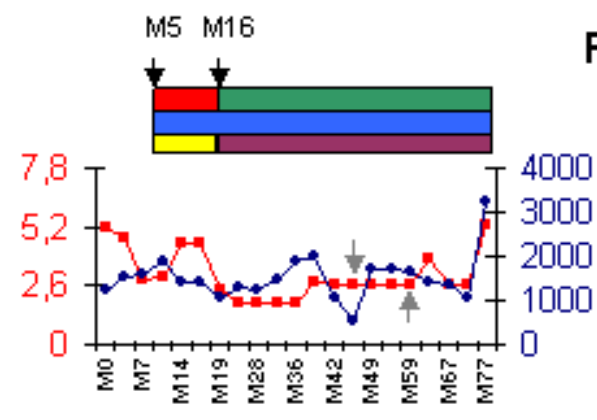

P 01
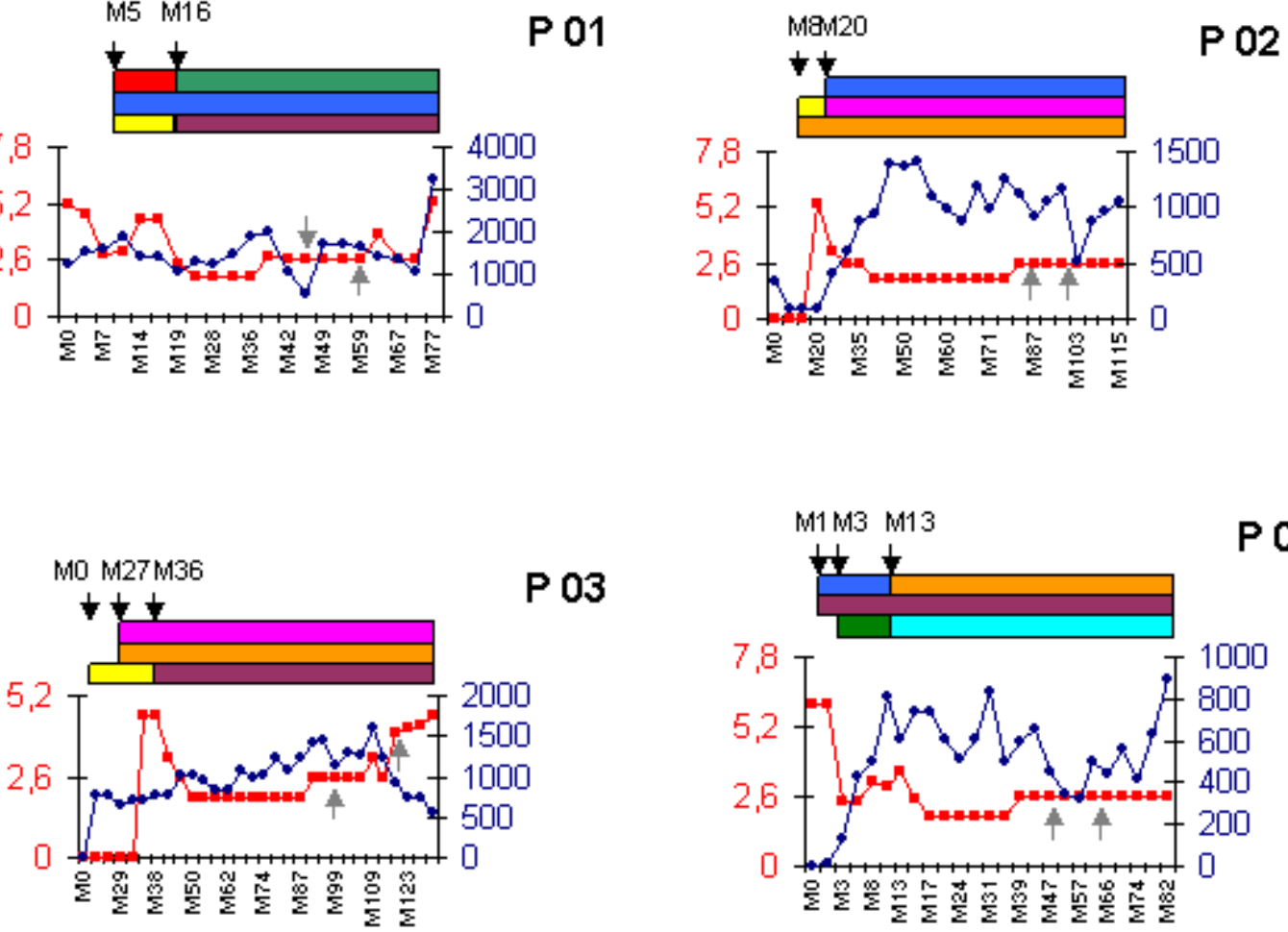

P 03
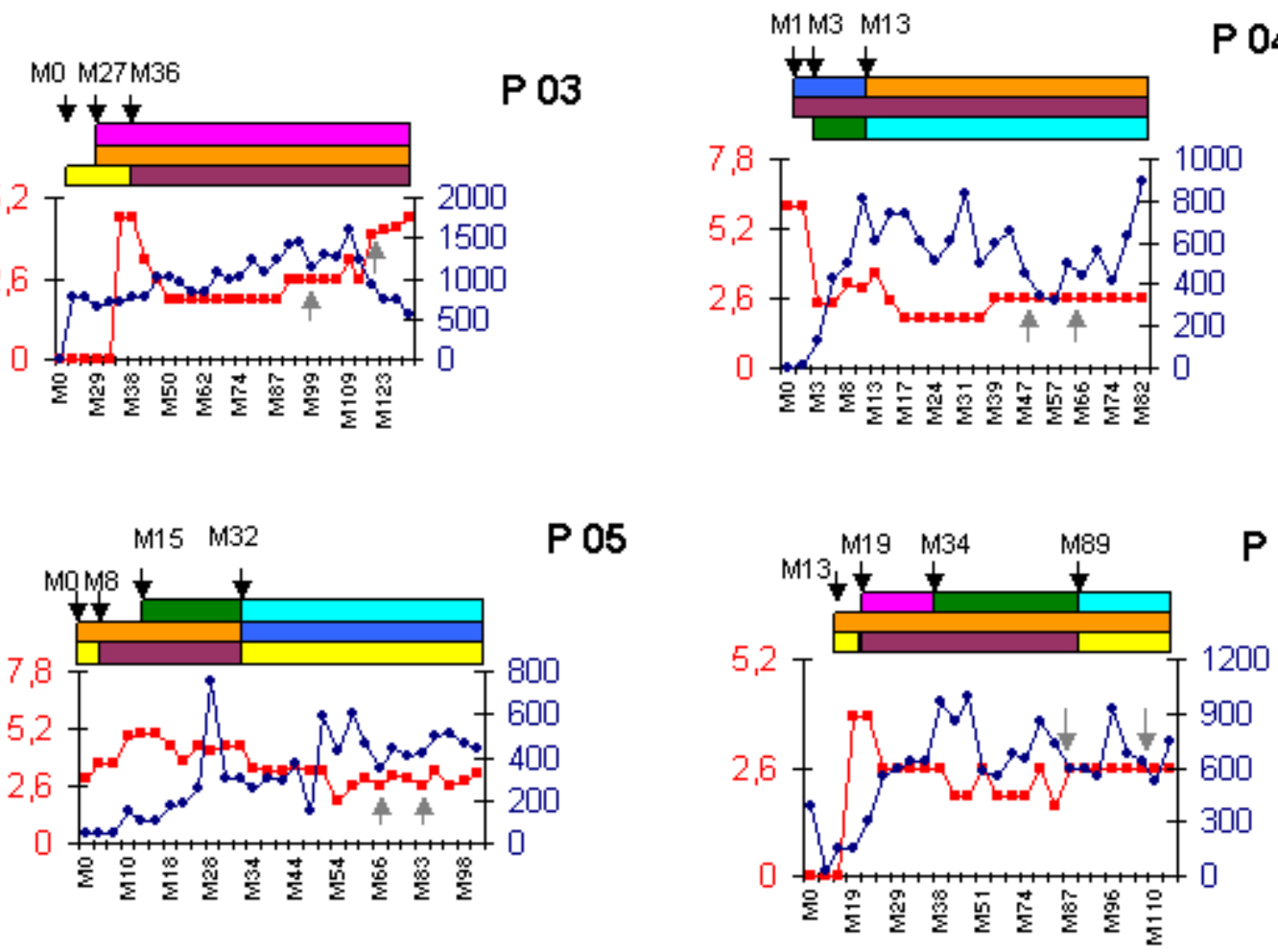


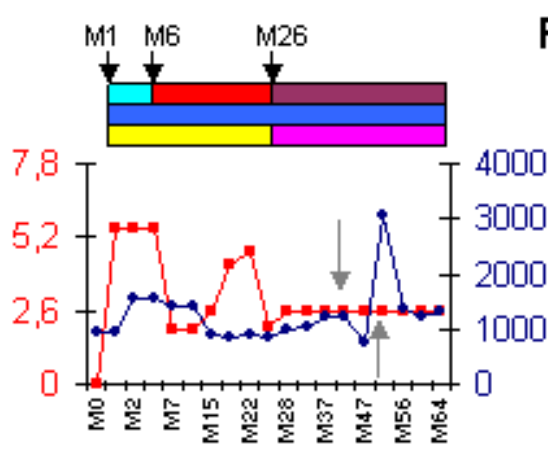

P 07

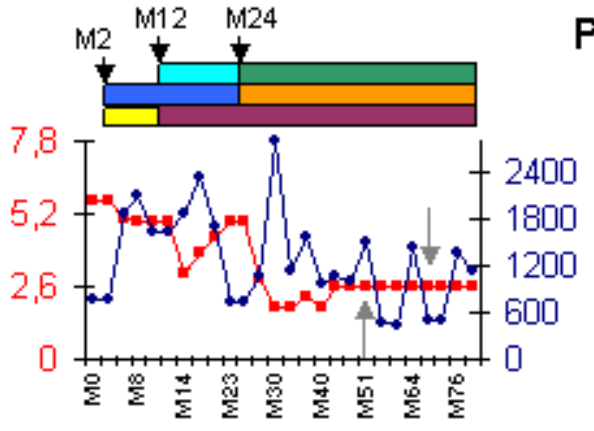

P 08

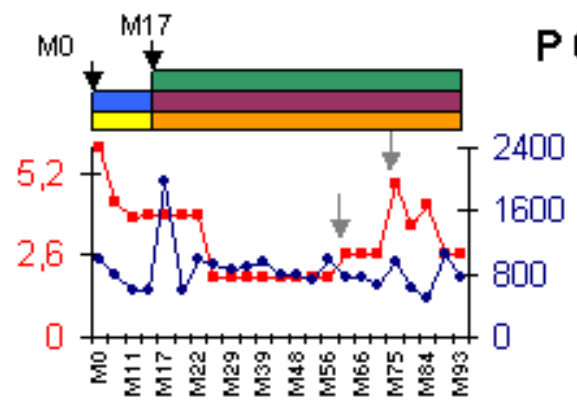

P 09
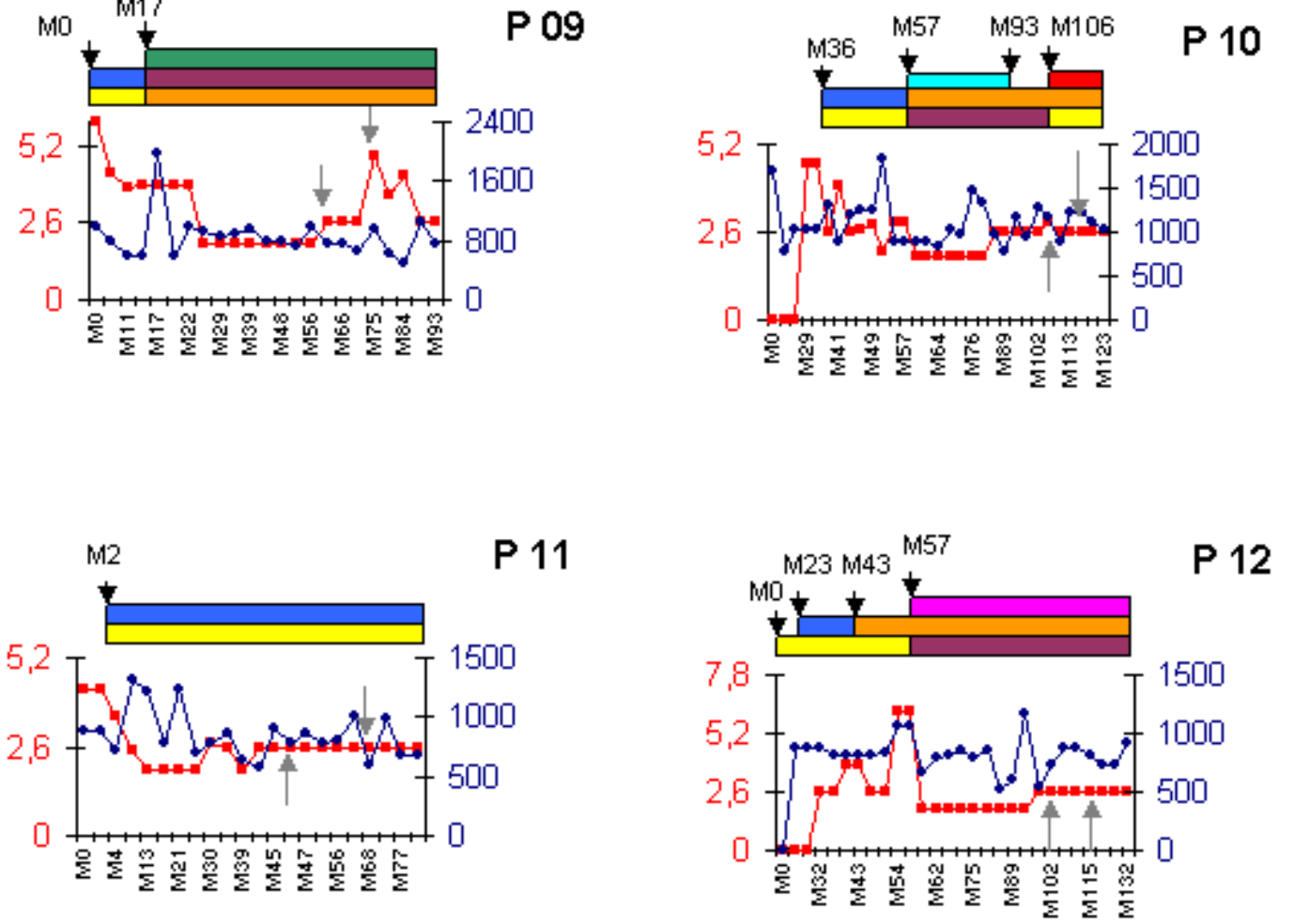

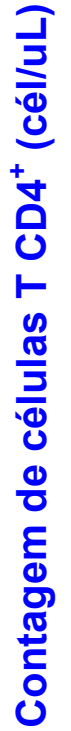
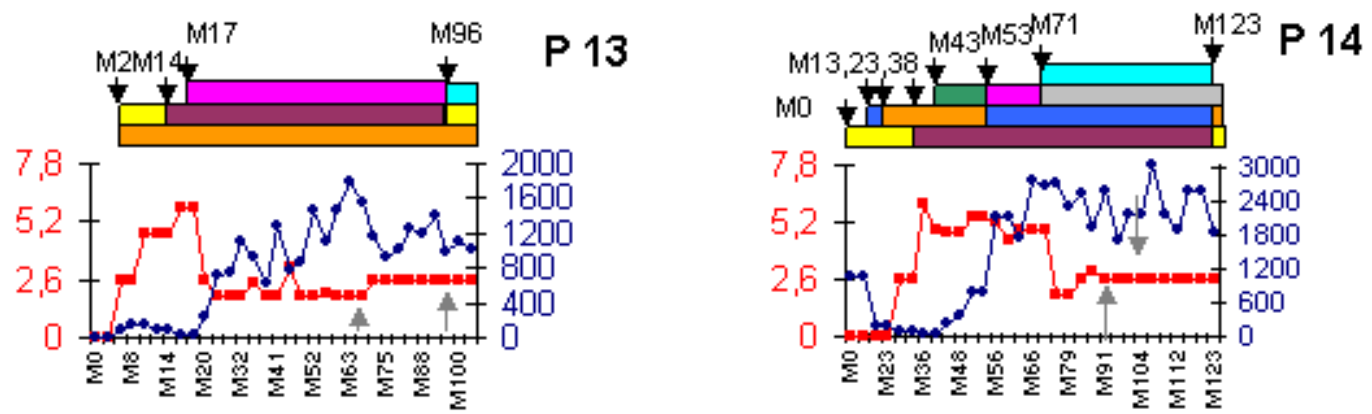


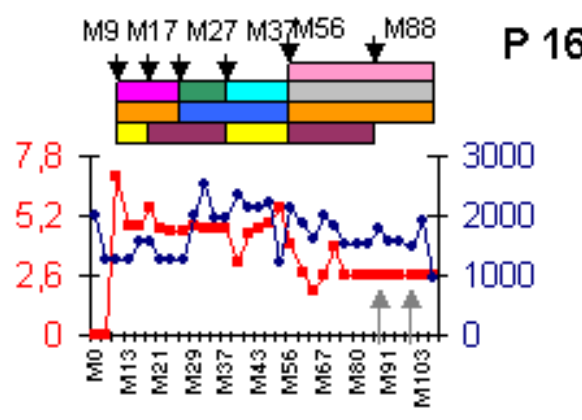

Figura 9 - Perfil terapêutico, imunológico e virológico dos pacientes.

A contagem de células $\mathrm{CD}^{+}$(círculo azul) e os níveis de RNA do HIV (quadrado vermelho) são mostrados em função do tempo de acompanhamento dos pacientes no CEADIPe. As setas pretas (em cima) indicam o início do tratamento (em meses de acompanhamento). As setas cinzas indicam os momentos das coletas incluídas no estudo. O limite de detecção para a quantificação da carga viral foi $<400 \mathrm{cp} / \mathrm{ml}(\log 2,59)$. As barras coloridas representam o tratamento com as drogas indicadas. $\mathrm{CV}=$ carga viral. AZT, zidovudina; DDI, didanosina; 3TC, lamivudina; D4T, estavudina; NVP, nevirapina; EFV, efavirenz; NFV, nelfinavir; RTV, ritonavir; $\mathrm{LPV} / \mathrm{r}$, lopinavir/ritonavir; ATV, atazanavir; ABC, abacavir. 
5.DISCUSSÃO 
Apesar dos muitos progressos na terapia anti-retroviral, a falta de adequadas formulações pediátricas para algumas drogas, juntamente com a manutenção do regime terapêutico, traz uma limitação ao tratamento de crianças infectadas pelo HIV-1 (Resino et al, 2004).

A diminuição da carga viral resultante do tratamento anti-retroviral geralmente é alcançada apenas por determinados períodos de tempo devido às dificuldades em manter uma boa adesão e ao desenvolvimento de resistência a drogas (Richman et al, 2004; Tamalet et al, 2003).

As implicações clínicas são preocupantes visto que resistência a múltiplas drogas pode resultar em falha do tratamento e progressão da infecção em pacientes apresentando vírus resistentes. Apesar disso, mutações de resistência nos genes principais pode conferir fitness deteriorado e reduzida capacidade replicativa (Ghosn et al, 2006).

A testagem genotípica do perfil de resistência do HIV-1 já está implantada no seguimento de pacientes com falha virológica a fim de obter melhores resultados na estratégia de tratamento e tem sido usada também na profilaxia em casos de acidente ocupacional, transmissão vertical e pacientes com infecção primária.

Durante o curso do tratamento anti-retroviral, a análise genotípica pode trazer importantes informações a serem consideradas como base para 
estratégias terapêuticas. Sabe-se que cada ITRN induz um grupo previsível de alterações genéticas, geralmente de maneira gradativa, com mutações primárias (que conferem resistência, mas afetam o fitness viral) surgindo primeiro e mutações secundárias (que restauram a capacidade replicativa do vírus) se desenvolvendo durante terapia continuada (Tamalet et al, 2003)

No presente estudo, avaliamos o perfil de resistência genotípica do HIV-1 em pacientes que conseguem supressão viral abaixo de $400 \mathrm{cp} / \mathrm{mL}$, a fim de observar a eventual relação entre o perfil genotípico e a resposta ao TARV nesses pacientes.

Para todos os pacientes envolvidos no estudo $(n=16)$ foram avaliadas 2 amostras em momentos distintos. Nossas análises revelaram alta prevalência de vírus com mutações em códons associados com resistência a drogas nas duas coletas, com percentagens variando de acordo com as classes específicas de drogas.

Na primeira coleta as percentagens encontradas para cada classe de drogas foram de $31,3 \%$ para os ITRN, $12,5 \%$ para os ITRNN e $31,3 \%$ para os IP. Na segunda coleta observamos $37,5 \%, 18,8 \%$ e $31,3 \%$ de freqüência de mutações associadas com resistência aos ITRN, ITRNN e IP, respectivamente. 
Estudo realizado por De la Rosa e colaboradores (2004), avaliando adultos com viremia abaixo de 50 cópias $/ \mathrm{mL}$, demonstrou apenas $40 \%$ de vírus isolados de células mononucleares de sangue periférico apresentando no mínimo uma mutação associada com resistência. Cohen Stuart et al (2001) avaliando plasma com CV de 76 cópias $/ \mathrm{mL}$, em média, encontraram $72,7 \%$ de vírus com mutações de resistência a uma ou mais drogas.

Ao avaliarmos a região da transcriptase reversa do HIV-1 encontramos freqüência de aminoácidos com substituições de 6,0\% (18/299) na primeira coleta e 5,0\% (15/299) na segunda e, diferente da PR, o número de polimorfismos foi menor que a freqüência de mutações importantes.

As mutações que conferem resistência aos ITRN são classificadas de acordo com as diferentes drogas. As mutações aos análogos de timidina (TAMs) são específicas para AZT e d4T, mas quando presentes juntamente com outras mutações podem resultar em elevados níveis de resistência a outras drogas como ABC e ddl. As TAMs incluem as mutações M41L, D67N, K70R, L210W, T215Y/F e K219Q (Turner, Brenner \& Wainberg, 2004).

Na primeira coleta observamos substituições nos códons 41, 67 e 215 numa freqüência de $19 \%$, e menos que $13 \%$ para os resíduos 70 e 219 . A única mutação do grupo das TAMs não encontrada no presente estudo foi no aminoácido 210. 
Uma das mutações mais precoces que aparecem em pacientes em monoterapia com AZT é a K70R, com aparecimento subseqüente da T215Y/F. Esta confere elevados níveis de resistência ao AZT e envolve alteração por duas bases (Huang et al, 1998). Uma via compreende T215Y, que pode estar associada à L210W e a outra, T215F, pode surgir juntamente com a K219Q (Clavel \& Hance, 2004).

O único paciente apresentando vírus mutante K219Q também apresentou a T215F, de acordo com relatado por Clavel e Hance (2004). Todas as TAMs observadas estavam presentes em vírus isolados de pacientes expostos ao AZT. Em apenas um caso uma mutação não se manteve na segunda amostra, sendo a D67N (ID 03) encontrada em vírus com exposição prévia ao AZT.

Outro fato notado em nosso estudo foi com relação à mutação no aminoácido 41 que, de acordo com Huang e colaboradores (1998), tem sua Metionina freqüentemente substituída por uma Leucina em vírus com a mutação no códon 215.

As mutações E44D e V118I, também conhecidas como mutações aos análogos nucleosídeos (NAMs), são mais freqüentes em vírus de pacientes que já usaram AZT e 3TC, sendo responsáveis por altos níveis de resistência ao AZT. São comumente selecionadas por regime terapêutico 
contendo AZT e ddl. O significado clínico de cada uma quando ocorrem isoladamente não é conhecido (Johnson et al, 2003).

A freqüência dessas mutações foi baixa na população estudada. Apenas 1/16 paciente (ID 05) mostrou isolado viral contendo a V118I e 1/16 paciente (ID 08) apresentou mistura E44DE, que não se manteve na segunda amostra.

Outras mutações importantes (K65R, L74V, Q151M e M184I/V), além das TAMS K70R e T215Y/F, são capazes de causar, por si só, resistência a determinadas drogas. Ocorrem próximo ao sítio de ligação da droga e é provável que afetem diretamente a posição, estabilidade ou reatividade do análogo ligado à enzima (Huang et al, 1998).

A mutação no códon 184 foi encontrada no perfil genotípico de vírus isolados de 2/16 pacientes (12,5\%). Os dois (ID 05 e 13) haviam sido expostos ao 3TC.

Algumas mutações selecionadas por uma droga podem suprimir a resistência fenotípica a outras drogas. A M184V, selecionada pelo 3TC e $A B C$, é um exemplo capaz de suprimir ou reduzir o surgimento de fenótipo resistente a AZT (Cohen et al, 2002). Aparentemente, essa mutação causa reduzida capacidade replicativa em vírus mutante M184V (De Clerq, 2003; Stone et al, 2004). 
Por outro lado, algumas mutações, apesar de não serem relacionadas diretamente com ocorrência de resistência, são importantes para recuperação do fitness viral e são desenvolvidas no contexto de dupla resistência a AZT e 3TC: H208Y, R211K, L214F e G333E/D (Walter et al, 2002).

A substituição R211K, no presente estudo, foi encontrada numa freqüência de $31,25 \%$ na primeira coleta e $43,75 \%$ na segunda coleta. A mutação L214F estava presente em 18,75\% dos vírus analisados nas duas coletas.

Com relação aos ITRNN, todas as mutações a eles relacionadas encontram-se dentro de regiões específicas da TR do HIV-1, principalmente nos códons 98-108 e 179-190. Além disso, a mutação no resíduo 230 está associada com resistência à DLV. A mutação Y318F é uma exceção, com efeito significante na susceptibilidade à DLV quando presente sozinha e, quando em combinação com outras mutações de resistência aos ITRNN, também altera a susceptibilidade ao EFV e NVP (Larder, 2001).

A98G, V106A e V179D são resíduos na região de ligação dos ITRNN na subunidade p66 da RT e associados com diferentes níveis de resistência às drogas dessa classe. Existem relatos do surgimento da mutação K103N e mutações principais adicionais associadas com resistência aos ITRNN em pessoas não tratadas (Lal, Chakrabarti \& Yang, 2005). 
No presente estudo foram encontradas as substituições A98G numa freqüência de $12,5 \%$ na primeira coleta e $18,75 \%$ na segunda, e K103N em vírus isolados de apenas um paciente (ID 05) na primeira coleta e que não se manteve na segunda.

Acredita-se que a mutação $\mathrm{K} 103 \mathrm{~N}$ causa alto nível de resistência aos ITRNN e tem pouco efeito no fitness viral. Então, a continuação de esquema terapêutico com essa classe de drogas na presença da referida mutação pode trazer benefício clínico limitado, além de complicar o uso de IP por causa de interações das drogas com os ITRNN (Lucas, 2005).

Observamos que em 62,5\% (10/16) dos pacientes não houve alteração relevante no genótipo viral. Do restante, em 83,3\% (5/6) surgiram novas substituições na região da transcriptase reversa no momento da segunda coleta, todas relacionadas com resistência, localizadas nos resíduos 41, 98, 184, 208 e 215, aumentando suas freqüências. Em outros $50 \%(3 / 6)$ algumas mutações observadas na primeira coleta não se mantiveram na segunda amostra, também relacionadas a resistência, nos resíduos 44, 67 e 103

$\mathrm{Na}$ avaliação da região da protease do gene pol foram encontradas várias substituições. 
Os padrões genotípicos em pacientes com HIV resistente a IP são altamente complexos (Mo et al, 2005). Na ausência de qualquer exposição a drogas, a TR e a PR apresentam polimorfismos em cerca de $40 \%$ dos primeiros 240 aminoácidos da TR e 30\% dos 99 aminoácidos da PR. Algumas dessas substituições ocorrem em posições associadas com resistência a drogas no subtipo $B$ e podem ser resultado da rápida replicação viral e da elevada taxa de substituições incorretas durante a transcrição reversa do HIV (Lal, Chakrabarti \& Yang, 2005).

A comparação seqüencial de indivíduos tratados e não tratados identificou mutações na protease nas posições $20,36,63,71,77$ e 93 como "mutações secundárias" (ou acessórias) (Lal, Chakrabarti \& Yang, 2005). No entanto, substituições em vários outros códons também são relatadas como mutações secundárias (Gavin \& Yogev, 2002). Mutações nessas posições não causam altos níveis de resistência por si só, mas contribuem para resistência quando presentes com certas mutações primárias, ou agem como compensatórias à reduzida eficiência catalítica causada pelas mutações primárias selecionadas pelos IP (Johnson et al, 2003).

As mutações primárias (ou principais), centrais para o desenvolvimento de elevado nível de resistência, ocorrem no sítio ativo da enzima e estão nas posições 30, 46, 48, 50, 82, 84 e 90 (Gavin \& Yogev, 2002). 
Na primeira coleta encontramos variação em 28,3\% (28/99) das posições da seqüência do gene, sendo a maioria deles apenas polimorfismos já previamente descritos (Gavin \& Yogev, 2002). As principais freqüências encontradas nesse estudo foram no resíduo 63 (56\%) e nos resíduos 36 e 41 (37,5\%).

A mutação L63P, encontrada em 5/16 amostras (31,25\%) nesse estudo, ocorre em vírus que nunca foram expostos aos IP e pode ser mais prevalente em vírus de pacientes cujo regime contendo IP tenha falhado. Essa mutação, quando presente com múltiplas outras mutações, está associada com falha clínica (Johnson et al, 2003).

Encontrada numa freqüência de $25 \%$, a substituição M36I, contribui para resistência ao RTV e NFV. De acordo com Pieniazek et al (2000) e Cornelissen et al (1997), a Metionina na posição 36 pode representar um polimorfismo específico do subtipo $B$, visto que sua freqüência é extremamente maior entre as cepas não-B e, mais especificamente, representa assinatura do subtipo $F$.

Entre as mutações principais encontramos $12,5 \%(n=2)$ da mutação D30N. Essa mutação, selecionada pelo NFV, pode reduzir a susceptibilidade à droga em aproximadamente 6 vezes, mas também causa redução do fitness viral (Fitzgibbon et al, 2001). Um dos pacientes com vírus contendo a mutação referida (ID 03) não foi exposto ao NFV, sendo uma das possíveis 
explicações a presença de vírus adquirido arquivado contendo a substituição D30N.

Encontramos ainda a substituição V82I em 1/16 paciente (ID 07), exposto apenas a uma droga da classe dos IP, o RTV. A mutação V82I ocorre em cerca de 1\% dos indivíduos HIV-1 não tratados. Essa mutação sozinha confere pouca resistência aos IP disponíveis, no entanto, substituições no aminoácido V82 que resultem em V82A,F,S ou T estão associados com elevado grau de resistência à maioria dos inibidores da protease (Lal, Chakrabarti \& Yang, 2005).

As mutações I84V e L90M, comumente encontradas em pacientes expostos aos IP, foram encontradas em 1/16 paciente. O perfil genotípico do vírus isolado desse paciente chamou bastante atenção. Após exposição prévia a vários esquemas contendo AZT, 3TC, NFV e RTV, alcançou primeira indetecção com esquema d4T+ddl+EFV+LPV/r em outubro de 2001 e mantém-se com supressão viral completa (<400cópias $/ \mathrm{mL}$ ) desde então, apresentando apenas um episódio de viremia $(\log 3,0)$ um ano após a primeira indetecção. No entanto, apresentou perfil genotípico com mutações de resistência às 3 classes de drogas utilizadas. Quando avaliamos as mutações encontradas no algoritmo da RENAGENO, observamos susceptibilidade apenas ao LPV/r.

A provável explicação para o fato pode estar, mais uma vez, relacionada com o fitness viral. O termo se refere à capacidade do vírus de 
se replicar num dado ambiente e pode explicar parcialmente a falta de associação entre resistência a drogas e progressão clínica. Especificamente, as mutações que surgem com exposição a drogas permitem que o HIV continue se replicando na presença da droga, mas com custos para o vírus (Lucas, 2005). Devereux e colaboradores (1999) observaram a redução de vírus resistentes após interrupção da terapia e o reaparecimento de vírus tipo selvagem, juntamente com a elevação da replicação viral.

Ghosn et al (2006) observaram caso semelhante em dois pacientes apresentando vírus resistentes a no mínimo 2 classes de drogas das 3 em uso e mantiveram supressão viral completa por 24 e 48 meses. Os autores sugerem controle da replicação viral mediado por células $T$, com reconhecimento de epitopos variantes ou ainda anticorpos neutralizantes, fatores genéticos do hospedeiro, bem como polimorfismos no receptor de quimiocinas.

Na segunda coleta encontramos freqüência de $23,2 \%$ (23/99) de substituições na região da protease. Novamente, as posições mais freqüentes apresentando substituições foram os resíduos 63 (62,5\%), 41 $(48 \%)$ e $36(31,25 \%)$.

Foi possível observar que em $37,5 \%$ (6/16) dos pacientes não houve alteração relevante no genótipo viral. Do restante, em 30\% (3/10) surgiram novas substituições na região da protease no momento da segunda coleta, 
todas relacionadas com polimorfismos. Em outros $30 \%(3 / 10)$ algumas mutações observadas na primeira coleta não se mantiveram na segunda amostra, sendo relacionadas a polimorfismos em dois deles e a mutação principal D30N em uma amostra (ID 03), referido como vírus deteriorado já discutido anteriormente.

Tendo em vista que o material genômico foi extraído de linfócitos, reservatório natural do vírus, e diretamente amplificado sem produção de clones, tal amostra (ID 03) poderia se tratar de vírus arquivado (que não se manteve na segunda amostra) apresentando capacidade replicativa deteriorada.

Teoricamente a possibilidade de que alguns pacientes tenham se infectado com um vírus resistente ou que as mutações foram selecionadas durante a fase inicial do HAART não pode ser descartada (Cohen Stuart et al, 2001).

Nos 3/10 pacientes restantes $(30 \%)$, houve as duas situações de aparecimento e omissão relacionados a polimorfismos. Em nenhum dos 10 pacientes aqui citados houve troca de esquema anti-retroviral. Essa diversidade pode resultar do arquivo sucessivo de diversos vírus do plasma pré-HAART. Os vírus isolados de linfócitos não expostos a drogas préHAART podem corresponder a clones "ancestrais", que se mantêm apesar 
da evolução viral decorrente de replicação viral residual nos linfócitos (Lambotte et al, 2004).

Ruff e colaboradores (2002) sugerem que a persistência de vírus com níveis amplamente variáveis de resistência genotípica a drogas é consistente com a idéia de que vírus em reservatórios latentes estão livres da pressão seletiva de drogas ARV.

Entre os 16 pacientes envolvidos no estudo, observamos elevação da carga viral em 3 (ID 03, 05 e 09), sendo todos provavelmente associados à fraca adesão ao esquema terapêutico, sugerida pelos clínicos e notada pelos rebotes com retorno à indetecção sem alteração das drogas em uso. Um paciente (ID 05) chamou a atenção por apresentar rebotes de baixa viremia com presença de grande número de substituições associadas à resistência no perfil genotípico do vírus.

A adesão ao tratamento e o desenvolvimento de resistência aos IP estão ligados. Fraca adesão à medicação resulta em exposição insuficiente à droga e a pressão seletiva causa evolução de vírus resistentes. Níveis intermediários de adesão, apesar de fornecer a droga, permitem replicação intermitente ou de baixo nível e, conseqüentemente, elevam o risco de desenvolvimento de resistência (Lucas, 2005). 
Foi possível perceber que, apesar do sucesso no controle da replicação viral, uma grande proporção dos pacientes analisados apresentou cepas virais mutantes presentes nos linfócitos.

É importante frisar que, por termos trabalhado com amostras de células mononucleares de sangue periférico, obtivemos um retrato de vírus presentes em um dos reservatórios virais.

A supressão viral completa, com manutenção dos níveis de RNA plasmático abaixo dos níveis detectáveis em ensaios comerciais, é considerada o principal alvo e indicador de sucesso terapêutico. Entretanto, na prática clinica, especialmente no atendimento de crianças, é mais difícil atingir níveis de viremia indetectáveis, fato obtido por uma porcentagem pequena dentre o universo de crianças em tratamento (Chougnet et al, 2004). Mesmo quando isso ocorre, muitas delas não conseguem manter essa condição por períodos prolongados. Inúmeras podem ser as causas desta dificuldade, e vão desde as dificuldades na adesão aos esquemas terapêuticos (Reddington et al, 2000), às características do sistema imune desta faixa etária.

Van Rossum, Fraaij, de Groot (2002) demonstraram que a resposta virológica varia muito e depende de fatores como o tempo entre a infecção e o inicio do tratamento e principalmente, com o esquema anti-retroviral 
utilizado. Pode variar entre 14 a $87 \%$ a porcentagem de indivíduos que atinge a indetecção de RNA viral.

Luzuriaga et al (1997), avaliando a resposta a um esquema sem inibidor de protease (zidovudina, didanosina,nevirapina) observaram que apenas 2 crianças em 8 mantiveram níveis indetectáveis de viremia por período prolongado. Resultados mais animadores foram encontrados por Starr et al (1999), em esquema contendo efavirenz, nelfinavir e um ITRN, com $63 \%$ das crianças atingindo cargas virais inferiores a 50 cópias $/ \mathrm{mL}$.

Desse modo, as crianças e adolescentes que participaram desse estudo fazem parte de um grupo privilegiado, uma vez que ao serem selecionadas, as mesmas encontravam-se há pelo menos 12 meses em vigência de supressão viral completa.

No momento da inclusão no estudo, a mediana das idades foi de 10 anos (intervalo: 6 -15 anos), sendo esse dado um fator importante no sucesso terapêutico. Sabe-se que as crianças apresentam cargas virais elevadas nos primeiros anos de vida, atingindo um estado de equilíbrio com cargas virais mais baixas ao redor dos 6 anos de idade. Assim, o fato de terem idades iguais ou maiores de 6 anos, pode ter facilitado, em vigência de tratamento adequado, que atingissem níveis de carga viral indetectáveis. 
Quatorze das 16 crianças estudadas estavam em uso de HAART contendo três $(\mathrm{N}=13)$ ou quatro $(\mathrm{N}=1)$ drogas anti-retrovirais. Duas delas estavam em vigência do primeiro esquema anti-retroviral (IDs 11 e 15). Duas crianças (IDs 10 e 11) estavam em uso de esquema duplo mantendo cargas virais indetectáveis. Dois pacientes fizeram troca de esquema anti-retroviral, ambos por motivos de eventos adversos como lipodistrofia e sonolência (IDs 06 e 10), sendo importante ressaltar que em ambos o perfil genotípico não mostrou alterações relevantes. Em estudo comparativo, Hirsh et al (1999) demonstraram que a combinação de três drogas é melhor do que o uso de terapia com dois análogos de nucleosideos ou de monoterapia com inibidor de protease. Mesmo em pacientes com uso prévio de anti-retroviral, Gulick et al (1997) demonstraram supressão viral mais prolongada em uso de esquema com três drogas.

Apesar da melhora importante na evolução clínica de pacientes que atingem a supressão viral, há persistência de vírus em vários reservatórios (Chun et al, 1997; Finzi et al, 1997; Siliciano et al, 2003). Entre eles, um "pool" de células infectadas latentes, no compartimento das células T CD4 ${ }^{+}$ em repouso, tem sido muito estudado e considerado um dos maiores impedimentos à erradicação do HIV (Zhang et al, 1999; Furtado et al, 1999).

Com relação ao comportamento imunológico do grupo estudado, é importante frisar a contagem de células $\mathrm{T} \mathrm{CD4}^{+}$no momento da inclusão no estudo (mediana = 1046,50; intervalo: $347-2588 \mathrm{cel} / \mathrm{mm}^{3}$ ). Além disso, 
apesar de o critério de inclusão ser de 12 meses de indetecção da carga viral, a mediana de tempo com supressão viral no grupo estudado foi de 35,5 meses (intervalo de 12 a 63 meses), sendo que os pacientes com mais tempo de indetecção (IDs 06 $=63$ meses e $15=60$ meses) apresentavam poucas substituições relacionadas com diminuição da susceptibilidade do vírus às drogas ARV. Apesar de 6 crianças serem da categoria imunológica 3, ou seja, em algum momento da vida já terem apresentado comprometimento imunológico grave, não houve diferença estatisticamente significante entre estas e 0 restante do grupo que apresentou comprometimento moderado $(\mathrm{N}=6)$ ou nenhum comprometimento imunológico $(\mathrm{N}=4)$, quando avaliados com a relação à presença de mutações de resistência por grupo.

Além disso, apenas 2 crianças (ID 04 e 05) apresentavam valores absolutos de células T CD4 ${ }^{+}$abaixo de $500 \mathrm{cel} / \mathrm{mm}^{3}$, o normal esperado para crianças acima de 6 anos de idade. Esse fato confirma achados prévios que apontam um aumento progressivo de células $\mathrm{T} \mathrm{CD4}^{+}$após o inicio de HAART. Essajee et al (1999) e Gibb et al (2000) mostraram que em pacientes com boa resposta imunológica a HAART, $70 \%$ das células responsáveis pelo aumento de células $\mathrm{T} C D 4^{+}$total eram células "naive" ou jovens, não sensibilizadas. $\mathrm{O}$ mesmo grupo demonstrou ainda três padrões distintos de recuperação imune: o primeiro caracteriza-se por um rápido aumento de células que se estabiliza uma vez que a contagem atinge valores próximos ao normal; o segundo mostra um aumento de $\mathrm{T} \mathrm{CD} 4^{+}$mais 
lento e gradual; um terceiro padrão é caracterizado por um aumento inicial de células $\mathrm{T} \mathrm{CD}^{+}$, seguido por uma queda de pelo menos $10 \%$ em relação ao pico, mas, apesar da queda, ainda mantém-se níveis pelo menos $5 \%$ maiores que o valor pró-HAART (de Rossi et al, 2002). No grupo estudado, podemos observar que a supressão viral prolongada trouxe benefícios em termos de recuperação ou manutenção dos valores de células $\mathrm{T} \mathrm{CD}^{+}$em níveis satisfatórios para as respectivas idades.

A evolução clínica do grupo mostrou poucas intercorrências durante o período de acompanhamento, confirmando o benefício da manutenção da supressão viral prolongada. Além do pequeno número de intercorrências clínicas observadas, não houve nenhum episódio considerado grave.

A presença de mutações em vírus arquivados não interferiu com a resposta virológica, imunológica ou clínica do grupo estudado, nem esseve relacionada com falha posterior.

A manutenção de períodos prolongados de supressão viral em crianças continua um desafio, mas, frente aos benefícios conquistados pelo grupo em estudo, será sempre um importante alvo a ser buscado. 
6.CONCLUSÕES 
- Apesar da supressão viral completa e prolongada, o perfil de resistência genotípica aos anti-retrovirais em crianças com carga viral indetectável mostrou freqüência elevada de polimorfismos na região do genoma que codifica a enzima protease, enquanto que na região da transcriptase reversa encontramos maior número de mutações principais. Sua evolução genotípica observada no momento da segunda amostra (após média de 15,8 meses) mostrou grande alteração, contudo, não houve alteração significante no perfil de resistência, impossibilitando a previsão de falha virológica para esses pacientes.

- No grupo estudado não houve progressão da doença, confirmando o benefício da manutenção da supressão viral prolongada. 
7.ANEXOS 
ANEXO A

\section{HOSPITAL DAS CLÍNICAS}

DA

FACULDADE DE MEDICINA DA UNIVERSIDADE DE SÃO PAULO

TERMO DE CONSENTIMENTO LIVRE E ESCLARECIDO

I - DADOS DE IDENTIFICAÇÃO DO SUJEITO DA PESQUISA OU RESPONSÁVEL LEGAL

1.NOME DO PACIENTE .:

DOCUMENTO DE IDENTIDADE No :

SEXO : .M F

DATA NASCIMENTO: .......................

ENDEREÇO.

$\mathrm{N}^{\circ}$. APTO:

BAIRRO:

CIDADE CEP:

TELEFONE: DDD

2.RESPONSÁVEL LEGAL

NATUREZA (grau de parentesco, tutor, curador etc.).

DOCUMENTO DE IDENTIDADE :

SEXO: $M \quad F$

DATA NASCIMENTO.: .....................

ENDEREÇO:

CIDADE:

.........

BAIRRO:

.APTO:

TELEFONE: DDD

).

CEP.

\section{II - DADOS SOBRE A PESQUISA CIENTÍFICA}

1. TÍTULO DO PROTOCOLO DE PESQUISA

Avaliação clínica, imunológica e do perfil de resistência genotípica aos antiretrovirais de crianças infectadas pelo HIV-1 mantendo supressão viral prolongada em vigência de tratamento

PESQUISADOR RESPONSÁVEL: Dra. Daisy Maria Machado

CARGO/FUNÇÃO: Médica Pesquisadora

INSCRIÇÃO CONSELHO REGIONAL No 54983-SP

UNIDADE DO HCFMUSP: Laboratório de Virologia do Instituto de Medicina Tropical de São Paulo - FMUSP

PESQUISADOR EXECUTANTE: Daniela Souza Araújo de Angelis 
3. AVALIAÇÃO DO RISCO DA PESQUISA:

SEM RISCO RISCO MÍNIMO $X \quad$ RISCO MÉDIO

RISCO BAIXO RISCO MAIOR

(probabilidade de que o indivíduo sofra algum dano como conseqüência imediata ou tardia do estudo)

4.DURAÇÃO DA PESQUISA :

2 anos 


\section{INTRODUÇÃO}

Antes de decidir se seu filho (a) participará desse estudo, queremos fornecer-lhe algumas informações.

Esse é um formulário de consentimento, que fornece informações sobre a pesquisa. Você e a equipe de pesquisadores analisarão juntos as informações. Faça perguntas quando quiser. Se concordar em permitir que seu filho (a) participe da pesquisa, você deverá assinar esse formulário. Forneceremos uma cópia para você guardar consigo.

\section{POR QUE ESTAMOS REALIZANDO ESTA PESQUISA?}

O objetivo principal do tratamento da infecção pelo HIV é controlar a multiplicação do vírus, diminuindo, assim, a destruição das defesas das pessoas infectadas por ele. Algumas pessoas recebendo os remédios contra - HIV conseguem ter uma boa resposta a esse tratamento, porém, isso não acontece com todas. As crianças têm um pouco mais de dificuldade em responder bem ao tratamento. Assim, esse estudo procura entender melhor o grupo de crianças do ambulatório do Centro de Atendimento da Disciplina de Infectologia Pediátrica - CEADIPe - UNIFESP, que conseguiu uma ótima resposta ao tratamento. $O$ melhor entendimento desse grupo nos trará informações importantes para ajudarmos aqueles que não estão respondendo ao tratamento. Portanto, sua participação é de extrema importância para todos os envolvidos no acompanhamento de pessoas infectadas pelo HIV.

\section{O QUE DEVO FAZER SE MEU FILHO (A) PARTICIPAR DESTA PESQUISA?}

Seu filho (a) foi selecionado para participar desta pesquisa pois está respondendo muito bem ao tratamento com as medicações contra o HIV há mais de 12 meses. Se você concordar que ele (a) participe desta pesquisa, ao realizar seus exames de rotina, será coletada também de seu filho (a) uma amostra de sangue ( $5 \mathrm{ml} / 1$ colher de chá) para a realização de um teste conhecido como "Genotipagem". Esse teste avalia se o vírus da criança está ficando resistente ao tratamento. Não será feito nenhum outro procedimento além dos habituais no acompanhamento da criança.

\section{QUANTAS PESSOAS PARTICIPARÃO DA PESQUISA?}

Aproximadamente 50 crianças ou adolescentes participarão da pesquisa. 


\section{QUANTO TEMPO DURARÁ NOSSA PARTICIPAÇÃO NA PESQUISA?}

Seu filho (a) participará da pesquisa por aproximadamente 24 meses, sendo acompanhado clinicamente com a freqüência habitual do serviço . Caso você não seja mais o tutor legal da criança, a permanência da criança no estudo dependerá de um outro consentimento do novo tutor legal.

\section{QUAIS SÃO OS RISCOS DA PESQUISA?}

Riscos da coleta de sangue

As coletas de sangue podem causar algum desconforto, sangramento e/ou aparecimento de mancha roxa no local em que a agulha perfura a pele.

\section{HÁ VANTAGENS EM PARTICIPAR DESTA PESQUISA?}

É possível que seu filho (a) não receba qualquer benefício direto ao participar desta pesquisa, mas as informações coletadas nesta pesquisa podem ajudar outras crianças portadoras do HIV que não essejam conseguindo responder bem ao tratamento .

\section{E A DIVULGAÇÃO DOS DADOS DA PESQUISA?}

Os registros referentes ao seu filho (a) permanecerão confidenciais até o limite permitido por lei, sendo que as informações pessoais contidas nos registros não serão divulgadas sem sua expressa autorização. Além disso, no caso de publicação desse estudo, não serão utilizados seus nomes ou qualquer dado que os identifiquem.

As pessoas que podem examinar seus registros são: a equipe de pesquisadores e os monitores da pesquisa.

\section{QUAL É O CUSTO PARA MIM/MEU FILHO (A)?}

Não haverá nenhum custo a você /seu filho (a) para participar do estudo.

\section{EU/MEU FILHO (A) RECEBEREMOS ALGUM PAGAMENTO?}

Você não receberá nenhum pagamento para participar do estudo.

\section{QUAIS SÃO OS MEUS DIREITOS E OS DO MEU FILHO (A) NA PESQUISA?}

Participar desta pesquisa é totalmente voluntário. Você pode escolher não permitir que o seu filho (a) participe. Você pode retirar seu filho (a) da 
pesquisa em qualquer momento. Você e o seu filho (a) serão tratados da mesma forma, o que quer que você decida, e seu filho (a) terá garantia de acesso a tratamento hospitalar (HSP) quando necessário.

Se quiser receber os resultados da pesquisa, informe isto à equipe de pesquisadores.

\section{O QUE FAÇO EM CASO DE DÚVIDAS OU PROBLEMAS?}

Para solucionar dúvidas relativas a esse estudo, entre em contato com a Biomédica Daniela Souza Araújo de Angelis ou com a Dra. Daisy Maria Machado, que podem ser encontradas no Laboratório de Virologia do Instituto de Medicina Tropical, Av. Dr. Enéas de Carvalho Aguiar, 470, $2^{\circ}$ andar. Fone: 30667020 - Ramal 102. Se tiver alguma consideração ou dúvida sobre a ética da pesquisa, entre em contato com o Comitê de Ética para Análise de Projetos de Pesquisa (CAPPesq) pelo telefone 3069-6442.

\section{ASSINATURAS}

Se você leu esse formulário de consentimento (ou se alguém explicou seu conteúdo para você), se todas as perguntas foram respondidas e você concordou que seu filho (a) participe desta pesquisa, assine abaixo.

$\overline{\text { Nome do participante (por extenso) }}$

Representante legal do participante (por extenso)

Membro da equipe de pesquisa que conduziu a discussão do consentimento (por extenso)

Testemunha (por extenso)
Assinatura do participante e data

Assinatura do representante legal do participante (se aplicável) e data

Assinatura do membro da equipe e data
Assinatura da testemunha e data (se aplicável) 
ANEXO B 
ANEXO C 
ANEXO D

\section{Avaliação Clínico-laboratorial}

Nome

RG do HSP

Data do Nascimento

Data da $1^{\text {a }}$ Consulta
Sexo ( )
(1) Fem
(2) Masc
Cor ( )
(1) Branco
(2) Amarelo
(3) Negro
(4) Mulato
(5) Índio

Dados da Infecção HIV/aids

Data do início dos sintomas

Classificação clinico-laboratorial no início do acompanhamento

Classificação clinico-laboratorial na $1^{\text {a }}$ coleta

Classificação clinico-laboratorial na $2^{\mathrm{a}}$ coleta

Classificação clinico-laboratorial na época da $1^{a}$ indetecção

\section{Dados relacionados à TARV}

Data do início da TARV:

Valor do CD4 pré-TARV:

Valor da CV pré-TARV:
Método ( )
(1) RT-PCR
(2) NASBA

Esquema terapêutico inicial

Esquema terapêutico no momento da $1^{\mathrm{a}}$ indetecção

Esquema terapêutico no momento da primeira coleta

( )

Esquema terapêutico no momento da segunda coleta
(1) $A Z T+d d l$
(2) $A Z T+d d l+N V P$
(3) $A Z T+d d l+E F V$
(4) $A Z T+d d l+R T V$
(5) $A Z T+d d l+N F V$
(6) $A Z T+$ ddl + Kaletra
(7) $A Z T+3 T C$
(8) $A Z T+3 T C+N V P$

(13) D4T + ddl

(14) $\mathrm{D} 4 \mathrm{~T}+\mathrm{ddl}+\mathrm{NVP}$

(15) $D 4 T+d d l+E F V$

(16) $\mathrm{D} 4 \mathrm{~T}+\mathrm{ddl}+\mathrm{RTV}$

(17) $\mathrm{D} 4 \mathrm{~T}+\mathrm{ddl}+\mathrm{NFV}$

(18) $D 4 T+d d l+$ Kaletra

(19) $\mathrm{D} 4 \mathrm{~T}+3 \mathrm{TC}$

(20) D4T + 3TC + NVP 
(9) $A Z T+3 T C+E F V$

(10) $A Z T+3 T C+R T V$

(11) $A Z T+3 T C+N F V$

(12) $A Z T+3 T C+$ Kaletra

(13) $A Z T+3 T C+A B C+$ Kaletra
(21) $\mathrm{D} 4 \mathrm{~T}+3 \mathrm{TC}+\mathrm{EFV}$

(22) $\mathrm{D} 4 \mathrm{~T}+3 \mathrm{TC}+\mathrm{RTV}$

(23) $\mathrm{D} 4 \mathrm{~T}+3 \mathrm{TC}+\mathrm{NFV}$

(24) D4T + 3TC + Kaletra

(24) Outro ( especificar):

\section{Seguimento clínico-laboratorial}

Data da $1^{\mathrm{a}}$ avaliação ( $1^{\mathrm{a}}$ coleta)

Diagnósticos na $1^{a}$ avaliação
Data da $2^{\mathrm{a}}$ avaliação ( $2^{\mathrm{a}}$ coleta)

Diagnósticos na $2^{a}$ avaliação

Intercorrências no período inter-coletas:

\begin{tabular}{|c|c|c|c|c|c|}
\hline Data & Diagnósticos: 1 & 2 & 3 & 4 & 5 \\
\hline & & & & & \\
\hline & & & & & \\
\hline & & & & & \\
\hline & & & & & \\
\hline
\end{tabular}

Valores de CD4/CD8 e CV durante período de acompanhamento:

\begin{tabular}{|c|c|c|c|c|c|}
\hline Data & CD4/CD8 & CV & Data & CD4/CD8 & CV \\
\hline & & & & & \\
\hline & & & & & \\
\hline
\end{tabular}


8.REFERÊNCIAS 
Ammaranond P, Cunningham P, Oelrichs R, Suzuki K, Harris C, Leas L, Grulich A, Cooper DA, Kelleher AD. Rates of transmission of anti-retroviral drug resistant strains of HIV-1. J Clin Virol. 2003;26(2):153-61.

Bacheler L, Jeffrey S, Hanna G, D'Aquila R, Wallace L, Logue K, Cordova B, Hertogs K, Larder B, Buckery R, Baker D, Gallagher K, Scarnati H, Tritch R, Rizzo C. Genotypic correlates of phenotypic resistance to efavirenz in virus isolates from patients failing nonnucleoside reverse transcriptase inhibitor therapy. J Virol. 2001 Jun;75(11):4999-5008.

Barbosa AF, Machado DM, Succi RC. [Acquired immunodeficiency syndrome in children: pathogenesis, prognostic markers, and treatment]. J Pediatr (Rio J). 1999 Jul;75(Suppl 1):S3-8. Portuguese.

Barré-Sinoussi, F. HIV as the cause of AIDS. Lancet. 1996;348(9019):31-5.

Barreca ML, Lee KU, Chinirri A \& Briggs JM. Molecular dynamics studies of the wild-type and double mutant HIV-1 integrase complexed with the 5CITEP inhibitor: mechanism for inhibition and drug resistance. Biophys J. 2003;84(3):1450-63.

Bi X, Gatanaga H, Ida S, Tsuchiya K, Matsuoka-Aizawa S, Kimura S, Oka S. Emergence of protease inhibitor resistance-associated mutations in plasma 
HIV-1 precedes that in proviruses of peripheral blood mononuclear cells by more than a year. J Acquir Immune Defic Syndr. 2003;34(1):1-6.

Blankson JN, Persaud D, Siliciano RF. The challenge of viral reservoirs in HIV-1 infection. Annu Rev Med. 2002;53:557-93.

Bogerd HP, Fridell RA, Madore S, Cullen BR. Identification of a novel cellular cofactor for the Rev/Rex class of retroviral regulatory proteins. Cell. 1995;82(3):485-94.

Bongertz, V. Vertical human immunodeficiency vírus type 1- HIV-1 transmission - a review. Mem Inst Oswaldo Cruz. 2001; 96(1):1-14.

Brindeiro PA, Brindeiro RM, Mortensen C, Hertogs K, De Vroey V, Rubini NP, Sion FS, De Sa CA, Machado DM, Succi RC, Tanuri A. Testing genotypic and phenotypic resistance in human immunodeficiency virus type 1 isolates of clade B and other clades from children failing anti-retroviral therapy. J Clin Microbiol. 2002 Dec;40(12):4512-9.

Camacho, R. Resistência aos anti-retrovirais. HIV-Aids Virtual Congress. $1^{\circ}$ Congresso. [online]. Portugal 2000. Disponível em www.aidscongress.net/article.php?id_comunicação=31. Acessado em 29/05/06 
CDC. Caldwell MB, Oxtoby MJ, Simonds RJ, Lindegren ML \& Rogers MF. 1994 revised classification system for human immunedeficiency virus infection in children less than 13 years of age. [online]. MMWR. 1994;43(RR12-1). Available from www.cdc.gov/mmwr/preview/mmwrhtml/ 0032890.htm. Acessed in 29/05/06.

Cherepanov P, Maertens G, Proost P, Devreese B, Van-Beeumen J, Engelborghs $\mathrm{Y}$, De Clercq E \& Debyser Z. HIV-1 integrase forms stable tetramers and associates with LEDGF/p75 protein in human cells. J Biol Chem. 2003;278(1):372-81.

Chun TW, Stuyver L, Mizell SB, Ehler LA, Mican JA, Baseler M, Lloyd AL, Nowak MA, Fauci AS. Presence of an inducible HIV-1 latent reservoir during highly active anti-retroviral therapy. Proc Natl Acad Sci U S A. 1997;94(24):13193-7.

Chun TW, Nickle DC, Justement JS, Large D, Semerjian A, Curlin ME, O'Shea MA, Hallahan CW, Daucher M, Ward DJ, Moir S, Mullins JI, Kovacs C, Fauci AS. HIV-infected individuals receiving effective antiviral therapy for extended periods of time continually replenish their viral reservoir. J Clin Invest. 2005;115(11):3250-5.

Clavel F \& Hance AJ. HIV drug resistance. N Engl J Med. 2004;350(10):1023-35. 
Cohen NJ, Oram R, Elsen C, Englund JA. Response to changes in antiretroviral therapy after genotyping in human immunodeficiency virus-infected children. Pediatr Infect Dis J. 2002;21(7):647-53.

Cohen Stuart JW, Wensing AM, Kovacs C, Righart M, de Jong D, Kaye S, Schuurman R, Visser CJ, Boucher CA. Transient relapses ("blips") of plasma HIV RNA levels during HAART are associated with drug resistance. J Acquir Immune Defic Syndr. 2001;28(2):105-13.

Colonno R, Rose R, McLaren C, Thiry A, Parkin N, Friborg J. Identification of $150 \mathrm{~L}$ as the signature atazanavir (ATV)-resistance mutation in treatmentnaive HIV-1-infected patients receiving ATV-containing regimens. J Infect Dis. $2004 ; 189(10): 1802-10$.

Cooley LA, Lewin SR. HIV-1 cell entry and advances in viral entry inhibitor therapy. J Clin Virol. 2003;26(2):121-32.

Cooper DA. Update on didanosine. J Int Assoc Physicians AIDS Care (Chic III). 2002 Winter;1(1):15-25.

Cornelissen M, van den Burg R, Zorgdrager F, Lukashov V, Goudsmit J. pol gene diversity of five human immunodeficiency virus type 1 subtypes: evidence for naturally occurring mutations that contribute to drug resistance, 
limited recombination patterns, and common ancestry for subtypes B and D. J Virol. 1997;71(9):6348-58.

De Clercq E. Clinical potential of the acyclic nucleoside phosphonates cidofovir, adefovir, and tenofovir in treatment of DNA virus and retrovirus infections. Clin Microbiol Rev. 2003;16(4):569-96.

De la Rosa R, Ruiz-Mateos E, Rubio A, Abad MA, Vallejo A, Rivero L, Genebat M, Sanchez-Quijano A, Lissen E, Leal M. Long-term virological outcome and resistance mutations at virological rebound in HIV-infected adults on protease inhibitor-sparing highly active anti-retroviral therapy. $\mathbf{J}$ Antimicrob Chemother. 2004;53(1):95-101.

Demeter LM, Shafer RW, Meehan PM, Holden-Wiltse J, Fischl MA, Freimuth WW, Para MF, Reichman RC. Delavirdine susceptibilities and associated reverse transcriptase mutations in human immunodeficiency virus type 1 isolates from patients in a phase $\mathrm{I} / \mathrm{II}$ trial of delavirdine monotherapy (ACTG 260). Antimicrob Agents Chemother. 2000;44(3):794-7.

De Rossi A, Masiero S, Giaquinto C, Ruga E, Comar M, Giacca M, ChiecoBianchi L. Dynamics of viral replication in infants with vertically acquired human immunodeficiency virus type 1 infection. J Clin Invest. 1996;97(2):323-30. 
De Rossi, A. Primary Hiv infection in infants: impact of highly active antiretroviral therapy on the natural course. J Biol Regul Homeost Agents. 2002;16(1):53-7.

De Souza, M.V.N. \& De Almeida, M.V. Drogas anti-HIV: passado, presente e perspectivas futuras. Quim Nova. 2003;26:366-72.

Devereux HL, Youle M, Johnson MA, Loveday C. Rapid decline in detectability of HIV-1 drug resistance mutations after stopping therapy. AIDS. 1999;13(18):F123-7.

Doukhan L, Delwart E. Population genetic analysis of the protease locus of human immunodeficiency virus type 1 quasispecies undergoing drug selection, using a denaturing gradient-heteroduplex tracking assay. J Virol. 2001;75(14):6729-36.

Eshleman SH, Hackett J Jr, Swanson P, Cunningham SP, Drews B, Brennan C, Devare SG, Zekeng L, Kaptue L, Marlowe N. Performance of the Celera Diagnostics ViroSeq HIV-1 Genotyping System for sequence-based analysis of diverse human immunodeficiency virus type 1 strains. J Clin Microbiol. 2004;42(6):2711-7.

Essajee SM, Kim M, Gonzalez C, Rigaud M, Kaul A, Chandwani S, Hoover W, Lawrence R, Spiegel H, Pollack H, Krasinski K, Borkowsky W. 
Immunologic and virologic responses to HAART in severely immunocompromised HIV-1-infected children. AIDS. 199913(18):2523-32.

Finzi D, Hermankova M, Pierson T, Carruth LM, Buck C, Chaisson RE, Quinn TC, Chadwick K, Margolick J, Brookmeyer R, Gallant J, Markowitz M, Ho DD, Richman DD, Siliciano RF. Identification of a reservoir for HIV-1 in patients on highly active anti-retroviral therapy. Science. 1997;278(5341):1295-300.

Fitzgibbon JE, Gaur S, Walsman SM, Janahi M, Whitley-Williams P, John JF Jr. Emergence of drug resistance mutations in a group of HIV-infected children taking nelfinavir-containing regimens. AIDS Res Hum Retroviruses. 2001;17(14):1321-8.

Freed EO, Englund G, Maldarelli F, Martin MA. Phosphorylation of residue 131 of HIV-1 matrix is not required for macrophage infection. Cell. 1997;88(2):171-3; discussion 173-4.

Frenkel LM, Wagner II LE, Atwood SM, Cummins TJ, Dewhurst S. Specific, sensitive, and rapid assay for human immunodeficiency virus type 1 pol mutations associated with resistance to zidovudine and didanosine. J Clin Microbiol 1995;33(2):342-7.

Furtado MR, Callaway DS, Phair JP, Kunstman KJ, Stanton JL, Macken CA, 
Perelson AS, Wolinsky SM. Persistence of HIV-1 transcription in peripheralblood mononuclear cells in patients receiving potent anti-retroviral therapy. $\mathbf{N}$ Engl J Med. 1999;340(21):1614-22.

Galli RA, Sattha B, Wynhoven B, O'Shaughnessy MV, Harrigan PR. Sources and magnitude of intralaboratory variability in a sequence-based genotypic assay for human immunodeficiency virus type 1 drug resistance. J Clin Microbiol. 2003;41(7):2900-7.

Gao Q, Gu Z, Parniak MA, Cameron J, Cammack N, Boucher C, Wainberg MA. The same mutation that encodes low-level human immunodeficiency virus type 1 resistance to $2^{\prime}, 3^{\prime}$-dideoxyinosine and 2',3'-dideoxycytidine confers high-level resistance to the (-) enantiomer of 2',3'-dideoxy-3'thiacytidine. Antimicrob Agents Chemother. 1993;37(6):1390-2.

Gavin PJ, Yogev R. The role of protease inhibitor therapy in children with HIV infection. Paediatr Drugs. 2002;4(9):581-607.

Ghosn J, Pellegrin I, Goujard C, Deveau C, Viard JP, Galimand J, Harzic M, Tamalet C, Meyer L, Rouzioux C, Chaix ML; French PRIMO Cohort Study Group (ANRS CO 06). HIV-1 resistant strains acquired at the time of primary infection massively fuel the cellular reservoir and persist for lengthy periods of time. AIDS. 2006;20(2):159-70. 
Gibb DM, Newberry A, Klein N, de Rossi A, Grosch-Woerner I, Babiker A. Immune repopulation after HAART in previously untreated HIV-1-infected children. Paediatric European Network for Treatment of AIDS (PENTA) Steering Committee. Lancet. 2000;355(9212):1331-2.

Gotte M, Li X, Wainberg MA. HIV-1 reverse transcription: a brief overview focused on structure-function relationships among molecules involved in initiation of the reaction. Arch Biochem Biophys. 1999;365(2):199-210.

Grant RM, Kuritzkes DR, Johnson VA, Mellors JW, Sullivan JL, Swanstrom R, D'Aquila RT, Van Gorder M, Holodniy M, Lloyd Jr RM Jr, Reid C, Morgan GF, Winslow DL. Accuracy of the TRUGENE HIV-1 genotyping kit. J Clin Microbiol. 2003;41(4):1586-93.

Gulick RM, Mellors JW, Havlir D, Eron JJ, Gonzalez C, McMahon D, Richman DD, Valentine FT, Jonas L, Meibohm A, Emini EA, Chodakewitz JA. Treatment with indinavir, zidovudine, and lamivudine in adults with human immunodeficiency virus infection and prior anti-retroviral therapy. $\mathbf{N}$ Engl $\mathbf{J}$ Med. 1997;337(11):734-9.

Havlir DV, O'Marro SD. Atazanavir: new option for treatment of HIV infection. Clin Infect Dis. 2004;38(11):1599-604. 
Hermankova M, Ray SC, Ruff C, Powell-Davis M, Ingersoll R, D'Aquila RT, Quinn TC, Siliciano JD, Siliciano RF, Persaud D. HIV-1 drug resistance profiles in children and adults with viral load of $<50$ copies $/ \mathrm{ml}$ receiving combination therapy. JAMA. 2001;286(2):196-207.

Hermione Lyall EG. Paediatric HIV in 2002 - a treatable and preventable infection. J Clin Virol. 2002;25(2):107-19.

Huang H, Chopra R, Verdine GL, Harrison SC. Structure of a covalently trapped catalytic complex of HIV-1 reverse transcriptase: implications for drug resistance. Science. 1998;282(5394):1669-75.

Iglesias-Ussel MD, Casado C, Yuste E, Olivares I, Lopez-Galindez C. In vitro analysis of human immunodeficiency virus type 1 resistance to nevirapine and fitness determination of resistant variants. J Gen Virol. 2002;83(Pt 1):93-101.

Izopet J, Sailler L, Sandres K, Pasquier C, Bonnet E, Aquilina C, Puel J, Massip P, Marchou B. Intermittent selection pressure with zidovudine plus zalcitabine treatment reduces the emergence in vivo of zidovudine resistance HIV mutations. J Med Virol. 1999;57(2):163-8.

Jagodzinski LL, Cooley JD, Weber M, Michael NL. Performance characteristics of human immunodeficiency virus type 1 (HIV-1) genotyping 
systems in sequence-based analysis of subtypes other than HIV-1 subtype B. J Clin Microbiol. 2003;41(3):998-1003.

Janeway CA, Travers P, Walport M and Shlomchick M. Immunobiology: the immune system in health and disease. [online]. New York; 2001. Available from: www.ncbi.nlm.nih.gov/entrez/query.fcgi?CMD=search\&DB=books. Acessed in 29/05/06.

Japour AJ, Mayers DL, Johnson VA, Kuritzkes DR, Beckett LA, Arduino JM, Lane J, Black RJ, Reichelderfer PS, D'Aquila RT, et al. Standardized peripheral blood mononuclear cell culture assay for determination of drug susceptibilities of clinical human immunodeficiency virus type 1 isolates. The RV-43 Study Group, the AIDS Clinical Trials Group Virology Committee Resistance Working Group. Antimicrob Agents Chemother. 1993;37(5):1095-101.

Johnson VA, Brun-Vezinet F,Clotet B, Conway B, D'Aquila R, Demeter LM, Kuritzkes DR, Pillay D, Schapiro JM, Telenti A \& Richman DD. Drugs resistance mutations in HIV-1. Top HIV Med. 2003;11(6):215-21.

King JR, Kimberlin DW, Aldrovandi GM, Acosta EP. Anti-retroviral pharmacokinetics in the paediatric population: a review. Clin Pharmacokinet. 2002;41(14):1115-33. 
Kozal MJ, Shah N, Shen N, Yang R, Fucinin R, Merigan TC, Richman DD, Morris D, Hubbell Chee M, Gingeras TR. Extensive polymorphisms observed in HIV-1 clade B protease gene using high-density oligonucleotide array. Nat Med. 1996; 2(7): 753-9.

Lal RB, Chakrabarti S, Yang C. Impact of genetic diversity of HIV-1 on diagnosis, anti-retroviral therapy \& vaccine development. Indian J Med Res. 2005;121(4):287-314.

Lam E, Parkin NT. Amprenavir resistance imparted by the $150 \mathrm{~V}$ mutation in HIV-1 protease can be suppressed by the N88S mutation. Clin Infect Dis. 2003;37(9):1273-4.

Lambotte O, Chaix ML, Gubler B, Nasreddine N, Wallon C, Goujard C, Rouzioux C, Taoufik Y, Delfraissy JF. The lymphocyte HIV reservoir in patients on long-term HAART is a memory of virus evolution. AIDS. 2004;18(8):1147-58.

Larder B. Mechanisms of HIV-1 drug resistance. AIDS. 2001;15 Suppl 5:S2734.

Lehmann-Che J, Saib A. Early stages of HIV replication: how to hijack cellular functions for a successful infection. AIDS Rev. 2004;6(4):199-207. 
Lucas GM. Anti-retroviral adherence, drug resistance, viral fitness and HIV disease progression: a tangled web is woven. J Antimicrob Chemother. 2005;55(4):413-6.

Luzuriaga K, Bryson Y, Krogstad P, Robinson J, Stechenberg B, Lamson M, Cort S, Sullivan JL. Combination treatment with zidovudine, didanosine, and nevirapine in infants with human immunodeficiency virus type 1 infection. $\mathbf{N}$ Engl J Med. 1997;336(19):1343-9.

Luzuriaga K, Sullivan JL. Pediatric HIV-1 infection: advances and remaining challenges. AIDS Rev. 2002;4(1):21-6.

Mangasarian A, Trono D. The multifaceted role of HIV Nef. Res Virol. 1997;148(1):30-3.

Mansky LM, Temin HM. Lower in vivo mutation rate of human immunodeficiency virus type 1 than that predicted from the fidelity of purified reverse transcriptase. J Virol. 1995;69(8):5087-94.

Marcelin AG, Dalban C, Peytavin G, Lamotte C, Agher R, Delaugerre C, Wirden M, Conan F, Dantin S, Katlama C, Costagliola D, Calvez V. Clinically relevant interpretation of genotype and relationship to plasma drug concentrations for resistance to saquinavir-ritonavir in human 
immunodeficiency virus type 1 protease inhibitor-experienced patients. Antimicrob Agents Chemother. 2004;48(12):4687-92.

Marcello A. Latency: the hidden HIV-1 challenge. Retrovirology. $2006 ; 3(1): 7$.

Marcus U, Dittmar MT, Krausslich HG. HIV: epidemiology and strategies for therapy and vaccination. Intervirology. 2002;45(4-6):260-6.

Martinez E. The reassurance of experience. Int J STD AIDS. 2003 Oct;14 Suppl 1:20-8.

Matthews T, Salgo M, Greenberg M, Chung J, DeMasi R, Bolognesi D. Enfuvirtide: the first therapy to inhibit the entry of HIV-1 into host CD4 lymphocytes. Nat Rev Drug Discov. 2004;3(3):215-25.

Maxeiner HG, Keulen W, Schuurman R, Bijen M, de Graaf L, van Wijk A, Back N, Kline MW, Boucher CA, Nijhuis M. Selection of zidovudine resistance mutations and escape of human immunodeficiency virus type 1 from anti-retroviral pressure in stavudine-treated pediatric patients. J Infect Dis. 2002;185(8):1070-6. 
McColl DJ, Miller MD. The use of tenofovir disoproxil fumarate for the treatment of nucleoside-resistant HIV-1. J Antimicrob Chemother. 2003;51(2):219-23.

Miller MD. K65R, TAMs and tenofovir. AIDS Rev. 2004;6(1):22-33.

Mitsuya H \& Erickson J. Drug development: discovery and development of anti-retroviral therapeutics for HIV infection. In: Merigan Jr TC, Bartlett JG \& Bolognesi. Aids Medicine. $2^{\text {nd }}$ ed. Baltimore: Williams \& Wilhins; 1999: 751806.

Mo H, King MS, King K, Molla A, Brun S, Kempf DJ. Selection of resistance in protease inhibitor-experienced, human immunodeficiency virus type 1infected subjects failing lopinavir- and ritonavir-based therapy: mutation patterns and baseline correlates. J Virol. 2005;79(6):3329-38.

Montes B, Segondy M. Amino acid substitutions at position 69 of the reverse transcriptase of human immunodeficiency virus type 1 are frequent in zalcitabine-naive anti-retroviral-drug-experienced patients. Antimicrob Agents Chemother. 2002;46(9):3110-1.

Moyle G. Resistance and cross-resistance to abacavir. HIV Med. 2001;2(3):154-62. 
Mulder LCF, Chakrabarti LA \& Muesing MA. Interaction of HIV-1 integrase with DNA repair protein hRad18. J Biol Chem. 2002;277(30):27489-93.

Mulky A, Sarafianos SG, Arnold E, Wu X, Kappes JC. Subunit-specific analysis of the human immunodeficiency virus type 1 reverse transcriptase in vivo. J Virol. 2004 Jul;78(13):7089-96.

Mullen J, Leech S, O'Shea S, Chrystie IL, Du Mont G, Ball C, Sharland M, Cottam F, Zuckerman M, Rice P, Easterbrook P. Anti-retroviral drug resistance among HIV-1 infected children failing treatment. J Med Virol. 2002;68(3):299-304.

Nisole S, Saib A. Early steps of retrovirus replicative cycle. Retrovirology. 2004;1(1):9

Ohtaka H, Velazquez-Campoy A, Xie D, Freire E. Overcoming drug resistance in HIV-1 chemotherapy: the binding thermodynamics of Amprenavir and TMC-126 to wild-type and drug-resistant mutants of the HIV1 protease. Protein Sci. 2002;11(8):1908-16.

Palella FJ, Delaney KM, Moorman AC, Loveless MO, Fuhrer J, Satten GA \& Holmberg SD. Declining morbidity and mortality among patients with advanced human immunodeficiency virus infection. N Engl J Med. 1998;338(13):853-60. 
Paulsen D, Elston R, Snowden W, Tisdale M, Ross L. Differentiation of genotypic resistance profiles for amprenavir and lopinavir, a valuable aid for choice of therapy in protease inhibitor-experienced HIV-1-infected subjects. $\mathbf{J}$ Antimicrob Chemother. 2003;52(3):319-23.

Peçanha EP, Antunes OAC \& Tanuri A. Estratégias farmacológicas para a terapia anti-AIDS. Quim Nova. 2002;40:4512-9.

Persaud D, Pierson T, Ruff C, Finzi D, Chadwick KR, Margolick JB, Ruff A, Hutton N, Ray S, Siliciano RF. A stable latent reservoir for HIV-1 in resting CD4(+) T lymphocytes in infected children. J Clin Invest. 2000;105(7):9951003.

Persaud D, Siberry GK, Ahonkhai A, Kajdas J, Monie D, Hutton N, Watson DC, Quinn TC, Ray SC, Siliciano RF. Continued production of drug-sensitive human immunodeficiency virus type 1 in children on combination antiretroviral therapy who have undetectable viral loads. J Virol. 2004;78(2):96879.

Petropoulos CJ, Parkin NT, Limoli KL, Lie YS, Wrin T, Huang W, Tian H, Smith D, Winslow GA, Capon DJ, Whitcomb JM. A novel phenotypic drug susceptibility assay for human immunodeficiency virus type 1. Antimicrob Agents Chemother. 2000;44(4):920-8. 
Pieniazek D, Rayfield M, Hu DJ, Nkengasong J, Wiktor SZ, Downing R, Biryahwaho B, Mastro T, Tanuri A, Soriano V, Lal R, Dondero T. Protease sequences from HIV-1 group M subtypes A-H reveal distinct amino acid mutation patterns associated with protease resistance in protease inhibitornaive individuals worldwide. HIV Variant Working Group. AIDS. 2000;14(11):1489-95.

Potter SJ, Chew CB, Steain M, Dwyer DE, Saksena NK. Obstacles to successful anti-retroviral treatment of HIV-1 infection: problems \& perspectives. Indian J Med Res. 2004 Jun;119(6):217-37.

Reddington C, Cohen J, Baldillo A, Toye M, Smith D, Kneut C, Demaria A, Bertolli J, Hsu HW. Adherence to medication regimens among children with human immunodeficiency virus infection. Pediatr Infect Dis J. 2000;19(12):1148-53.

Resino S, Bellon JM, Resino R, Navarro ML, Tomas Ramos J, de Jose Ml, Mellado MJ, Munoz-Fernandez MA. Extensive implementation of highly active anti-retroviral therapy shows great effect on survival and surrogate markers in vertically HIV-infected children. Clin Infect Dis. 2004;38(11):160512. 
Richman DD, Morton SC, Wrin T, Hellmann N, Berry S, Shapiro MF, Bozzette SA. The prevalence of anti-retroviral drug resistance in the United States. AIDS. 2004;18(10):1393-401.

Rosenthal N. Fine structure of a gene--DNA sequencing. N Engl J Med. 1995;332(9):589-91.

Ruff CT, Ray SC, Kwon P, Zinn R, Pendleton A, Hutton N, Ashworth R, Gange S, Quinn TC, Siliciano RF, Persaud D. Persistence of wild-type virus and lack of temporal structure in the latent reservoir for human immunodeficiency virus type 1 in pediatric patients with extensive antiretroviral exposure. J Virol. 2002;76(18):9481-92.

Saitoh A, Hsia K, Fenton T, Powell CA, Christopherson C, Fletcher CV, Starr SE, Spector SA. Persistence of human immunodeficiency virus (HIV) type 1 DNA in peripheral blood despite prolonged suppression of plasma HIV-1 RNA in children. J Infect Dis. 2002;185(10):1409-16.

Sanger F, Nicklen S, Coulson AR. DNA sequencing with chain-terminating inhibitors. Proc Natl Acad Sci U S A. 1977;74(12):5463-7.

Sarafianos SG, Das K, Clark AD Jr, Ding J, Boyer PL, Hughes SH, Arnold E. Lamivudine (3TC) resistance in HIV-1 reverse transcriptase involves steric 
hindrance with beta-branched amino acids. Proc Natl Acad Sci U S A. 1999;96(18):10027-32.

Sayer DC, Land S, Gizzarelli L, French M, Hales G, Emery S, Christiansen FT, Dax EM. Quality assessment program for genotypic anti-retroviral testing improves detection of drug resistance mutations. J Clin Microbiol. 2003;41(1):227-36.

Schmidt B, Korn K, Moschik B, Paatz C, Uberla K, Walter H. Low level of cross-resistance to amprenavir (141W94) in samples from patients pretreated with other protease inhibitors. Antimicrob Agents Chemother. 2000;44(11):3213-6.

Serchuck LK, Welles L \& Yarchoan R. Drug development: anti-retroviral treatment for HIV infection. In: Merigan Jr TC, Bartlett JG \& Bolognesi. Aids Medicine. $2^{\text {nd }}$ ed. Baltimore: Williams \& Wilhins; 1999: 751-806.

Siliciano JD, Kajdas J, Finzi D, Quinn TC, Chadwick K, Margolick JB, Kovacs C, Gange SJ, Siliciano RF. Long-term follow-up studies confirm the stability of the latent reservoir for HIV-1 in resting CD4+ T cells. Nat Med. 2003;9(6):727-8.

Sluis-Cremer N, Tachedjian G. Modulation of the oligomeric structures of HIV-1 retroviral enzymes by synthetic peptides and small molecules. Eur $\mathbf{J}$ Biochem. 2002;269(21):5103-11. 
Sociedade Brasileira de Infectologia. Tratamento hoje. Boletim terapêutico de HIVIAids, DST e Hepatites virais. São Paulo 2003;I (3).

Starr SE, Fletcher CV, Spector SA, Yong FH, Fenton T, Brundage RC, Manion D, Ruiz N, Gersten M, Becker M, McNamara J, Mofenson LM, Purdue L, Siminski S, Graham B, Kornhauser DM, Fiske W, Vincent C, Lischner HW, Dankner WM, Flynn PM. Combination therapy with efavirenz, nelfinavir, and nucleoside reverse-transcriptase inhibitors in children infected with human immunodeficiency virus type 1. Pediatric AIDS Clinical Trials Group 382 Team. N Engl J Med. 1999;341(25):1874-81.

Stevens W, Kaye S, Corrah T. Anti-retroviral therapy in Africa. BMJ. 2004;328(7434):280-2 .

Stone C, Ait-Khaled M, Craig C, Griffin P, Tisdale M. Human immunodeficiency virus type 1 reverse transcriptase mutation selection during in vitro exposure to tenofovir alone or combined with abacavir or lamivudine. Antimicrob Agents Chemother. 2004;48(4):1413-5.

Sturmer M, Berger A, Preiser W. HIV-1 genotyping: comparison of two commercially available assays. Expert Rev Mol Diagn. 2004;4(3):281-91. 
Sundaravaradan V, Hahn T, Ahmad N. Conservation of functional domains and limited heterogeneity of HIV-1 reverse transcriptase gene following vertical transmission. Retrovirology. 2005;2:36.

Tamalet C, Fantini J, Tourres C, Yahi N. Resistance of HIV-1 to multiple antiretroviral drugs in France: a 6-year survey (1997-2002) based on an analysis of over 7000 genotypes. AIDS. 2003;17(16):2383-8.

Trono D. HIV accessory proteins: leading roles for the supporting cast. Cell. 1995;82(2):189-92.

Turner BG, Summers MF. Structural biology of HIV. J Mol Biol. 1999;285(1):1-32.

Turner D, Brenner B, Wainberg MA. Relationships among various nucleoside resistance-conferring mutations in the reverse transcriptase of HIV-1. J Antimicrob Chemother. 2004;53(1):53-7.

UNAIDS/WHO. Aids epidemic update: december 2005: special section on HIV prevention [online]. Geneva - Switzerland. Avaiable from: www.unaids.org/epi/2005/index.asp. Acessed in 29/05/06.

Usuku S, Noguchi Y, Sakamoto M, Adachi T, Sagara H, Sudo K, Nishizawa M, Kondo M, Tochikubo O, Imai M. Analysis of a long-term discrepancy in 
drug-targeted genes in plasma HIV-1 RNA and PBMC HIV-1 DNA in the same patient. Jpn J Infect Dis. 2006 Apr;59(2):122-5.

van Rossum AM, Fraaij PL, de Groot R. Efficacy of highly active antiretroviral therapy in HIV-1 infected children. Lancet Infect Dis. 2002;2(2):93-102.

Vergne L, Peeters M, Mpoudi-Ngole E, Bourgeois A, Liegeois F, Toure-Kane C, Mboup S, Mulanga-Kabeya C, Saman E, Jourdan J, Reynes J, Delaporte E. Genetic diversity of protease and reverse transcriptase sequences in nonsubtype-B human immunodeficiency virus type 1 strains: evidence of many minor drug resistance mutations in treatment-naive patients. J Clin Microbiol. 2000;38(11):3919-25.

Walker, MR. Guia de rotas na tecnologia do gene. Tradução de Fernando Salvador Moreno. São Paulo: Atheneu; 1999.

Walter $\mathrm{H}$, Schmidt B, Werwein M, Schwingel E, Korn K. Prediction of abacavir resistance from genotypic data: impact of zidovudine and lamivudine resistance in vitro and in vivo. Antimicrob Agents Chemother. 2002;46(1):89-94 . 
Wang WK, Chen MY, Chuang CY, Jeang KT \& Huang LM. Molecular biology of human immunodeficiency virus type-1. J Microbiol Immunol Infect. 2000;33(3):131-140.

Weinberg A, Pott GB. Immunity to human immunodeficiency virus (HIV) in children with chronic HIV infection receiving highly active anti-retroviral therapy. Clin Diagn Lab Immunol. 2003;10(5):821-5.

Whitcomb JM, Huang W, Limoli K, Paxinos E, Wrin T, Skowron G, Deeks SG, Bates M, Hellmann NS, Petropoulos CJ. Hypersusceptibility to nonnucleoside reverse transcriptase inhibitors in HIV-1: clinical, phenotypic and genotypic correlates. AIDS. 2002;16(15):F41-7.

White KL, Chen JM, Margot NA, Wrin T, Petropoulos CJ, Naeger LK, Swaminathan S, Miller MD. Molecular mechanisms of tenofovir resistance conferred by human immunodeficiency virus type 1 reverse transcriptase containing a diserine insertion after residue 69 and multiple thymidine analog-associated mutations. Antimicrob Agents Chemother. 2004;48(3):992-1003.

Yang QE. Eradication of HIV in infected patients: some potential approaches. Med Sci Monit. 2004 Jul;10(7):RA155-65. 
Yerly S, Vora S, Rizzardi P, Chave JP, Vernazza PL, Flepp M, Telenti A, Battegay M, Veuthey AL, Bru JP, Rickenbach M, Hirschel B, Perrin L; Swiss HIV Cohort Study. Acute HIV infection: impact on the spread of HIV and transmission of drug resistance. AIDS. 2001 Nov 23;15(17):2287-92.

Zhang L, Ramratnam B, Tenner-Racz K, He Y, Vesanen M, Lewin S, Talal A, Racz P, Perelson AS, Korber BT, Markowitz M, Ho DD. Quantifying residual HIV-1 replication in patients receiving combination anti-retroviral therapy. $\mathbf{N}$ Engl J Med. 1999;340(21):1605-13.

Zhong P, Kang L, Pan Q, Konings F, Burda S, Ma L, Xue Y, Zheng X, Jin Z, Nyambi P. Identification and distribution of HIV type 1 genetic diversity and protease inhibitor resistance-associated mutations in Shanghai, P. R. China. J Acquir Immune Defic Syndr. 2003 1;34(1):91-101. 
APÊNDICES 
Apêndice 1

\begin{tabular}{|c|c|c|}
\hline Letra & Símbolo & Nome do aminoácido \\
\hline$A$ & Ala & Alanina \\
\hline C & Cis ou Cys & Cisteína \\
\hline $\mathrm{D}$ & Asp & Aspartato \\
\hline$E$ & Glu & Glutamato \\
\hline $\mathrm{F}$ & Fen ou Phe & Fenilalanina \\
\hline G & Gli ou Gly & Glicina \\
\hline $\mathrm{H}$ & His & Histidina \\
\hline 1 & Ile & Isoleucina \\
\hline $\mathrm{K}$ & Lis ou Lys & Lisina \\
\hline $\mathrm{L}$ & Leu & Leucina \\
\hline$M$ & Met & Metionina \\
\hline $\mathrm{N}$ & Asn & Asparagina \\
\hline $\mathrm{P}$ & Pro & Prolina \\
\hline$Q$ & Gln & Glutamina \\
\hline $\mathrm{R}$ & Arg & Arginina \\
\hline $\mathrm{S}$ & Ser & Serina \\
\hline $\mathrm{T}$ & Ter ou Thr & Treonina \\
\hline V & Val & Valina \\
\hline W & Trp & Triptofano \\
\hline Y & Tir ou Tyr & Tirosina \\
\hline
\end{tabular}




\section{Apêndice 2}

\begin{tabular}{|c|c|}
\hline ID & MUTAÇÕES TRANSCRIPTASE REVERSA \\
\hline 01-1 & K49R;D86G;E89G;V118DV;D123E;I142T;Q197E;I202V;K220X;W229LW;V245E; A272P;Q278X;K281R;I293V \\
\hline $01-2$ & D123E;Q197E;I202V;V245E;A272P;I274FILV;K281R;R284KMRT;I293V \\
\hline $02-1$ & I2V;A62V;K102R;D121Y;K122E;I135T;D177E;G196E;T200I;E204K; R211G \\
\hline $02-2$ & K20R;A62V;K102R;K122E;I135T;D177E;M184V;G196E;T200I;E204K;R211G; I293V \\
\hline 03-1 & $\begin{array}{r}\text { D17N;G18S;E28K;E29K;K32R;E36K;E44K;G45E;G51K;E35K;D67N;W71*;R72K; D76N;G93K; D110N;D113N; } \\
\text { D121N;D123N;I135T;E138A;R143K;G152E;W153*;G155E;D185N;D186N;G190K;D192N; E194K;G196R;R199K;I202V;E203K; } \\
\text { R206K;R211K;G123E;W229*;E233K;D237N;W239*;V245M }\end{array}$ \\
\hline 03-2 & M41L;K43KN;N57H;N81D;K82R;Q85P;D113E;I135T;M184V;I202V;R211K;T215Y;V245M;A272P;I293V \\
\hline 04-1 & K11R;D123E;I159M;S162C;D177E;R211K;L264FL;A272P;K277R;T286A;I293V \\
\hline 04-2 & K11R;D123E;I159IM;S162C;D177E;R211K;L264FL;A272P;K277R;T286A;I293V \\
\hline $05-1$ & M41L;A62V;A98G;L100LV;K103N;V106I;V118IV;K122E;I135T;I142V;M184V;F214L;T215F;K249Q \\
\hline $05-2$ & $\begin{array}{c}\text { M41L;A62V;K70KQ;A98G;V106I;V118I;K122E;I135T;M164I;M184V;H208Y;F214L; } \\
\text { T215F;K249Q;K259X;A272P;K277R;R284KR;I293V }\end{array}$ \\
\hline 06-1 & V35I;K122E;1135T;I202V;V245E;K277Q;K281R;I293V \\
\hline 06-2 & D17E;E28D;I31L;A33PS;T39P;K122E;I135T;Q145K;G190GR;R211KR;V245E; K281G;T286PT;T290PT \\
\hline 07-1 & E6G;T27A;K49R;K122E;I135T;I202V;Q207D;R211X;V245I;V276I; L283I;I293V \\
\hline 07-2 & K49R;D121Y;K122E;I135T;I202V;Q207D;R211K;V245I;V276I; L283I;I293V \\
\hline $8-1$ & E44DE;|50V;I135T;F214L;V245E;A272P \\
\hline $8-2$ & $\begin{array}{c}\text { G45R;G51R;W71*;W88*;I135T;T165P;F214L;M230IM;W239RW;I244IK; V245EGKR;L246X; } \\
\text { S251RS;V254GV;Y271I;A272Q;I274L;V276X; Q278A;I293V }\end{array}$ \\
\hline $9-1$ & T27P;V60I;F116C;V118D;R125G;Y146N;P150A;L260ILV;V261AEGV; A272P;K281R;I293V \\
\hline $9-2$ & T39P;M41L;K49R;V60I;163L;N81Y;P97T;A98G;D110DN;K122E;I142T; T165L; Q197PQ; T215S;A272P;K281IR;T286A \\
\hline $10-1$ & V35I;T39P;P55PT;R83K;D123E;I178L;E204D;Q278X;I293V \\
\hline $10-2$ & T27A;V35I;V60E;R83K;W88*;S117P;V118D;K122E;I142T;I178IL; E204D;I293V \\
\hline $11-1$ & V35I;S68G;I135T;D177N;V245I;K249Q;T286A;I293V \\
\hline $11-2$ & V35I;S68G;I135T;D177N;V245I;K249Q;T286A;I293V \\
\hline $12-1$ & $\begin{array}{c}\text { M16I;K32R;M41I;G45X;G51R;W71*W;R78K;W88*;G93R;G99R;G112S;K122E;I142S;G190R;G196R;T200A;R211K;G213R;W229*;M } \\
\text { 230I;W252*; G262R;W266* }\end{array}$ \\
\hline $12-2$ & K32R;L100*;I142V;L149I;T200A;R206G;R211K;K272Q;I293V \\
\hline 13-1 & E6D;D17G;M41L;I135T;R172K;D177E;I178M;M184V;T215Y;V245K \\
\hline $13-2$ & E6D;M41L;I135T;D177E;I178M;M184V;T215Y;V245K \\
\hline $14-1$ & V35I;V60I;D67N;T69D;K70R;A98G;D121Y;K122E;I135T;R211K;F214L;T215F; D218E;K219Q;V245M;A272P;I293V \\
\hline 14-2 & V35I;V60I;D67N;T69D;K70R;A98G;D121Y;K122E;I135T;H208Y;R211K;F214L; T215F; D218E;K219Q; V245M;A272P;I293V \\
\hline 15-1 & V35M;D67N;K70R;L100*;S105A;K122E;I135M;D177N;I202V;R211K;V245E;K277R \\
\hline $15-2$ & V35M;D67N;K70R;S105A;K122E;I135M;D177N;I202V;R211K;V245E \\
\hline 16-1 & K101R;D121Y;K122E;S162C;K277R;T286A;I293V \\
\hline $16-2$ & K101R;D121Y;K122E;S162C \\
\hline
\end{tabular}

Mutações associadas com resistência a ITR

Mutações inesperadas em códons de resistência

Polimorfismos 


\section{Apêndice 3}

\begin{tabular}{|c|c|}
\hline ID & MUTAÇÕES PROTEASE \\
\hline 01-1 & I15E;G16E;L24*;D29E;V32G;N37T;I47R;H69K \\
\hline 01-2 & G16E;N37T;H69K \\
\hline 02-1 & K14R;K20R;R41K;A71V;I72T;I93L \\
\hline $02-2$ & K14R;K20R;D25A;R41K;A71V;I72T;I93L \\
\hline \multirow{2}{*}{ 03-1 } & G16E;E21K;D25N;D30N;E34K;E35N;M36I;P39S;R41K; \\
\hline & W42*;M46I;G48E;G49R;G51E;D60N;I62V;I64V;G68E;K70R;G86R;R87K \\
\hline 03-2 & T12A;G16E;E35D;M36I;P39S;R41K;K45R;I62V; I64V;K70R \\
\hline 04-1 & E35D;M36I;R41K;L63S;H69K;Q92E \\
\hline 04-2 & E35D;M36I;R41K;L63S;H69K;Q92X \\
\hline 05-1 & I13V;I15V;D30N;L33F;M36L;G40G_N;R57K;D60E;L63P;A71V;I72V;N88D \\
\hline $05-2$ & I13V;I15V;L19I;D30N;L33F;M36L;R41KR;R57K; D60E;L63P;I72V;N83D \\
\hline 06-1 & K14KR;I64V \\
\hline $06-2$ & K14KR;l64V \\
\hline 07-1 & I64V;V77I;V82I \\
\hline 07-2 & I13V;R57K;I64V;V77I;V82I \\
\hline 8-1 & I15V;L19Q;N37E;L63I \\
\hline $8-2$ & I15V;L19Q;N37E;G51R;L63S;V77I;G78R; G94S \\
\hline $9-1$ & K14R;N37E;L63A;C67D;H69K;T74AT \\
\hline $9-2$ & R8LR;L10I;I13IL;K14R;N37E;Q61QR;L63A;C67D;H69K; T74AT;V77I \\
\hline $10-1$ & E35D;I47M;G48R;L63P;E65D \\
\hline $10-2$ & E35D;L63P;E65D \\
\hline $11-1$ & M36I;164V \\
\hline $11-2$ & $\mathrm{~L} 63 \mathrm{H} ; \mathrm{I} 64 \mathrm{~V}$ \\
\hline $12-1$ & G16E;L33V;E34K;N37S;G40R;W42*;G49R;G51R;G52S;G73S;G86R;L89M \\
\hline $12-2$ & L33V;N37S;L89M \\
\hline 13-1 & I13V;G17E;R41K;D60E;Q61E;I62V;L63P;I64V; H69Y \\
\hline 13-2 & I13V;G17E;R41K;D60E;Q61E;I62V;L63P;I64V; H69Y \\
\hline 14-1 & L10I;E35D;M36V;N37H;R41K;I62V;L63P;H69Q;T74S;I84V;L90M \\
\hline 14-2 & L10I;E35D;M36V;N37H;R41K;I54V;I62V;L63P;H69Q;T74S;L90M \\
\hline 15-1 & M36I;L63S;I64L;I72V \\
\hline $15-2$ & M36I;L63S;164L;172V \\
\hline 16-1 & N37S;R41K;L63P;L90V \\
\hline $16-2$ & N37S;R41K;L63P;T80A;N88D \\
\hline
\end{tabular}

Mutações associadas com resistência a IP

Mutações inesperadas em códons de resistência

Polimorfismos 
Apêndice 4

Alinhamento das seqüências obtidas para todas as amostras, realizado pelo ClustalW, através do software MegAlign DNA Star.

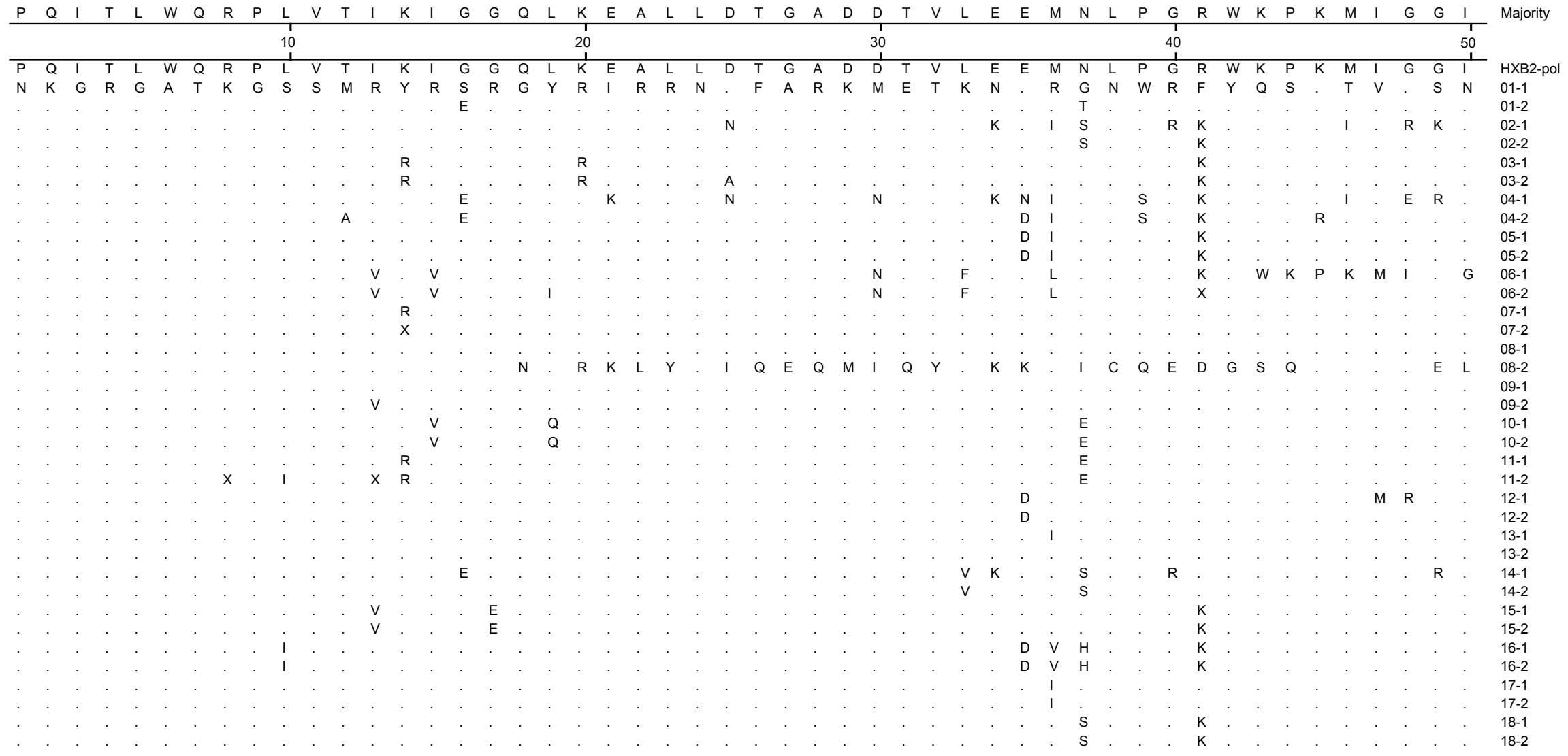




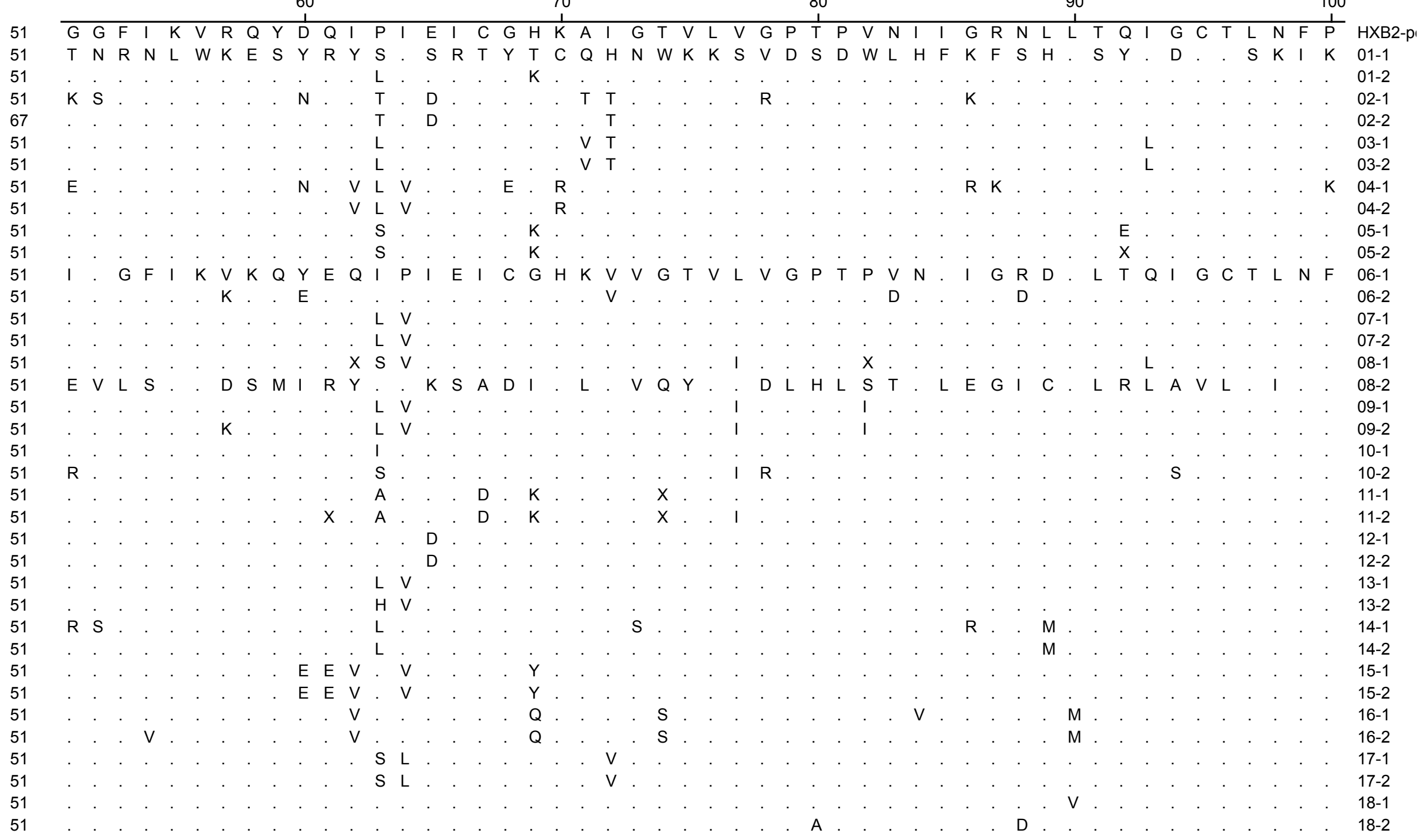




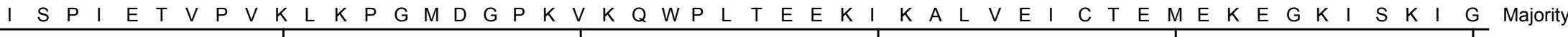

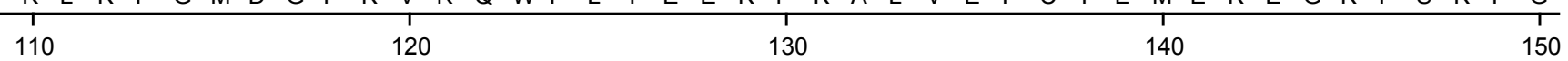

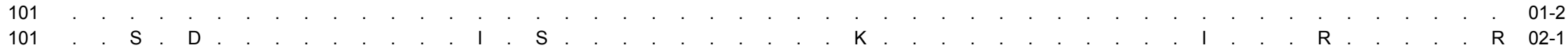

101 . S . D . . . . . . . . I . S . . . . . . . . . K . . . . . . . . . . . I . . . R . . . . R $02-1$

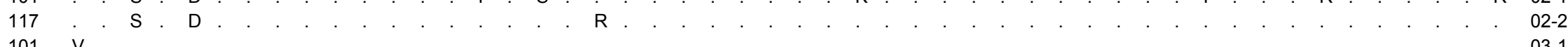

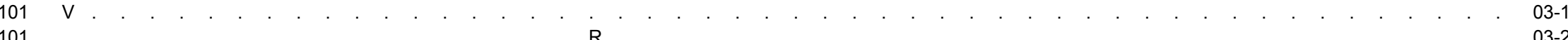

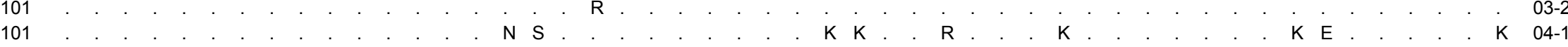

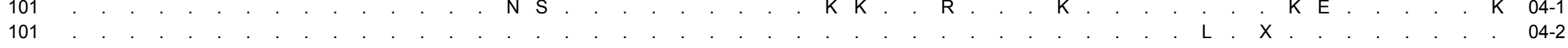

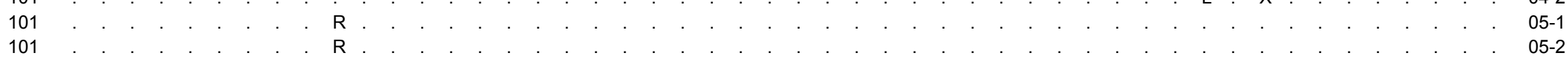

101 P I S P I E T V P V K L K P G D G P K K K W P L T. E K I K A L V E I C T E L E K E K I S K I O6-1

$\mathrm{L}$

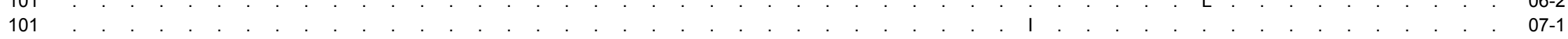

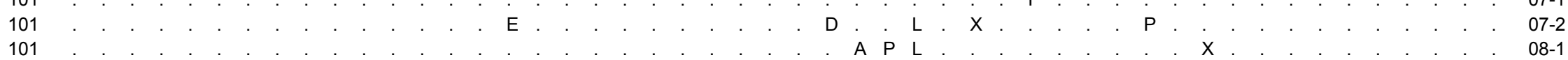

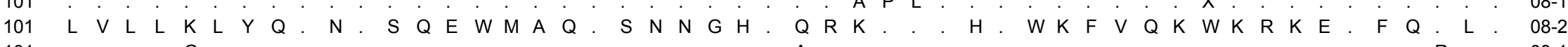

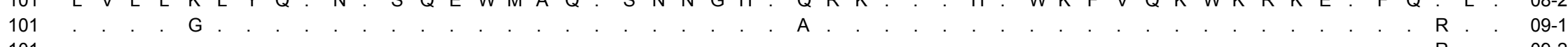

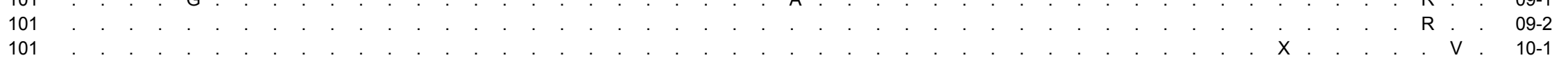

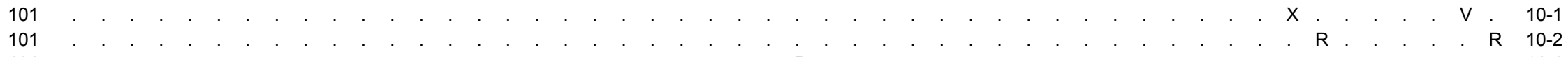

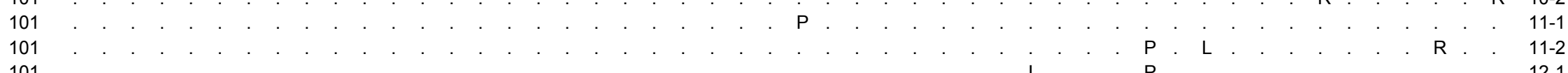

101 . . . . . . . . . . . . . . . . . . . . . . . . . . . . . . . . . . .

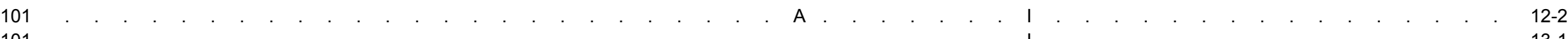

101

101

101

101

101

101
101

101

101

101
101

$$
\begin{aligned}
& \mathrm{R} \\
& \mathrm{R}
\end{aligned}
$$

E

R $13-2$

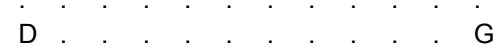

G.

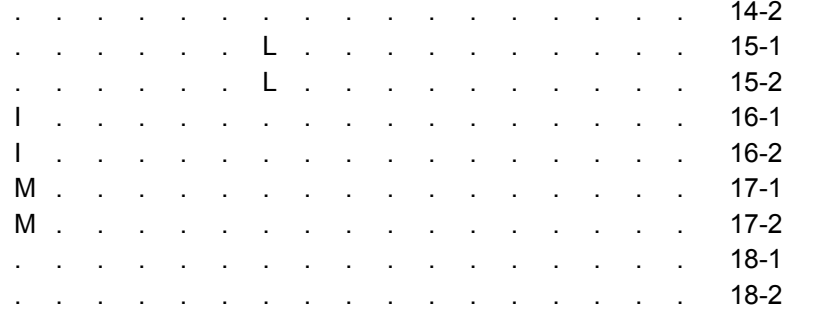




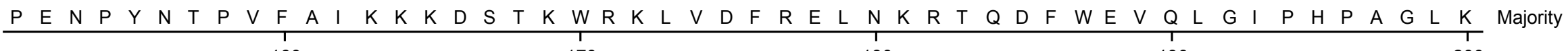

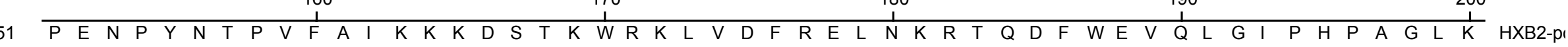

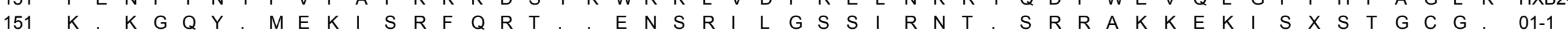

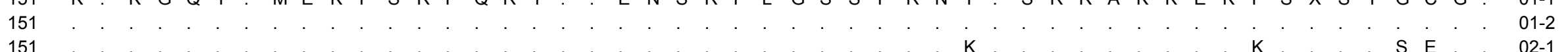

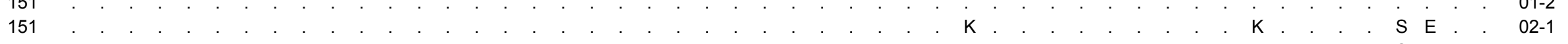

167

151

151
151

151

151

151
151

151
151

151

151

151

151
151

151
151
151

151
151

151
151

151
151

151

151

151

151
151

151

151
151

151

151
151

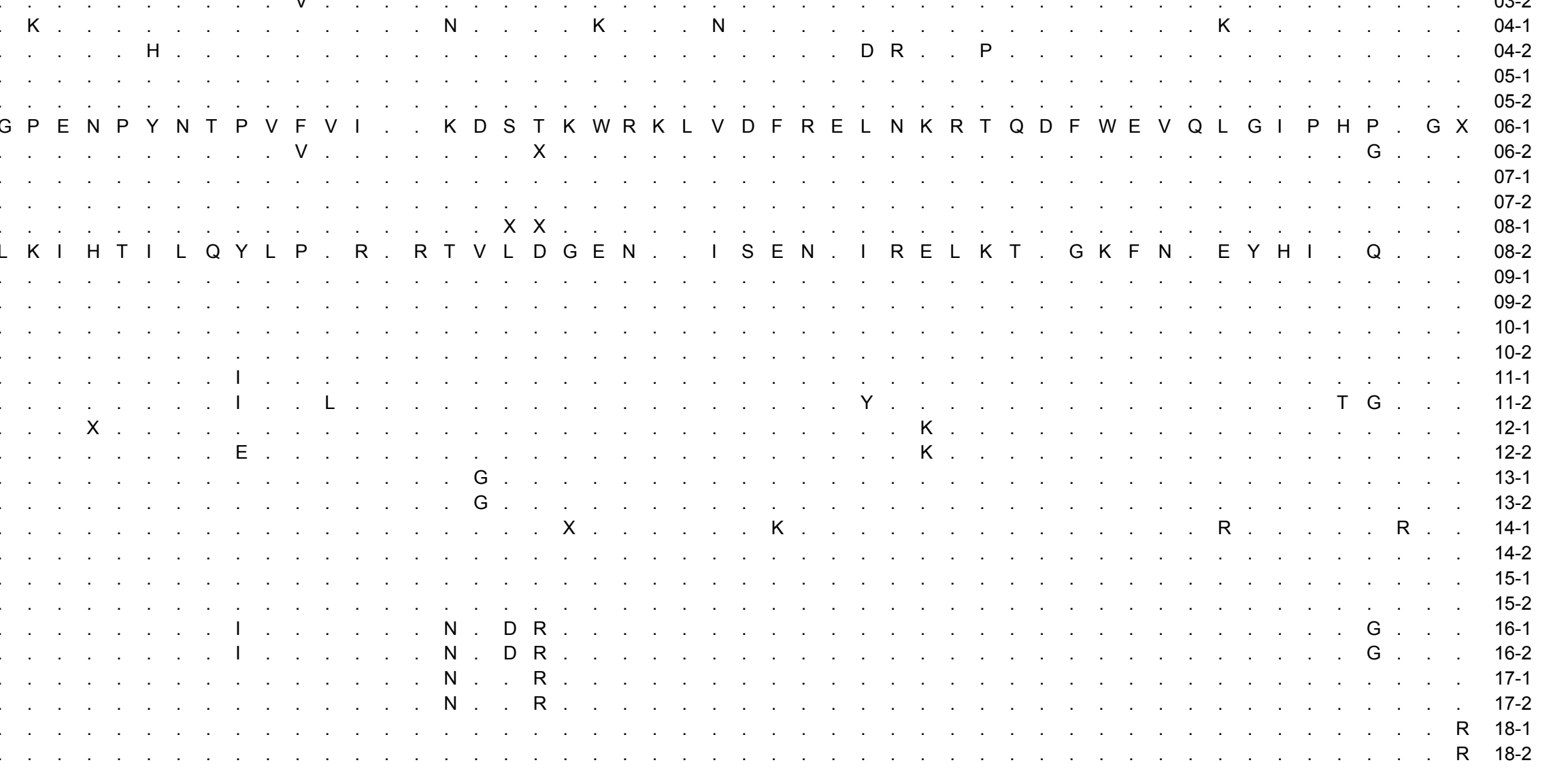




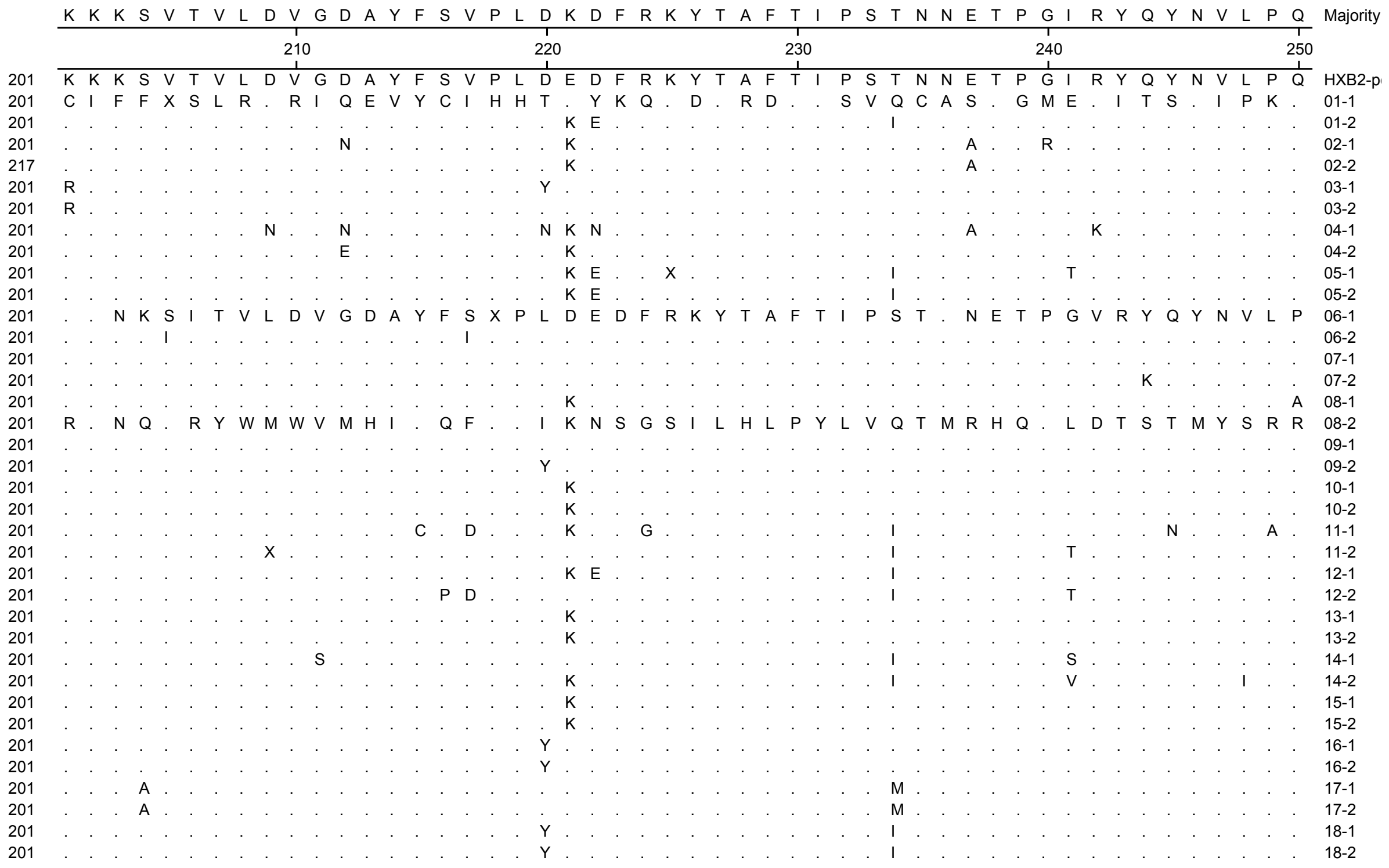




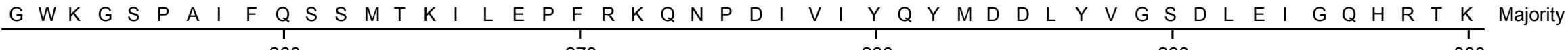

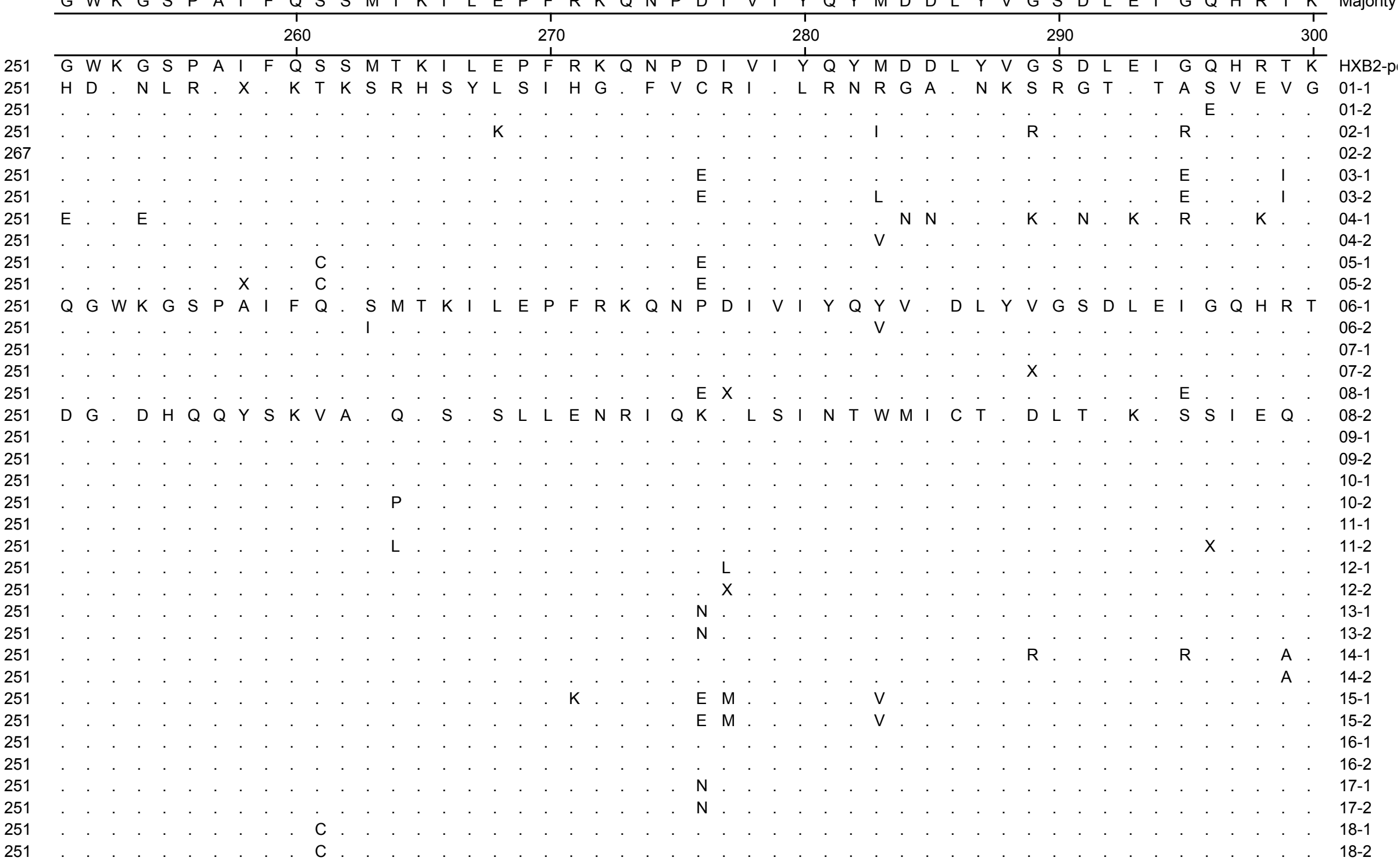




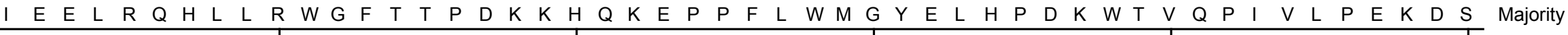
$3100320 \quad 330 \quad 340$ 350

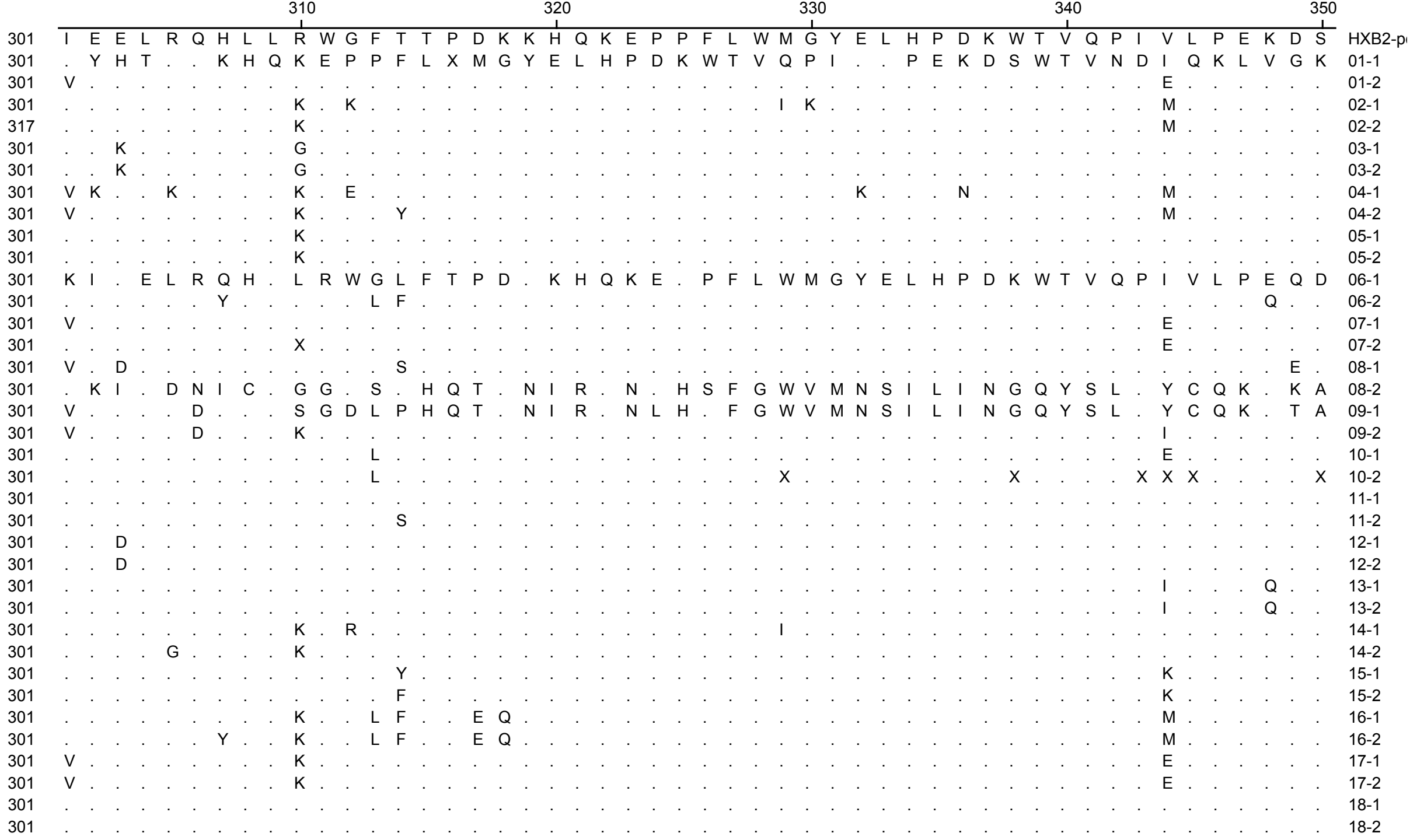




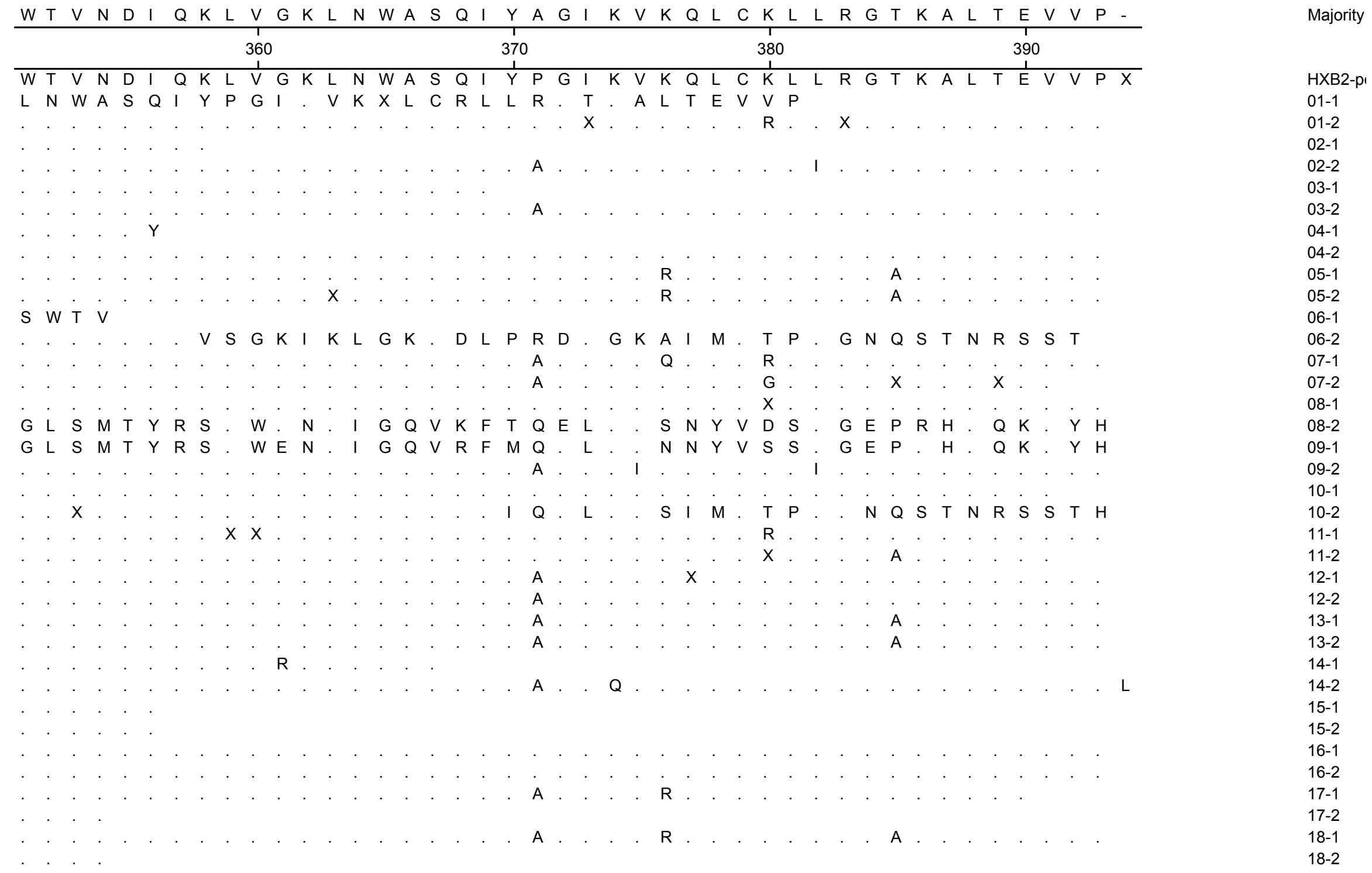


